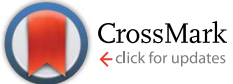

Cite this: RSC Adv., 2016, 6, 89523

Received 9th June 2016

Accepted 5th September 2016

DOI: 10.1039/c6ra15057h

www.rsc.org/advances

\section{Nanostructured platinum-free electrocatalysts in alkaline direct alcohol fuel cells: catalyst design, principles and applications}

\author{
Kenneth Ikechukwu Ozoemena*abc
}

\begin{abstract}
The alkaline direct alcohol fuel cell (ADAFC) is an environmentally friendly electrochemical energy source that can drive a plethora of consumer and portable electronics. Research in ADAFCs has continued to attract major attention due to their several advantages over conventional proton-exchange membrane fuel cells (PEMFC); these include the emergence of anion-exchange membranes (AEM), easy handling of liquid alcohol fuels compared to hydrogen, higher volumetric energy densities of alcohols compared to hydrogen, enhanced reaction kinetics of alcohols and oxygen reduction reaction in alkaline media. Further developments in this field are dependent on improving the performance of nanostructured electrocatalysts and AEMs. This review is an overview of some notable advances made in recent years. Importantly, it provides an excellent insight into the fundamental principles that allow for the intelligent design and synthesis of non-precious metal nanostructured electrocatalysts for the cathode and anode reactions of ADAFCs. This review is an attempt to find answers to questions such as "Why should I use a particular catalyst for the ADAFC?", "What are the underlying principles that must inform my choice in designing such a catalyst?", and "What synthesis method(s) or catalyst supports should be considered to prepare catalysts with the appropriate physicochemical properties for high-performance?" The knowledge provided in this review can be applied not only to ADAFCs, but also to several other electrocatalytic systems (such as various other fuel cell systems, electrochemical sensors, and metal-air batteries).
\end{abstract}

\section{Introduction}

The last five years, more than any other in the history of mankind, have witnessed the most important developments in

${ }^{a}$ Energy Materials, Materials Science and Manufacturing, Council for Scientific and Industrial Research (CSIR), Pretoria 0001, South Africa.E-mail: kozoemena@csir.co. za; Tel: +27128413664

${ }^{b}$ Department of Chemistry, University of Pretoria, Pretoria 0002, South Africa the global quest for a clean and sustainable environment. These developments include the United Nations' Sustainable Development Goal (SDG), the recent landmark agreement by 195 countries to protect the environment and avoid the global temperature rising by the 'psychological' $2{ }^{\circ} \mathrm{C}$ at the Paris

${ }^{c}$ Molecular Sciences Institute, School of Chemistry, University of the Witwatersrand, Johannesburg 2050, South Africa

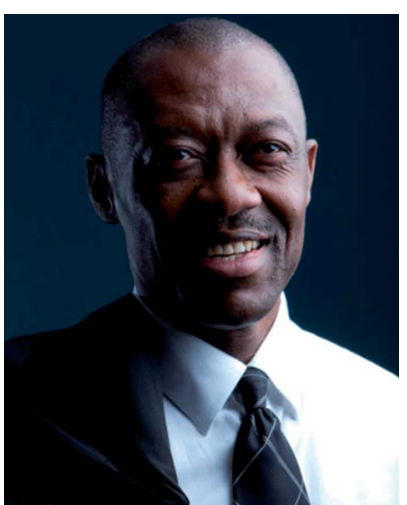

Kenneth Ozoemena is Chief Research Scientist at the Council for Scientific and Industrial Research (CSIR), which is South Africa's premier science council. He holds a BSc (Hons) degree in Industrial Chemistry from Abia State University (Nigeria), double MSc degrees (Chemistry and Pharmaceutical Chemistry) from the University of Lagos (Nigeria), and a PhD degree (Chemistry) from Rhodes University, South Africa (2003). He leads interdisciplinary research. programmes spanning several areas of materials science and engineering, from renewable energy technologies (such as fuel cells, lithium-ion batteries, and supercapacitors) to smart electrochemical sensors (for health, environmental, and industrial applications). Prof Ozoemena has authored/co-authored over 140 peerreviewed articles, 3 edited books, 10 book chapters and 7 patent applications. He is an elected Fellow of the African Academy of Science (FAAS), Fellow of the Royal Society of Chemistry (FRSC), and currently holds extraordinary/visiting professorships at the University of Pretoria and the University of the Witwatersrand, South Africa. He serves on the editorial Boards of several leading journals, including Electrochemistry Communications and Current Opinion in Electrochemistry. 
meeting of the United Nations' twenty-first session of the Conference of the Parties and the eleventh session of the Conference of the Parties, serving as the meeting of the Parties to the Kyoto Protocol (COP 21/CMP 11), and the Obama Climate Action Plan, to name a few. Countries and businesses that had ignored the impact of global warming are retracing their steps and supporting efforts for a sustainable environment. These developments promise to stimulate new research directions in low-carbon investments and innovations in renewable energy technologies (such as fuel cells) in the coming decades.

A fuel cell (FC) may simply be described as an electrochemical device that can directly convert chemical energy to electrical energy. Direct alcohol fuel cells (DAFCs) are acidbased fuel cells, while alkaline direct alcohol fuel cells (ADAFCs) operate in alkaline media; both directly oxidize alcohols, generating electricity in the process. Both DAFCs and ADAFCs have several advantages over their hydrogen-fed counterparts, proton-exchange membrane fuel cells (PEMFCs) and alkaline fuel cells (AFCs). One of the main challenges with hydrogen is that it is not a primary fuel; it is obtained from many other sources, such as coal-to-gas processes, electrochemical water-splitting or electrolysis, and reforming of natural gas. ${ }^{1}$ Also, large-scale production and storage of hydrogen are fraught with challenges. The challenges associated with the use of hydrogen necessitated the search for potential liquid fuel alternatives. Although the AFC is the most mature fuel cell, its major technical problem of progressive carbonation of the electrolyte due to $\mathrm{CO}_{2}$ contamination from air remains to be solved. At the anode, the concentration of $\mathrm{CO}_{2}$ is $20-30 \%$ with reformed hydrogen. In addition, $\mathrm{CO}_{2}$ can be generated even at the open circuit voltage or at low current densities due to the slow rate of corrosion of the carbon support for the Pt catalysts.

Alcohol-based fuel cells attract a lot of attention as possible alternative power sources for portable and consumer electronics. Low-molecular-weight alcohols (methanol, ethanol, ethylene glycol, and glycerol) have been considered as potential alternatives to hydrogen because of their several advantages over hydrogen; they are liquids at ambient temperature and pressure, thereby easy to handle, store, distribute, or transport. $^{2-4}$ Moreover, the gravimetric energy densities of these alcohols (5-8 $\mathrm{kW} \mathrm{h} \mathrm{kg}^{-1}$ ) are close to that of gasoline (12 kW h $\mathrm{kg}^{-1}$ ) and they can be obtained from renewable sources such as biomass. The direct methanol fuel cell (DMFC) has been well described in the literature as the most promising DAFC system for portable application due to its many advantages, such as the ease of transport, storage and distribution of methanol. However, the key challenges that still conspire against the widespread commercialisation of DMFCs include the exorbitant cost (due to precious catalyst and membrane-electrode assembly (MEA) parts) and low power density or low cell performance compared to the proton-exchange membrane fuel cells (PEMFC) (due to poor kinetics of the anodic methanol oxidation reaction, poor proton conductivity, and methanol crossover through the polymer electrolyte membrane). To resolve the proton conductivity and methanol crossover, the proton electrolyte membrane must be able to filter off methanol but allow protons to pass through to the cathode.

ADAFCs have numerous advantages over DAFCs due to the facile electrochemistry in alkaline media. Alkaline environments provide unique characteristics for the efficient operation of alkaline-based fuel cells (hydrogen or alcohol fuels) with respect to both cathode and anode kinetics: ${ }^{5-7}$ (i) faster kinetics of the ORR and alcohol oxidation reactions (AOR) allow the use of low-cost, non-noble-metal electrocatalysts; (ii) facile AORs at low anodic overpotential; (iii) reduced alcohol cross-over; (iv) enhanced water management, since the electro-osmotic drag will remove water formed at the anode through the cathode side, avoiding the possibility of water-flooding; (v) reduced risks of the electrode materials being subjected to corrosion, thus ensuring longevity; and (vi) reduced risk of the spectator ions adsorbing onto the MEA, which might hamper the electrocatalytic process. Also, Pt is easily poisoned by CO during AORs in acidic media, but this poisoning effect is very weak in alkaline environments, which means that it is possible to employ low-cost electrocatalysts compared to platinum. ${ }^{8,9}$

Recent advances in the preparation of chemically stable alkaline anion-exchange membranes (AEMs) have begun to open windows of opportunity for the development of highperformance AFCs and ADAFCs. AEM-based alkaline fuel cells (AEM-AFCs) have several advantages over conventional AFCs or ADAFCs: (i) there is no carbonate precipitation, since there are no mobile cations in the system; (ii) there is no electrolyte weeping; (iii) alcohol crossover is reduced; (iv) since water generated at the anode is consumed at the cathode, water management is potentially simplified; and (v) corrosion is reduced.

There have been other related reviews, but they are either relatively old (if one considers the 'hotness' or the fast pace at which the subject is moving) or limited in information on relevant sub-topics. For example, Bidault et al. ${ }^{\mathbf{1 0}}$ dwelt only on gas diffusion cathodes, while Antolini and Gonzalez ${ }^{\mathbf{1 1}}$ focused on ADAFCs, but with limited information. As a contrast, this review is aimed at closing the knowledge gap by providing a more comprehensive insight into recent developments in AORs and ORRs in alkaline media, and AEM-based DAFCs (AEM-DAFCs, Fig. 1) using Pt-free nanostructured electrocatalysts are presented. Importantly, some basic principles underlying the design and development of nanostructured electrocatalysts are discussed.

\subsection{Basic principles underlying metal nanoparticle- enhanced electrocatalytic activity}

Metal nanoparticles carry out electrocatalysis more easily than large single-crystal catalysts. In his book, Roduner ${ }^{12}$ elegantly described the general principles of catalysis with nanoparticles. In a nutshell, there are several reasons why nanoparticles (clusters of atoms), often with irregular shapes, can perform better chemistry than single-crystal surfaces. The first reason is the irregularity of the particle surfaces, which provide a suitable environment for the occurrence of defects, steps, and kinks, which permit the creation of special bonding situations that are favourable for the breaking and making of bonds. The second 


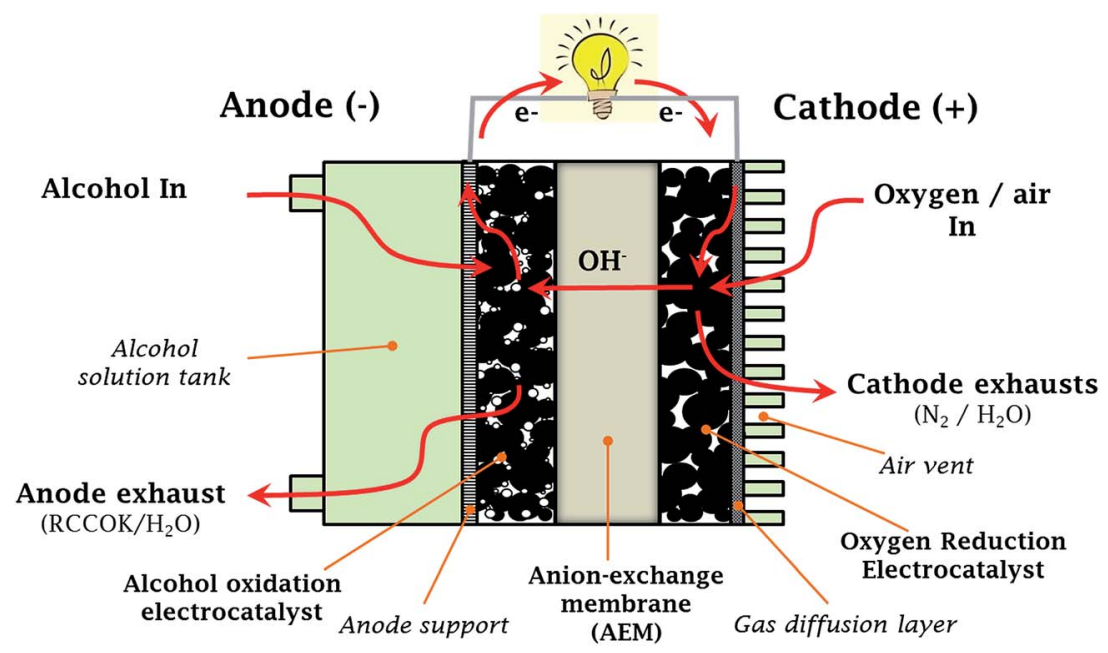

Fig. 1 Schematic of anion-exchange membrane-based direct alcohol fuel cell (AEM-DAFC).

reason is that the nanoparticles permit facile surface restructuring, unlike single crystals. It should be noted that surface restructuring constantly occurs to adapt to the adsorbate and thus the chemistry that takes place. Atoms close to the surface of small clusters are freer to move, since they have fewer neighbours to obstruct their movements compared to large single crystals.

The electrode reaction, defined as the current density drawn under an overpotential, $I$ (amperes per surface area of the electrode), is given by the following equation: ${ }^{13}$

$$
I\left(\mathrm{~A} \mathrm{~cm}^{-2}\right)=j\left(\mathrm{~A} \mathrm{~cm}^{-2}\right) s\left(\mathrm{~cm}^{2} \mathrm{~g}^{-1}\right) w\left(\mathrm{~g} \mathrm{~cm}^{-2}\right)
$$

where $j$ is the specific current density (amperes per real electrocatalyst surface area), $s$ is the specific surface area of the electrocatalyst (real catalyst surface area per mass), and $w$ is the amount of loaded electrocatalyst (mass per projected electrode surface area). Eqn (1) can be interpreted in several ways. For example, it suggests that when expensive precious noble metals (e.g., Pt, $\mathrm{Ru}$, or Pd) are deployed as catalysts, it makes more economic sense to simply increase $j$ and $s$ without increasing $w$. The value of $j$ can be increased by the co-operation of different metal catalysts (multi-metallic catalysts), by addition of adatoms, or by an alloying process. The value of $s$ can be increased if metal catalysts are dispersed as nanoparticles on highsurface-area support platforms.

(i) Effect of particle shape and surface structure. The critical determining factor for the electrocatalytic properties of a catalyst is the surface structure (i.e., particular style of faceting or the prevailing crystallographic directions and planes in the catalytic material, also known as the Miller indices) and not necessarily the shape of the nanocatalyst. ${ }^{\mathbf{1 4}}$ However, some shapes are preferred as they tend to give rise to the preferred atomic arrangement for enhanced electrocatalytic activity. Thus, what some researchers believe to be shape-dependent electrocatalytic activity is simply shapes of catalysts that give the right surface structure (Miller indices) for enhanced electrocatalysis. It is advisable, therefore, that every study attempts to explore the correlation between shape and surface structure, with a view to synthesizing nanocatalysts with shapes that give a preferential surface structure. For example, Hao and coworkers ${ }^{15}$ reported that cubic Pd nanocrystals $(7 \mathrm{~nm})$ exhibited much better electrocatalysis toward methanol oxidation in alkaline media (in terms of overpotential and large current response) compared to their spherical counterparts of a similar size. The result was attributed to the cubic nanocrystals, which contain more of the highly catalytically active $\{100\}$ facets than the spherical nanocrystals. Similarly, Narayanan and El-Sayed ${ }^{\mathbf{1 6}}$ proved in 2004 that Pt nanoparticles with a tetrahedral shape $(4.8 \mathrm{~nm})$ showed much faster reaction kinetics compared to the corresponding 'near-spherical' nanocrystals $(4.9 \mathrm{~nm})$ because the corner atoms of the tetrahedral particles are much more reactive than those of the spherical nanocrystals. It has been well documented that low-index crystal planes generally give poor catalytic properties, while high-index planes with a high concentration of atomic steps, ledges, and kinks generally give high electrocatalytic activity and stability. ${ }^{17-20}$ High-index planes are characterized by having at least one Miller index greater than 1. Today, one of the biggest challenges that confronts researchers is the ability to tune synthetic strategies that will produce nanocatalysts with only, or dominated by, high-index facets. This challenge should perhaps not be totally surprising if one understands that the high surface energy of a high-index plane allows it to respond much faster to the particle growth rate during synthesis than a low-index plane, thus leading to its rapid disappearance as the synthesis proceeds. According to Wang, ${ }^{21}$ the surface energy of different crystal planes of facecentered cubic (fcc) metals decreased in the order $\gamma\{h k l\}>\gamma$ $\{110\}>\gamma\{100\}>\gamma\{111\}$. The implication of this trend is that during shape-controlled synthesis of nanoparticles via conventional chemical methods, the growth rate along the normal direction of a low-index facet with low surface energy is much slower than in the direction perpendicular to a high-index facet. In other words, rapid growth in the direction perpendicular to high-index facets leads to rapid loss of high-index facets in favour of low-index facets, yielding NCs with cubic shapes, cuboctahedrons, tetrahedrons, and octahedrons. ${ }^{17}$ The 
inherent nature of nanocatalysts with high-index facets (extremely small-sized nanoparticles, with features only visible with high-resolution TEM) makes them suitable to positively impact on $j$ and $s$ in eqn (1).

The use of unit stereographic triangles (Fig. 2) to illustrate the co-ordinates of different crystal planes has been welldocumented in the literature, and is not intended to be repeated here. However, a short summary here may be appropriate to remind us of the Miller indices. As shown in Fig. 2, the three low-index or basal planes (i.e., (111), (100), and (110)) are at the three vertices, while the high-index planes (i.e., (331), (311), (310), (751), etc.) are located at the sidelines (i.e., (001), (011), and (110)) and inside the triangle. The (111) and (100) planes comprise closely packed and highly coordinated surface atoms, and the (110) plane comprises step atoms, whilst the high-index planes comprise kink atoms. Surface atoms are easily differentiated from one another by the so-called coordination numbers (CNs), which are the numbers of their nearest atoms; the smaller the $\mathrm{CN}$, the better the electrocatalytic performance of the nanoparticles. The CNs decrease as follows: 6 for planes in zone $\{001\}$ and inside the triangle, 7 for planes in zones $\{011\},\{110\}$, and (110), 8 for (100), and 9 for the (111) plane. ${ }^{17}$ Similarly, for the intrinsic triangle that coordinates the crystal surface index and the shape of metal nanocrystals (MNCs) (Fig. 2), the vertices describe the coordinates of polyhedral nanocrystals bounded by basal facets, i.e. the cube, octahedron, and rhombic dodecahedron are covered by $\{100\}$, $\{111\}$, and $\{110\}$, respectively. Inside the triangle are found the hexoctahedra bounded by $48\{h k l\}$, while in the sidelines of the triangle are the polyhedral MNCs, which are the tetrahexahedra (THH), trapezohedra, and trisoctahedra bounded by $\{h k 0\}$, $\{h k k\}$, and $\{h h l\}$ facets, respectively. ${ }^{17}$

(ii) Effect of particle size. Eqn (1) recognises the need for nano-sized particles (large surface area) for enhanced electrode reactions. There are two phenomena that explain the enhanced electrocatalysis of nanostructured catalysts: (i) an incompletely developed band structure: a small number of atoms in a nanoparticle is a clear indication of an incompletely developed band-structure, meaning that the electronic properties will be different from those of the bulk metal; and (ii) a low coordination number $(\mathrm{CN})$ : the smaller the size of the nanocatalyst, the smaller the number of atoms with low CNs in the surface, hence the electrocatalytic properties are improved. As already indicated, atoms with low CNs are generally more reactive than those with high CNs. It should be pointed out that electrocatalysis is a surface reaction, which simply means that it is only the atoms at the surface of the catalyst particle that can access the reaction intermediates, while those that are buried inside the particle cannot participate in the reaction process. To understand these phenomena, Shao et al. ${ }^{22}$ made some unique observations from their investigation of the commonly observed cubo-octahedral Pt particle. Firstly, the CNs of the $\{111\}$ and $\{100\}$ edges and vertices are 9, 8, 7, and 6, respectively. Secondly, as the particle size decreases, the fractions of atoms at the edges, vertices, and surface are increased, meaning that the loading of catalysts on electrodes for fuel cell applications can be remarkably reduced by nano-sizing of the catalyst particles. Finally, as the size of the catalyst becomes smaller and dispersion is increased (i.e., increased surface atoms), one observes a substantial reduction in the highly coordinated atoms $(\{111\}$ and $\{100\}$ ) compared to the low-coordinated atoms at the edges and vertices.

(iii) Effect of lattice-strain. The lattice parameter $(a)$ of metallic atoms significantly affects the electronic structure, and hence the catalytic reactivity. ${ }^{23-26}$ Compressive strain plays an important role in the electrode reaction; as the size of the metallic nanoparticle decreases (large surface area), compressive strain increases, thus catalytic activity increases with increased compressive strain. It has been well recognised that the amount of strain exerted on the metallic nanoparticles is strongly dependent on the location of the atoms, and decreases as edges/vertices $>\{111\}>\{100\} .{ }^{27}$ In fact, the strains in the low coordinated atoms are twice as large as those observed in the highly coordinated atoms of $\{111\}$ and $\{100\}$. One of the
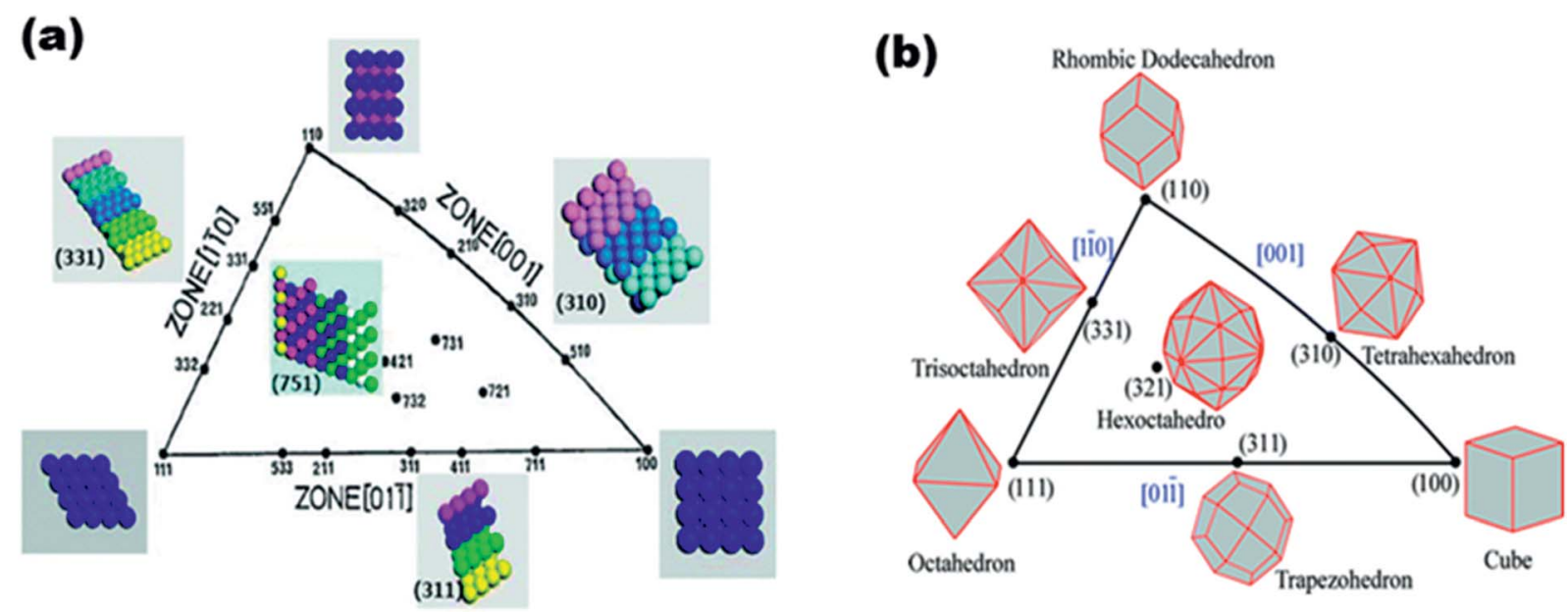

Fig. 2 (a) Unit stereographic triangle of fcc single-crystal and models of surface atomic arrangement, (b) unit stereographic triangle of polyhedral nanocrystals bounded by different crystal planes. Figure adapted from ref. 17 with permission. 
noticeable effects of alloying or core-shell catalysts (with the precious metal as the 'shell' and the transition metal as the 'core') is increased compressive strain. For example, Strasser et $a l .{ }^{28}$ studied the impact of the $\mathrm{Cu}$ content and preparation temperature on the lattice strain of the Pt shell of a Pt-Cu $\mathrm{Cu}_{x} @ \mathrm{Pt}$ core-shell catalyst and found that the average lattice parameters of the Pt shell $\left(a_{\text {shell }}\right)$ were smaller than those of the pure bulk Pt, suggesting that the Pt shells are under compressive strain. Also, higher $\mathrm{Cu}$ contents or an increased preparation temperature resulted in a decreased $a_{\text {shell }}$ and hence a larger magnitude of compressive strain. Also, in recent studies by Ozoemena and co-workers ${ }^{25,26}$ on an FeCo@Fe@Pd core-coreshell, they observed lattice strains induced in the Pd by the FeCo alloy. This phenomenon can easily be understood from the core-shell model: the lattice mismatch between the shell (Pd) and the core (FeCo) results in a reduced $\mathrm{Pd}-\mathrm{Pd}$ distance in the shell; the higher the transition metal content in the core, the smaller will be the lattice parameters and hence the higher the compressive strain being induced in the shell.

(iv) Effect of alloying: surface-segregation phenomenon. From the equation of the electrode reaction (eqn (1)), the $j$ value can be improved by strategic co-operation of different metals, by means of adatoms or alloying. ${ }^{13}$ Alloying is known to enhance the catalytic activity and/or stability of the base precious metals. The electrocatalytic activity of alloys is strongly dependent on the manner in which the atoms are arranged at the surface of the catalysts. ${ }^{29-31}$ This arrangement of the atoms is influenced by the ability of the atoms to migrate from the core of the particle to the surface layer (i.e., 'surface segregation'). The phenomenon of surface segregation has been shown by both theory and experiment to be of critical importance in the design and performance of new electrocatalysts. Some of the factors mentioned in the literature that determine surface segregation include the segregation energy, cohesive energy, surface energy, atomic radii, and electronegativity. ${ }^{32,33}$ For example, Wang and Johnson $^{33}$ reported that the tendency for atoms in metal nanoparticles to prefer the 'core' or 'shell' position of the alloys can be generally described by two independent factors; (i) cohesive energy (related to vapour pressure) and (ii) atomic size (quantified by the Wigner-Seitz (WS) radius), and the interplay between them. These two independent factors were found to determine the trends for surface segregation preference for atoms in nanoparticles and semi-infinite surfaces. Table 1

Table 1 Typical calculated segregation energies (eV) for binary alloy nanoparticles

\begin{tabular}{lllllll}
\hline & \multicolumn{1}{l}{ Shell } & & & & & \\
\cline { 2 - 7 } Core & $\mathrm{Ag}$ & $\mathrm{Pd}$ & $\mathrm{Ni}$ & $\mathrm{Ir}$ & $\mathrm{Co}$ & $\mathrm{Fe}$ \\
\hline $\mathrm{Ag}$ & 0 & -0.82 & -2.29 & -3.54 & -2.15 & -5.20 \\
$\mathrm{Pd}$ & 0.70 & 0 & -1.09 & -1.71 & -1.29 & -3.26 \\
$\mathrm{Ni}$ & 0.67 & 0.46 & 0 & -0.67 & -0.20 & -2.02 \\
$\mathrm{Ir}$ & 1.51 & 1.34 & 0.33 & 0 & -0.04 & -1.97 \\
$\mathrm{Co}$ & 0.36 & 0.75 & 0.15 & 0.04 & 0 & -2.24 \\
$\mathrm{Fe}$ & 0.60 & 0.74 & -0.10 & 0.00 & 0.07 & 0
\end{tabular}

exemplifies the segregation energies $(\mathrm{eV})$ of selected binary alloy nanocatalysts that are relevant for AFC systems. Note that a positive energy value, $\Delta E_{(\mathrm{X}) \mathrm{Y}}$, means that the core-shell structure prefers $\mathrm{X}$ in the core and $\mathrm{Y}$ in the shell, and the larger the value, the greater the tendency. As a contrast, a negative $\Delta E_{(\mathrm{X}) \mathrm{Y}}$ describes the opposite preference (i.e., $\mathrm{X}$ in the shell and $\mathrm{Y}$ in the core). For example, for an Ni-core and Pd-shell configuration, the positive $\mathrm{SE}(+0.46 \mathrm{eV})$ indicates that the present configuration is preferred, whereas a negative SE $(-1.09$ eV) for a Pd-core and Ni-shell configuration means that a Pdshell and Ni-core is preferred.

Three decades ago, Yamauchi ${ }^{34}$ formulated the rule that an element with a larger Wigner-Seitz radius (lower average electron density) in a binary alloy segregates to the surface. In other words, metallic elements with smaller atomic radii tend to occupy the core to relieve compressive strain. Thus, if one knows the WS radii or the electron densities of metals, one is then able to predict, design and make the desired nanocatalysts. For example, Table 2 compares the Wigner-Seitz radii and electron densities of some metallic elements that are useful for making alloy catalysts for AFC systems. Table 2 clearly indicates that $\mathrm{Pd}$, for example, has a stronger tendency to surface-segregate in $\mathrm{Ni}, \mathrm{Fe}$, or Fe-Co alloys.

This is in agreement with the recent finding by Ozoemena and co-workers, ${ }^{25,26,35,36}$ where Fe was found to occupy the 'shell' position in an FeCo alloy, and Pd occupied the 'shell' position in a high-performance sub $10 \mathrm{~nm}$ FeCo@Fe@Pd catalyst for alkaline direct alcohol fuel cell systems. Also, in an AgPd nanoalloy catalyst, ${ }^{37} \mathrm{Ag}$ is predicted to surface-segregate on Pd. It is believed that the enhanced ORR activity on the AgPd alloy was a combination of two factors; modification of the electronic structure and ensemble effects. Alloying was proved to alter the electronic structures of the two metals (by shifts in the binding energy in XPS). The ensemble effect simply describes the suitable arrangement of the $\mathrm{Ag}$ next to the Pd surface atoms.

Table 2 Representative Wigner-Seitz radii of some relevant metallic elements for making alloy nanocatalysts for application in Pt-free alkaline fuel cell systems

\begin{tabular}{|c|c|c|}
\hline Element & \multicolumn{2}{|c|}{ Wigner-Seitz radius, $r_{w s} / \AA ̊$} \\
\hline $\mathrm{Sn}$ & 1.89 & \multirow{9}{*}{ 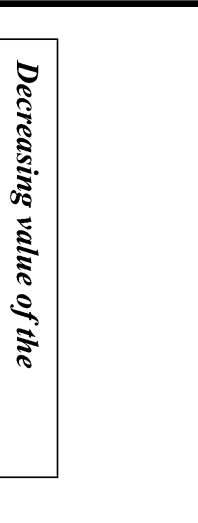 } \\
\hline $\mathrm{Ti}$ & 1.62 & \\
\hline $\mathrm{Ag}$ & 1.60 & \\
\hline $\mathrm{Pd}$ & 1.52 & \\
\hline Ir & 1.50 & \\
\hline $\mathrm{Mn}$ & 1.43 & \\
\hline $\mathrm{Fe}$ & 1.41 & \\
\hline $\mathrm{Co}$ & 1.39 & \\
\hline $\mathrm{Ni}$ & 1.38 & \\
\hline
\end{tabular}


(v) Effect of catalyst support. A fuel cell is expected to operate for thousands of hours or cycles during its life time. Catalyst-support materials remain one of the most critical components of the fuel cell that will allow for such long operation. Indeed, it is common knowledge that efficient interaction between the electrocatalyst and its supporting material is responsible for some of the important parameters that govern the efficient performance of fuel cells: particle size, catalyst dispersion, and stability. From the equation of the electrode reaction (eqn (1)) we noted that the performance of each of the two electrode reactions of the fuel cell is intrinsically linked to $s$ (i.e., the specific surface area of the electrocatalyst). To increase the value of $s$, the catalysts must be dispersed as nanoparticles (2-5 $\mathrm{nm}$ in diameter) on a high-surface-area support $(10-50 \mathrm{~nm}$ in diameter). An ideal support for the electrocatalyst should possess the following critical properties: $:^{38,39}$ (i) satisfactory electrical conductivity, (ii) strong catalyst-support interaction to reduce the possible deactivation of the catalysts and allow for efficient charge transport, (iii) large surface area, (iv) a suitable porous structure to permit good reactant and product flux, (v) good water-handling capability to avoid flooding, (vi) good resistance to corrosion to allow for high stability in fuel-cell operating environments, and (vii) ease of catalyst recovery.

Catalyst-supports for fuel cells may be conveniently divided into two categories: (i) carbon-based supports and (ii) noncarbon supports. Carbon materials are the most important catalyst-support materials for fuel-cell electrocatalysts. By adopting different types of synthesis methods, different morphologies of carbons have been obtained, including coreshells, spheres, hollow spheres, nanotubes, and onion-like. The importance of carbon as a catalyst-support material stems from its unique advantages, such as easy availability, low-cost, high stability in both acidic and basic media, and ability to be burnt off easily, thus allowing for easy recovery of the precious metal catalysts if needed. Despite these important advantages, carbons are plagued by the following shortcomings, which have limited their performance as catalyst-supports: (i) severe corrosion/ oxidation under normal operating conditions, leading to poor durability of the electrocatalysts as they are electrically isolated or separated from the support, and subsequent aggregation of small particles of these catalyst particles (Ostwald ripening), which can lead to the formation of an inhomogeneous structure over time. ${ }^{38,40,41}$ Indeed, the main reason for the loss of electrochemically-active surface area (ECSA) of the electrode and the consequent loss of electrocatalytic activity is related to (i) the ability of the small-sized particles to aggregate into large-sized particles via diffusion, accompanied by coalescence or the Ostwald ripening mechanism; (ii) the presence of a large amount of micropores $(<1 \mathrm{~nm})$, which can impede fuel supply to the surface, and present a low accessible surface area for the deposition of metal particles; (iii) low polarity and high hydrophobicity, which reduces the permeability of gases and liquids; and (iv) poor stability at temperatures higher than $373 \mathrm{~K}$ and lack of proton conductivity. ${ }^{\mathbf{4 2 , 4 3}}$

Several types of carbons have been investigated as catalystsupports and these include carbon blacks, carbon nanotubes
(CNTs), carbon microspheres, carbon nanofibers, and graphenes. Theoretical and experimental studies have shown how the physicochemical properties of the carbons can impact on their ability to strongly adsorb catalysts and improve fuel cell performances. Two such key features of the carbons are shapes and structures. For example, Cuong et al. ${ }^{\mathbf{4 4}}$ used DFT to unravel the interplay between different carbon supports (i.e., graphene sheet, a metallic single-wall carbon nanotube (SWCNT), and a series of semiconducting SWCNTs) and Pt nano-clusters, in determining the stability and electronic properties of Pt nanoclusters (Fig. 3). It was established that the Pt clusters were best stabilized by adsorption on carbon nanotubes, rather than on graphene supports, with the adsorption energy of Pt clusters on SWCNTs $(4.0 \mathrm{eV})$ being much higher than that of graphene $(2.21 \mathrm{eV})$.

The enhanced stability of the Pt cluster on SWCNTs was associated with the geometry of the SWCNTs; "due to the curvature-induced pyramidalization and misalignment of p-orbitals of carbon atoms in SWCNT, carbon atoms on the outside wall of the SWCNT have more $s p^{3}$ nature than those on a flat graphene sheet". ${ }^{44}$ This finding could well explain the generally high-performing ability of CNT-supported catalysts compared to catalysts adsorbed on graphite carbons. Considering that the metal-carbon bonding arises from the hybridization between d-states of the metal atoms and p-states of adjacent carbon atoms, this means that the high curvature of the CNTs is able to promote the overlap between $\mathrm{p}$ and $\mathrm{d}$ wave functions, thus increasing the adsorption energy of metal on CNTs.

Another key feature of a carbon surface that influences its ability to interact with metal catalysts is surface functional groups. The two main functionalities are oxygen and nitrogen (Fig. 4). The commonly observed oxygen functionalities are carboxyl $(-\mathrm{COOH})$, hydroxyl $(-\mathrm{OH})$, and carbonyl $(-\mathrm{C}=\mathrm{O})$ groups. Although a number of dopants are being reported on a constant basis, nitrogen-doping has emerged as an efficient strategy for tailoring the properties of carbons and tuning the physicochemical properties of carbon materials for a plethora of applications. ${ }^{45}$ For the nitrogen-doped carbons (Fig. 4), the three most commonly observed are the pyridinic, pyrrolic, and graphitic nitrogen groups. The main goal of surfacefunctionalization of carbon materials is to improve their hydrophilicity (e.g., treatment with acids and bases) or hydrophobicity (e.g., treatment with organic compounds such as benzene), with a view to enhancing their dispersibility in solvents and permitting anchorage of the metal catalysts. CNTs are attractive supports for electrocatalysts due to their excellent mechanical strength, high-surface area, high conductivity and, of course, their inherent geometry, which allows for the high binding energy with metal catalysts, as described above.

The surface-functional groups provide the binding sites for the growth of the metal catalyst ions. The conventional method for surface-functionalisation of CNTs, and indeed any carbon materials, involves treatment with acids or bases, a simple chemical treatment that permits the introduction of surface groups, such as carboxyl, hydroxyl, phenolic, sulfonyl, or sulfite groups on the carbon surfaces. About a decade ago, Kim and Park $^{46}$ investigated the effects of the chemical treatment of 
(a)

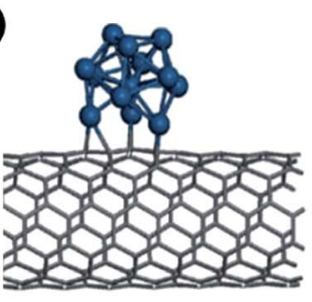

(b)

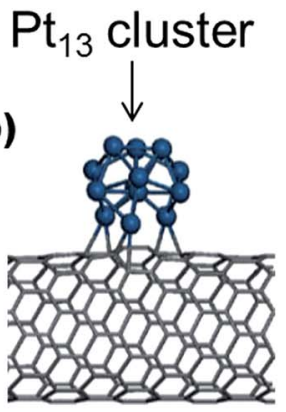

(c)

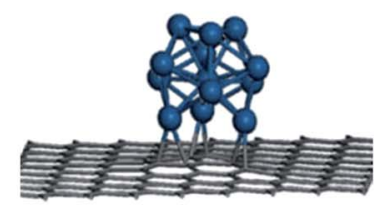

(d)

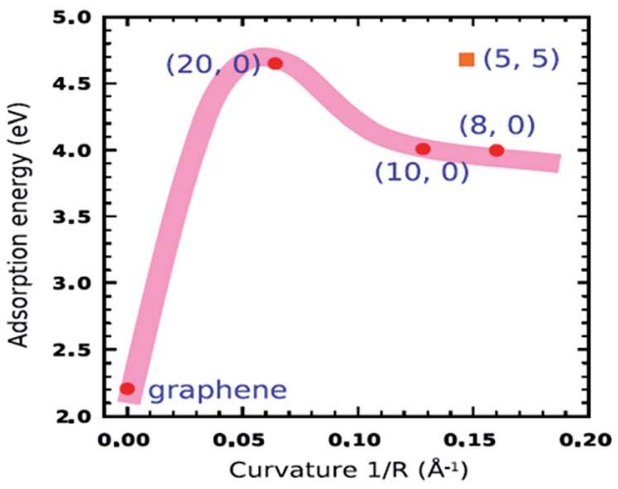

Fig. 3 The geometric structures of $\mathrm{Pt}_{13}$ clusters adsorbed on carbon supports: (a) metallic $(5,5)$ SWNT, (b) semiconducting (10, 0) SWNT, and (c) $(8 \times 8)$ graphene surface. (d) describes the dependence of the curvature of the carbon supports on the adsorption energy of $\mathrm{Pt}_{13} \mathrm{Clusters}$ on the SWNTs and graphene sheet. Figure adapted from ref. 44 with permission.

carbon supports on the electrochemistry of platinum catalysts. The following carbon supports were studied; virgin carbon blacks (CBs), neutral-treated carbon blacks (NCBs obtained by

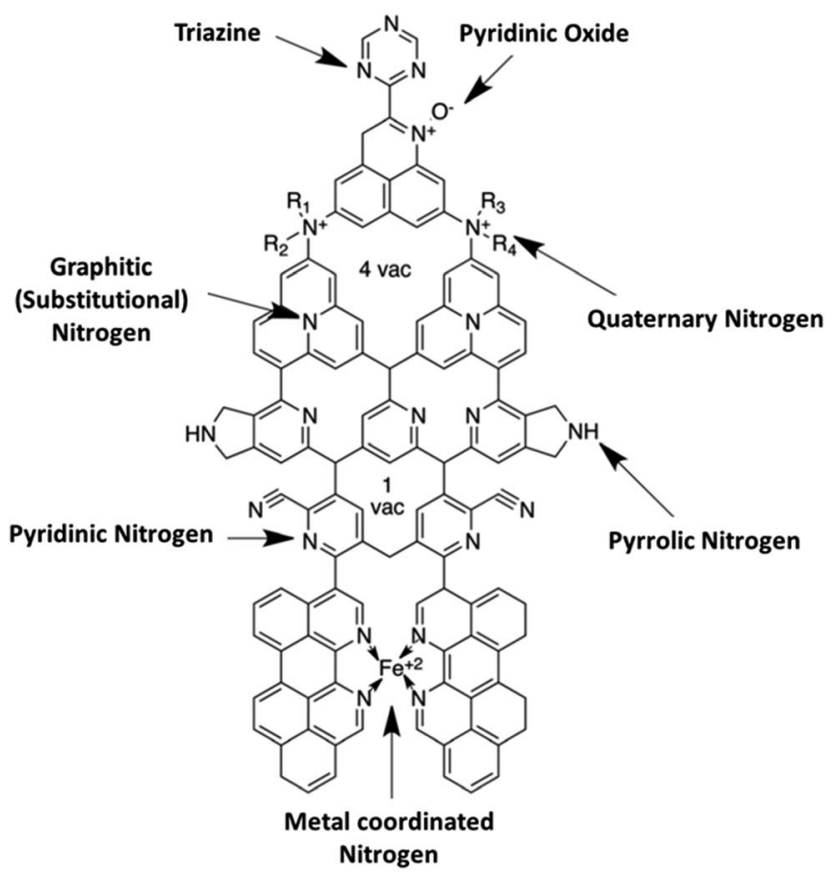

Fig. 4 Structure depicting nitrogen functionalities in nitrogen-doped carbon materials, the most commonly observed groups being the pyridinic, pyrrolic and graphitic. Figure adapted from ref. 45 with permission. treating CBs with $0.2 \mathrm{M}$ benzene), base-treated carbon blacks (BCBs, obtained by treating CBs with $0.2 \mathrm{M} \mathrm{KOH}$ ), and acidtreated carbon blacks (ACBs, obtained by treating CBs with $0.2 \mathrm{M} \mathrm{H}_{3} \mathrm{PO}_{4}$ ). The authors showed that the size and the catalystloading were strongly dependent on the surface characteristics of the carbon blacks: BCB-supported Pt yielded the smallest particle size $(2.65 \mathrm{~nm})$ and the highest loading (97\%) compared to the other carbons investigated. The electroactivity of the catalyst was enhanced with BCBs and NCBs, but deteriorated with ACBs.

Another interesting method of improving the surface properties of nanocarbon materials, including CNTs, is sulfonation, ${ }^{47-49}$ which was first introduced by Hara et al. in $2004 .^{50}$ In a recent review by Kang et al., ${ }^{47}$ the authors discussed a number of synthesis methods for sulfonated nanocarbons, including their applications. To improve the sulfonation process, Ozoemena and co-workers $^{51}$ first functionalised pristine CNTs to increase the concentration of the oxo-groups (mainly the $-\mathrm{COOH}$ ) by a threestep acid-treatment process: (i) refluxing in $2.6 \mathrm{M} \mathrm{HNO}_{3}$ for 24 h; (ii) sonicating in an $\mathrm{H}_{2} \mathrm{SO}_{4} / \mathrm{HNO}_{3}$ mixture (3:1 ratio) for $24 \mathrm{~h}$; and (iii) stirring in an $\mathrm{H}_{2} \mathrm{SO}_{4} / \mathrm{H}_{2} \mathrm{O}_{2}$ mixture $\left(4: 1\right.$ ratio) at $70{ }^{\circ} \mathrm{C}$. The acid-functionalised CNTs (MWCNT-COOH) were then sulfonated using a mixture of $\mathrm{H}_{2} \mathrm{SO}_{4}$ and acetic anhydride at $70{ }^{\circ} \mathrm{C}$ for $2 \mathrm{~h}$, using the procedure reported by Sun et al. ${ }^{48,49} \mathrm{The}$ catalysts were supported on the sulfonated-CNTs $\left(\mathrm{MWCNT}^{\left.-\mathrm{SO}_{3} \mathrm{H}\right)}\right.$ using rapid microwave irradiation, as shown in Fig. 5.

Sun et al. ${ }^{48,49}$ showed that a Pd catalyst supported on sulfonated MWCNT $\left(\mathrm{Pd} / \mathrm{MWCNT}-\mathrm{SO}_{3} \mathrm{H}\right)$ had an enhanced 


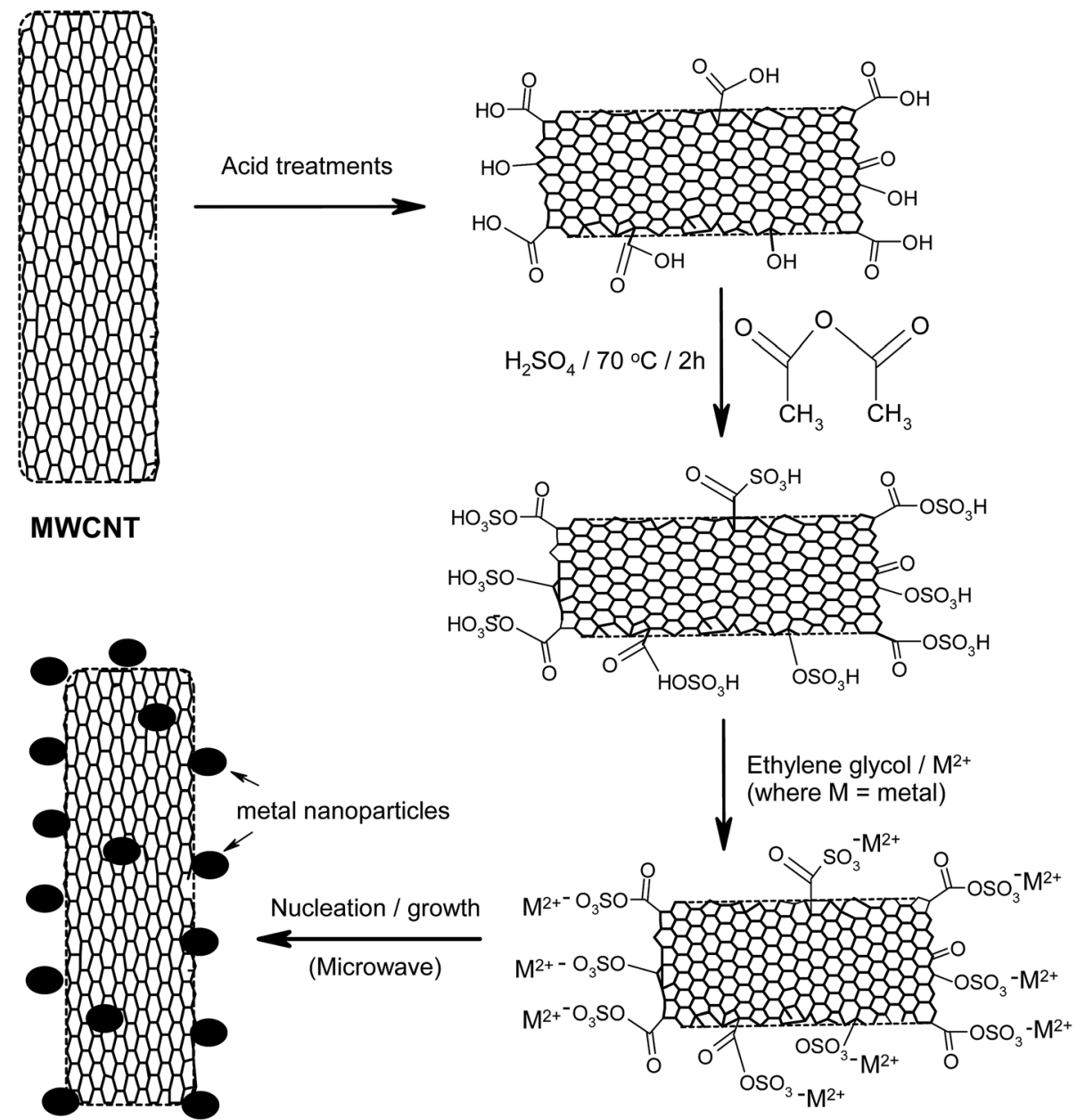

Fig. 5 Schematic of the sulfonation process for carbon nanotubes using microwave-assisted synthesis. Figure modified from ref. 51 with permission.

catalytic activity for methanol oxidation ${ }^{48}$ and the ethylene

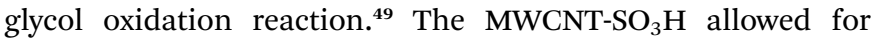
uniform dispersion of smaller-sized Pd nanoparticles $(\sim 4.5 \mathrm{~nm})$ compared to MWCNT supports that were not sulphonated. The uniform dispersion was associated with the specific electrostatic interactions between negatively charged MWCNTs and positively charged $\mathrm{Pd}\left(\mathrm{Pd}^{2+}\right)$. Ramulifho et al..$^{51}$ adopted similar functionalization of MWCNTs for the synthesis of bimetallic Pdbased catalysts using a microwave-assisted method, rather than the conventional $\mathrm{NaBH}_{4}$ reduction method used by Sun et al. ${ }^{\mathbf{4 8 , 4 9}}$ The authors showed that the catalytic properties of the PdSn catalyst followed this trend: $\mathrm{PdSn} / \mathrm{MWCNT}^{-\mathrm{SO}_{3} \mathrm{H}}>\mathrm{PdSn} /$ MWCNT-COOH $>$ PdSn/C.

To understand the effect of sulfonation on MWCNT supports, Ozoemena and co-workers recently investigated the catalytic properties of an FeCo@Fe@Pd nanocatalyst supported on MWCNT-COOH and MWCNT- $\mathrm{SO}_{3} \mathrm{H}$. The core-core-shell Pd-based nanocatalysts (FeCo@Fe@Pd) were obtained by what has been termed "microwave-induced top-down nanostructuring and decoration (MITNAD)", ${ }^{25}$ a process whereby a large-sized precursor core-shell alloy (FeCo@Fe, $\geq 0.5 \mu \mathrm{m}$ ) was reduced to a nano-sized structure and decorated with a Pd-shell
(FeCo@Fe@Pd, $\leq 10 \mathrm{~nm}$ ) by fast microwave irradiation (Fig. 6). The authors clearly proved that surface functionalities (mainly $-\mathrm{COOH}$ and $-\mathrm{SO}_{3} \mathrm{H}$ ) on the MWCNT support played a crucial role in the physico-chemistry of the FeCo@Fe@Pd catalyst toward the oxidation of polyhydric alcohols, ethylene glycol, and glycerol. The FeCo@Fe@Pd/MWCNT-COOH (Fig. 6A and B and 7) gave smaller-sized particles $(c a .7 .4 \mathrm{~nm})$, more uniform dispersion or loading of the catalyst on the support, a higher electrochemically active surface area (ECSA, $c a .75 \mathrm{~m}^{2}$ $\mathrm{g}^{-1}$ ) and an enhanced electrocatalytic activity compared to the FeCo@Fe@Pd/MWCNT-SO ${ }_{3} \mathrm{H}$ (Fig. 6C and D), with $c a .11 \mathrm{~nm}$ particle size and an ECSA of $c a .42 \mathrm{~m}^{2} \mathrm{~g}^{-1}$. This finding is in good agreement with the report by Kim and Park, ${ }^{46}$ as already discussed above, where carbon black treated with acid showed a poor catalyst loading compared to the base-treated or neutral carbon blacks. It is possible that the MWCNT-COOH support (a weak acid) might have led to complete reduction of the $\mathrm{Pd}^{2+}$, thus allowing a more uniform dispersion and higher loading of catalysts than the MWCNT- $\mathrm{SO}_{3} \mathrm{H}$ support (strong acid). Simply stated, the high catalytic performance of FeCo@Fe@Pd/ MWCNT-COOH may be related to the improved electronic properties of the catalyst, coupled with the high affinity of its 

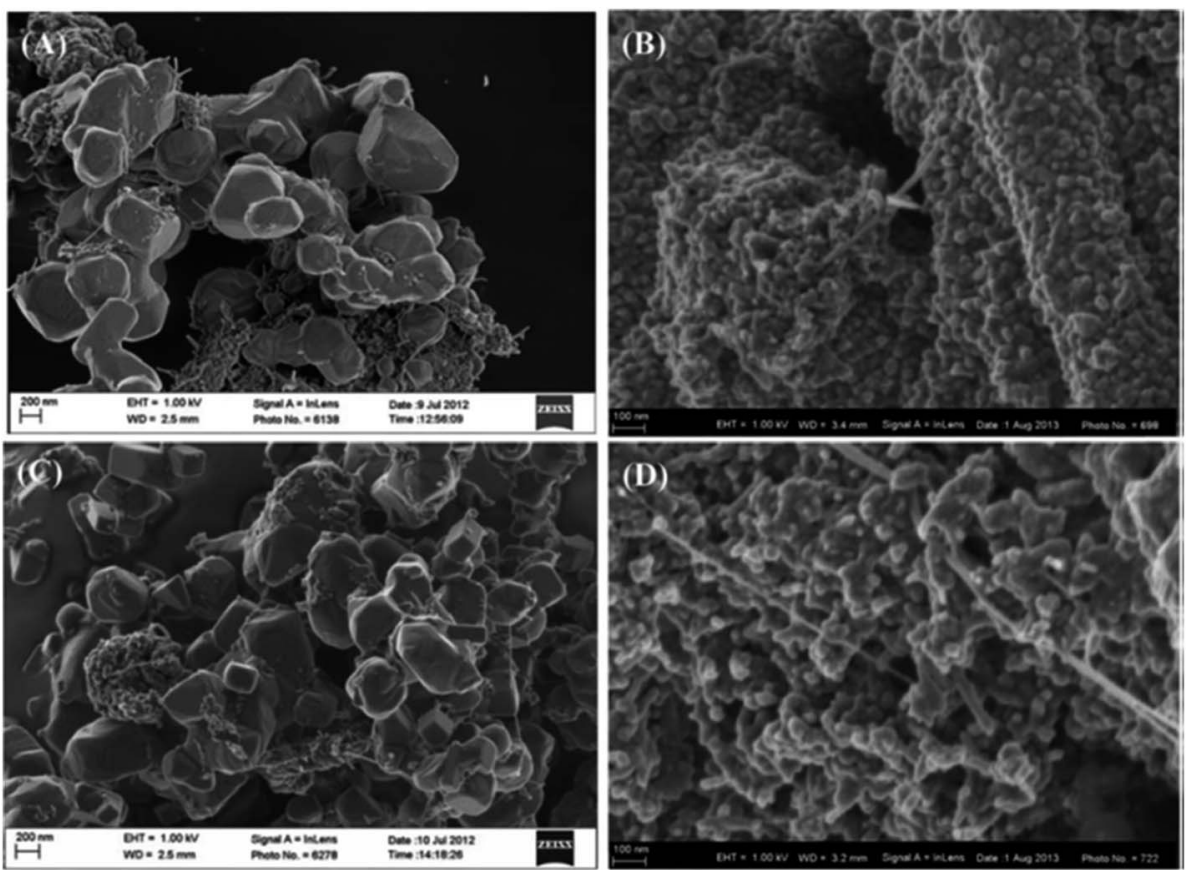

Fig. 6 FESEM images describing the importance of the "microwave-induced top-down nanostructuring and decoration" (MITNAD) process: (A) FeCo@Fe/MWCNT-COOH ( $\geq 0.5 \mu \mathrm{m}$ ), (B) FeCo@FeaPd/MWCNT-COOH ( $\leq 10 \mathrm{~nm}$ ), (C) FeCo@Fe/MWCNT-SO ${ }_{3} \mathrm{H}(\geq 0.5 \mu \mathrm{m})$, and (D) FeCo@$\mathrm{Fe} a \mathrm{Pd} / \mathrm{MWCNT}-\mathrm{SO}_{3} \mathrm{H}(\leq 10 \mathrm{~nm})$. Figure adapted from ref. 25 with permission.

- $\mathrm{COOH}$ surface with the catalyst. It should be noted, however, that this finding is in contradiction to previous findings, ${ }^{48,49,51}$ and this may be related to several factors, including the nature of the pristine CNTs used (i.e., the amount of - $\mathrm{COOH}$ available), the nature of the alloys (e.g., the arrangement of the Sn on Pd), and the synthesis method used (fast microwave-assisted acidfunctionalization $v s$. a lengthy hydrothermal reaction).

Despite the advantages of chemical oxidation of carbon supports to introduce surface-functional groups, it should be noted that the oxidised sites of the carbon supports may accelerate the degradation process of the support material, thereby inducing significant aggregation of the catalyst nanoparticles. One of the strategies to avoid the occurrence of these oxidation problems is to wrap the carbon support with polymeric materials that contain appropriate functional groups for

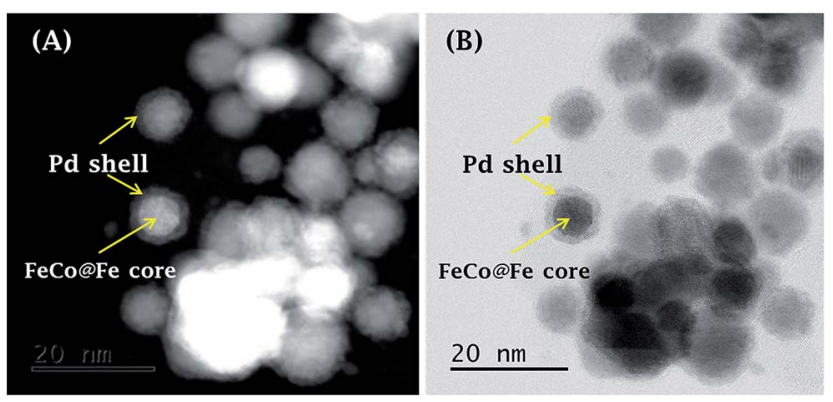

Fig. 7 (A) High-angle annular dark-field (HAADF)- and (B) bright-field (BF)-STEM images simultaneously acquired for FeCo@FeaPd/ MWCNT-COOH. Figure adapted and modified from ref. 25 with permission. the binding of the metal catalyst. For example, Fujigaya and coworkers elegantly wrapped CNTs with polymeric materials that contain nitrogen atoms (i.e., pyridine-doped polybenzimidazole $\left.{ }^{52}\right)$ and poly[2,29-(2,6-pyridine)-5,59-bibenzimidazole $^{53}$ ], sulfonic acid (i.e., sulfonated polysulfone and sulfonated polyimide ${ }^{54}$ ) and phosphonic acid groups (i.e., poly(vinyl phosphonic acid)-doped polybenzimidazole ${ }^{55}$ ). The catalysts displayed excellent stability with a durability 10 times higher than that of commercial carbon black/Pt.

To mitigate the problems of carbon-based supports in fuel cells, especially the issue of corrosion, several non-carbon supports for fuel cells are being developed without sacrificing the desirable properties of carbon, such as high surface area and high electrical conductivity. The non-carbon materials include the following: (i) conducting polymers, such as polypyrrole (PPY) and polyaniline (PANI); (ii) metal oxides and hydroxides, such as $\mathrm{ZrO}_{2}, \mathrm{CeO}_{2}, \mathrm{TiO}_{2}, \mathrm{MnO}_{2}$, and $\mathrm{Al}_{2} \mathrm{O}_{3}$; (iii) transition metal carbides, such as tungsten monocarbide (WC), and (iv) transition metal nitrides, including binary nitrides (e.g., $\mathrm{CrN}$, TiN) and ternary nitride (e.g., $\mathrm{Ti}_{0.5} \mathrm{Nb}_{0.5} \mathrm{~N}$ ) complexes. For more information on these non-carbon supports, the reader is referred to the recent book chapter by Ejikeme et al. ${ }^{56}$

(vi) Effect of synthesis method. All the parameters in eqn (1) $(j, s$, and $w)$ can be influenced by the synthesis protocol adopted by the researcher. It has continually been shown in the literature that catalysts with the same elemental compositions show different electrocatalytic properties. An important reason for this discrepancy is that the properties of several metal alloy catalysts are highly dependent on the synthesis method and post-treatment protocols. This should perhaps not be totally 
surprising if one considers that different synthetic techniques or post-treatments are capable of tuning the physicochemical properties of the alloys, such as the degree of alloying, particle size and the surface structure (i.e., Miller indices). For example, Wang et $a l .{ }^{57}$ proved that $\mathrm{PdCu}_{3}$ synthesised by a colloidal method exhibited high ORR activity in an acid medium compared to the same $\mathrm{PdCu}_{3}$ catalyst prepared by a thermodecomposition process; the former method yielded a more uniform alloy and smaller-sized particles than the latter. Also, other workers, such as Raghuveer et al. ${ }^{58}$ showed that a ternary PdCoAu catalyst obtained from the micro-emulsion method gave a high ORR activity compared to that obtained from using the $\mathrm{NaBH}_{4}$ reduction route, because of the higher degree of alloying and smaller-sized particles. Similarly, Liu and Manthiram $^{59}$ showed that post-treatment, such as increasing the

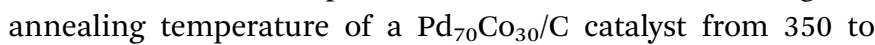
$500{ }^{\circ} \mathrm{C}$, increases the particle size and degree of alloying of the catalyst, thereby decreasing its catalytic activity towards the ORR. The next section is a succinct description of the synthesis methods for various nanoelectrocatalysts for AEM-ADAFCs and their effects on the surface structure.

\subsection{Synthesis of nanoelectrocatalysts for application in AEM-ADAFCs}

As already explained in the preceding section, the catalytic activities of nanostructured electrocatalysts strongly depend upon their elemental composition, size or surface area, shape with the preferred surface structure (exposed surface planes), and the extent of interaction with supports. For an anodic reaction (i.e., the alcohol oxidation reaction), Pd-based metal catalysts are used, while for a cathodic reaction (i.e., the oxygen reduction reaction), non-platinum group metal (non-PGM) catalysts or Pt-free catalysts are used. The catalysts (anodic and cathodic) are synthesized using similar methods. The key synthesis methods can be summarised as chemical reduction, galvanic replacement, seed-mediated growth, and electrochemical deposition. Each of these methods can be used alone or combined with another method to prepare a catalyst.

1.2.1 Chemical reduction method. Chemical reduction (for monometallic catalysts) or co-chemical reduction (for bimetallic or ternary catalysts) is a facile strategy for the synthesis of nanoelectrocatalysts. In this method, various reducing agents, including strong reductants, such as sodium borohydride and hydrazine, and mild reductants, such as alcohols (e.g., ethylene glycol, glycerol, methanol, 1,4-butanediol, and poly(vinyl pyrrolidone) (PVP)), ascorbic acid, and citric acid, have been used to reduce or co-reduce to nanocrystals of corresponding metals. The catalysts are usually dispersed in situ onto the supporting materials. Vulcan XC-72 carbon black remains the state-of-the-art carbon support for various catalysts, while nanocarbon materials (e.g., carbon nanotubes and graphenes) and non-carbon materials (e.g., conducting polymer composite matrices, and tungsten carbide) have also been reported. Microwave-assisted synthesis has also emerged as a facile strategy for the synthesis of various catalysts. Microwave irradiation, unlike traditional chemical methods, is simple, fast and provides homogeneous reaction conditions for obtaining high-performance catalysts. The hydrothermal method is another frequently employed technique due to its simplicity, and ease of shape-control of the metal catalyst.

Surfactants, such as PVP and CTAB, have the ability to tune the physico-chemistry of the catalysts and improve their catalytic performance. For example, Xia and coworkers ${ }^{60}$ demonstrated the synthesis of Pt-Pd alloy nanocrystals with welldefined shapes and twinned structures by simply heating an aqueous solution of $\mathrm{Na}_{2} \mathrm{PdCl}_{4}, \mathrm{~K}_{2} \mathrm{PtCl}_{4}$, and PVP at $80{ }^{\circ} \mathrm{C}$ for $18 \mathrm{~h}$. It was found that this lengthy or slow-reduction synthesis process with a weak reductant was responsible for the formation of the twinned structure. The PVP-mediated slow reduction rate (owing to the hydroxyl terminal group of the PVP) was able to retain the particles at small sizes for a long period of time before nucleation could start. The slow process allows for easy coalescence of small particles into larger particles, thereby reducing the surface-to-volume ratio, thus leading to the formation of twinned structures. When the process was repeated with ethylene glycol, which is a relatively high-rate reductant, a single-crystal structure of Pt-Pd nanocrystals with a truncated, octahedral shape was obtained.

Lee et al. ${ }^{61}$ obtained Au-Pd nanocrystals (NCs) (Fig. 8) enclosed exclusively by high-index facets $\{541\}$, by one-pot aqueous synthesis involving simultaneous reduction of $\mathrm{Au}$ and Pd precursors. The nanocrystals were made possible by manipulating the growth kinetics, by controlling the relative amounts of reductant, ascorbic acid (AA), to the metal (M) precursors. It is interesting to observe that AA plays a critical role in the morphology of the NCs. The co-reduction of Au and Pd precursor salts with $\mathrm{CTAB}$ in the absence of AA produced $\mathrm{Au} @ P d$ core-shell NCs with an octahedral shape (ca. $48 \mathrm{~h}$ at $90{ }^{\circ} \mathrm{C}$ ). On the contrary, however, the co-reduction of the metal precursor salts in the presence of $\mathrm{AA}$ at an $[\mathrm{AA}] /[\mathrm{M}]$ ratio of 0.75 (where $[\mathrm{M}]$ is the metal precursor concentration) ( $2 \mathrm{~h}$ at room temperature), yielded Au-Pd alloy NCs with $\{111\}$-faceted octahedral morphology. When the $[\mathrm{AA}] /[\mathrm{M}]$ ratio was 1 , rhombic

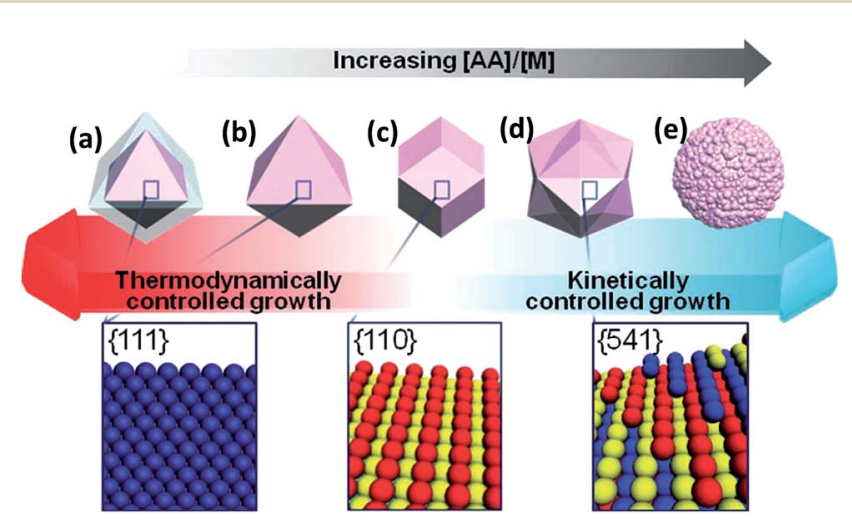

Fig. 8 Schematic of the correlation between the morphology of AuPd NCs and the NC growth kinetics; (a) core-shell octahedron, (b) octahedron, (c) rhombic dodecahedron (RD), (d) hexoctahedron $(\mathrm{HOH})$, and (e) flower-like structure. Corresponding 3D lattice models for the surface facets of NCs are shown below the scheme. Figure adapted from ref. 61 with permission. 
dodecahedral (RD) Au-Pd alloy NCs exclusively bound by $\{110\}$ facets were obtained. Increasing the $[\mathrm{AA}] /[\mathrm{M}]$ ratio to 4 yielded hexoctahedral $(\mathrm{HOH}) \mathrm{Au}-\mathrm{Pd}$ alloy NCs predominantly bound by high-index $\{541\}$ facets. The changes in the morphology of the NCs following changes in the $[\mathrm{AA}] /[\mathrm{M}]$ ratio are elegantly described by the authors (Fig. 8). As should be expected, the $\mathrm{HOH} \mathrm{Au}-\mathrm{Pd}$ alloy NCs showed a higher catalytic performance toward the electro-oxidation of ethanol in alkaline media than equivalent $\mathrm{RD}$ Au-Pd alloy NCs bound by low-index facets (Fig. 9c and d).

1.2.2 Galvanic replacement reaction. The galvanic replacement reaction (GRR) represents an effective synthetic route for controllably generating various types of bimetallic nanocrystals with different morphologies and surface structures. It is an etching process that does not require the use of hazardous reducing agents, thus it may be regarded as a "green" method for synthesizing nanocrystals. The GRR is a potentialdependent procedure that involves a sacrificial metal template and another metal ion in a solution phase. In other words, the GRR occurs by the oxidation and dissolution of the sacrificial template, accompanied by reduction of another metal ion and deposition of the resultant atoms on the surface of the template. In principle, the GRR can take place between any pair of metals that possesses an appropriate difference in their redox potentials. The GRR has been used to prepare several catalysts relevant for application in AFCs, e.g., $\mathrm{Pd}-\mathrm{Ag}^{62-67}$ and $\mathrm{PdNi}^{68}$ Despite the unique advantages of the GRR, the process can be somewhat discouraging due to its complex reaction steps, which require a highly skilled operator. To solve these problems, some attempts are being made by some researchers to develop simpler and more facile chemical reduction processes than the traditional GRR. For example, Chen et al. ${ }^{69}$ reported the development of a non-noble-metal sacrificial strategy for synthesising PdAg nanocrystals supported on reduced graphene oxide (RGO). More recently, Fu et al. ${ }^{65}$ introduced a straightforward and effective hydrothermal method for the synthesis of high-quality $\mathrm{Pd}-\mathrm{Ag}$ nanoalloy polyhedrons, following an underpotential deposition (UPD)-based epiphytic reduction mechanism.

1.2.3 Seed-mediated growth. The seed-mediated growth (SMG) process is a bottom-up synthesis method for controlling the shape and structure of nanocrystals. In the SMG process, a pre-synthesized seed of one metal serves as an initial site for the nucleation and growth of a second metal. Briefly stated, it involves the use of a seed solution (which contains the metal ions and reductant for the pre-synthesis of the nanoseed particles on a substrate, such as the ITO) and growth solution (which contains the metal ions, reductant, and capping agents for the nucleation, growth, and subsequent formation of the required nanocrystals). SMG is the conventional method for the synthesis of Au nanorods or nanocrystals in aqueous solution, but the method has been adapted by several researchers to control the size and structure of the nanoparticles, including the highly challenging synthesis of Pd nanocrystals covered by high-index facets. For example, SMG has been used to synthesise Pd concave nanocubes (PdCNs) covered by high-index $\{730\}$ facets, using different capping agents. ${ }^{70,71} \mathrm{Also}, \mathrm{a} \mathrm{Cu}(\mathrm{II})$-assisted SMG protocol has been used to synthesize PdCNs. ${ }^{72}$ Unfortunately, however, the SMG processes for these PdCNs involve several steps and yet do not give pure products, which make
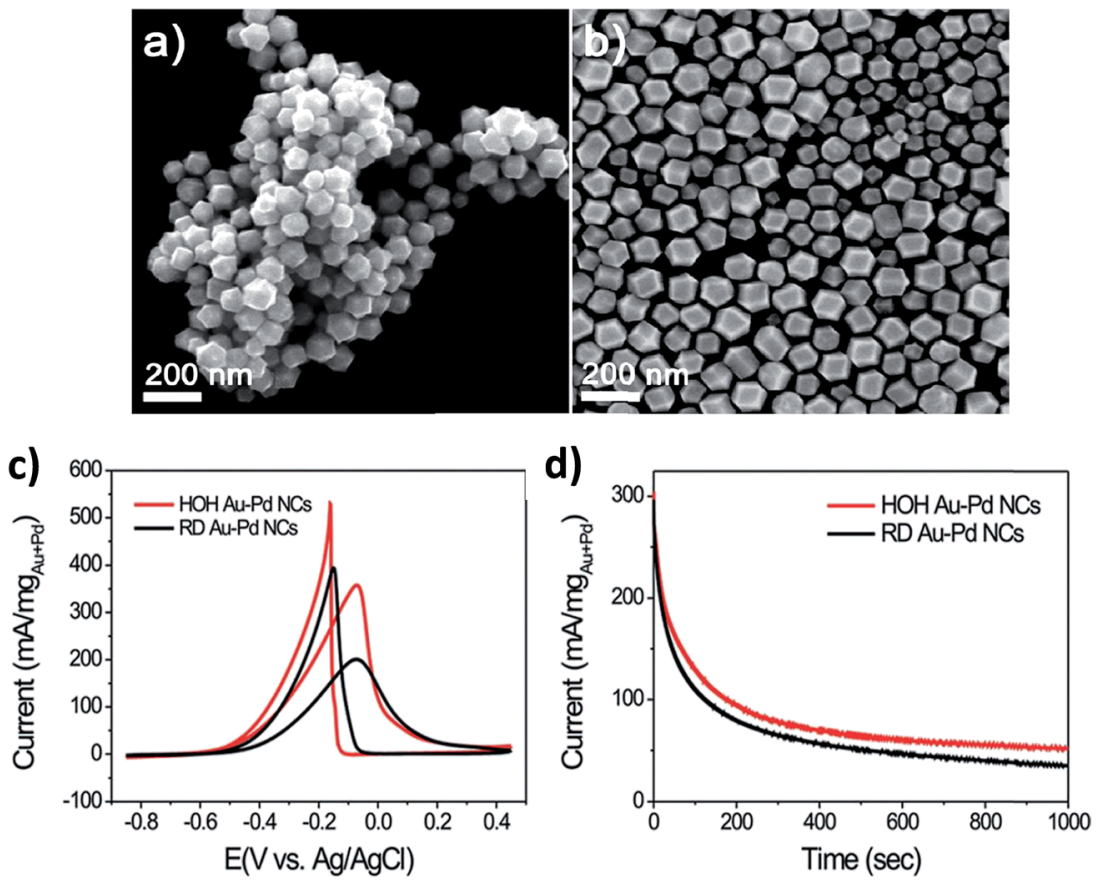

Fig. 9 SEM images of (a) HOH and (b) RD Au-Pd alloy NCs, (c) cyclic voltammograms of GCE-modified HOH and RD Au-Pd alloy NCs obtained in $0.1 \mathrm{M} \mathrm{KOH}+0.5 \mathrm{M}$ ethanol at a scan rate of $50 \mathrm{mV} \mathrm{s}^{-1}$, and (d) chronoamperograms of $\mathrm{HOH}$ and $\mathrm{RD} \mathrm{Au}-\mathrm{Pd}$ alloy NCs at $-0.1 \mathrm{~V} v$. Ag/AgCl. Figure adapted from ref. 61 with permission. 
them disadvantageous for large-scale production. ${ }^{73}$ These disadvantages have continued to motivate the search for simpler and more robust techniques for preparing high-quality nanocrystals enclosed with high-index facets. For example, Xie et $a l^{74}$ recently introduced an elegant one-pot strategy for the large-scale synthesis of high-quality palladium concave nanocubes (PdCNs) enclosed by high-index $\{730\}$ facets, using low temperature and an increased concentration of L-ascorbic acid (reductant) in the presence of CTAB (capping agent). Here, again, we observe how a high concentration of AA can positively impact on the morphology and electrocatalytic performance of the Pd NCs. The PdCNs showed good amounts of active sites (most notably, steps, corners and edges) (Fig. 10) resulting in a high-catalytic performance for the methanol oxidation reaction in an alkaline medium, compared to that of Pd nanocubes and commercial $\mathrm{Pd} / \mathrm{C}$.

1.2.4 Electrochemical deposition or electro-deposition and treatments. Electrochemical deposition (also known as "electrodeposition") may simply be defined as a process by which a metal catalyst film or its solid nanostructure is deposited onto an electrically conducting substrate or electrode surface from a solution containing a metal salt precursor. Electrodeposition can be used to form a monometallic catalyst or codeposit two or more metal nanoalloys. Electrodeposition is simple, and can be easily performed using cyclic voltammetry or chronoamperometry. There are several reports on the formation of nanocrystals by electrodeposition, especially Pdbased nanocrystals. For example, Feliu and coworkers ${ }^{75}$ successfully electrodeposited Pd adatoms on cubic Pt nanoparticles as an anode electrocatalyst toward formic acid oxidation in fuel cells. The authors proposed that the amounts of Pd on the Pt surfaces can be easily monitored in situ by observing the voltammetric changes during the deposition process.

In 2007, Sun and co-workers ${ }^{76,77}$ first reported the use of a square-wave potential treatment (SWPT) process for the synthesis of Pt nanocrystals covered with high-index facets. This unique process was able to generate high-index faceted Pt nano-crystals supported on carbon black with a small size (2-10 nm), comparable to that of the standard commercial $\mathrm{Pt} / \mathrm{C}$ catalysts. ${ }^{78}$ Since the introduction of this technique, other workers have also used the technique to transform the shapes of some nanocrystals. For example, Zhou et al. used the technique to transform Pt nanocubes to tetrahexahedra with an average size of $\sim 10 \mathrm{~nm} .{ }^{79}$ The technique was able to transform the surface structure from low-index facets $\{100\}$ to high-index facets $\{310\}$, thereby significantly improving the electrocatalysis of the ethanol oxidation reaction. In 2010 , the same authors ${ }^{80}$ slightly modified the technique for the synthesis of palladium nanocrystals with high-index facets, with an average particle diameter of $61 \mathrm{~nm}$. In 2015, Lin et al. adopted the method to synthesize Bi-decorated Pd tetrahexahedral nanocrystals for the ethanol oxidation reaction. ${ }^{81}$

In 2012, Vizza and co-workers ${ }^{82}$ reported a modified SWPT named electrochemical milling and faceting (ECMF). In this method, the authors first electrodeposited large Pd nanoparticles $\left(35 \mathrm{~nm}\right.$ ) with low-index facets supported on $\mathrm{TiO}_{2}$ nanotube arrays (TNTAs), and then applied a two-step SWPT (see Fig. 11) involving "heavy" and "mild" oxidation-reduction
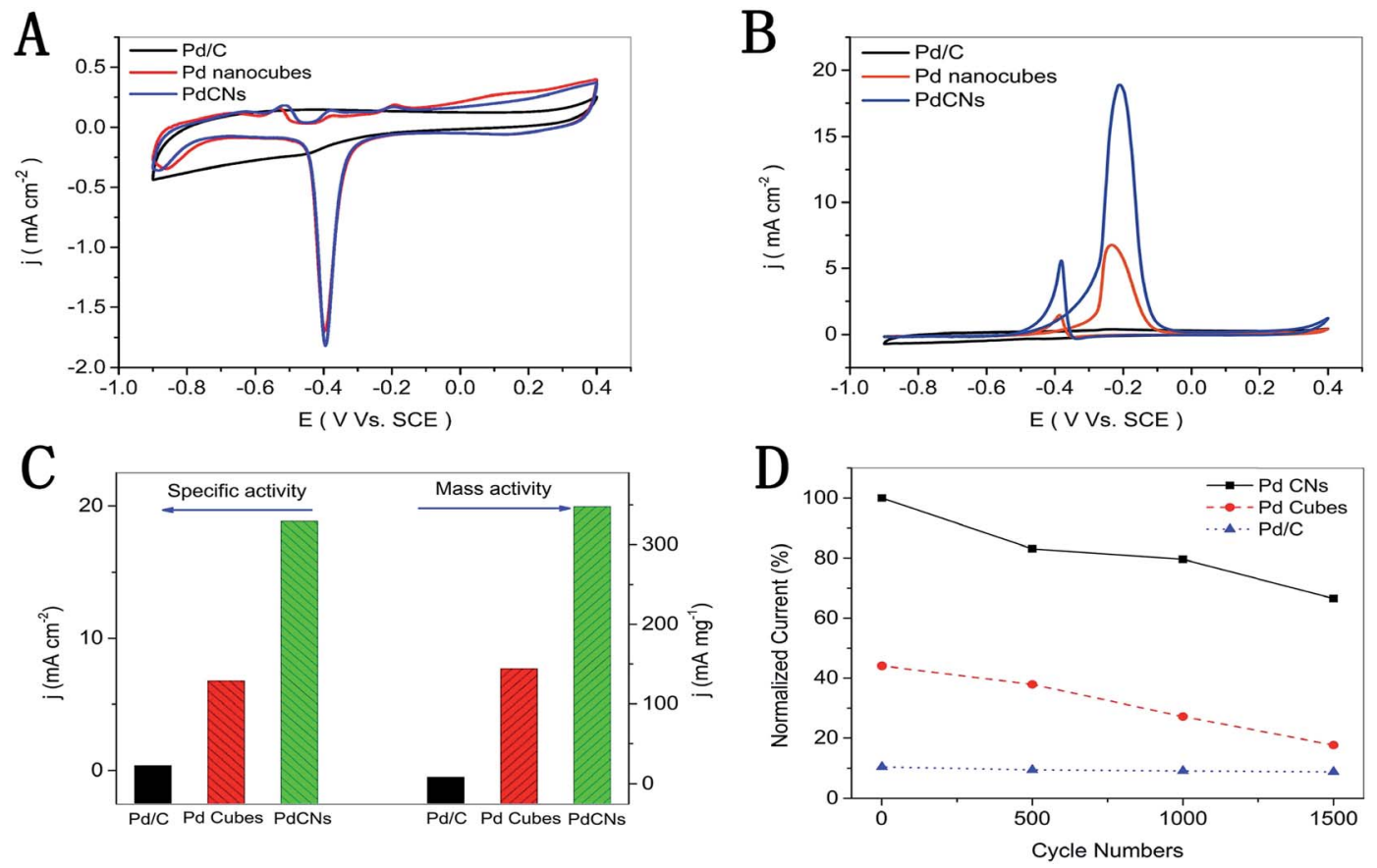

Fig. 10 Cyclic voltammograms of the PdCNs, Pd nanocubes, and commercial Pd/C, which are recorded at room temperature with a scan rate of $50 \mathrm{mV} \mathrm{s}^{-1}$ in (A) $1 \mathrm{M} \mathrm{KOH}$ solution; (B) $1 \mathrm{M} \mathrm{KOH}$ containing $1 \mathrm{M} \mathrm{CH}_{3} \mathrm{OH}$; (C) the mass and specific activities ( $-0.2 \mathrm{~V}$ vs. SCE); (D) normalized current of 1500 cycles. Figure adapted from ref. 74 with permission. 
A
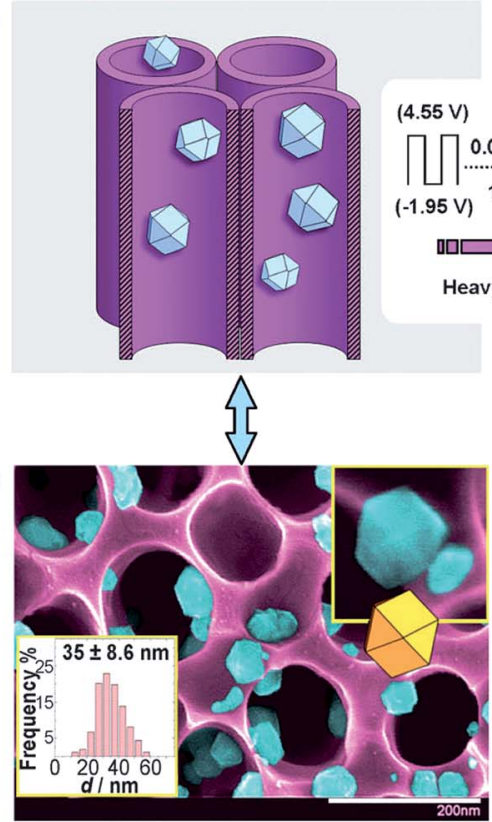

B

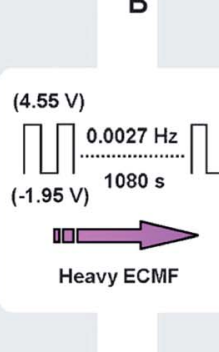

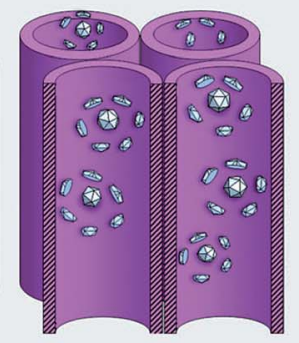

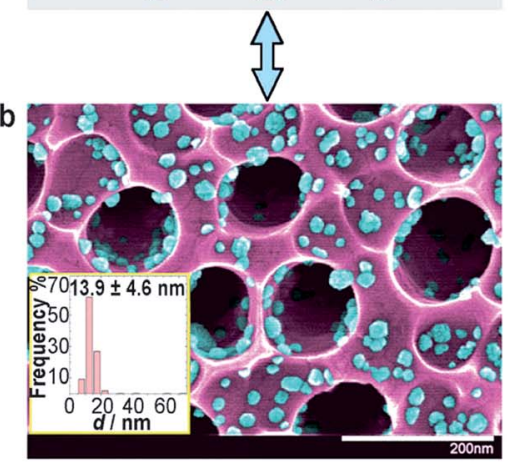

C
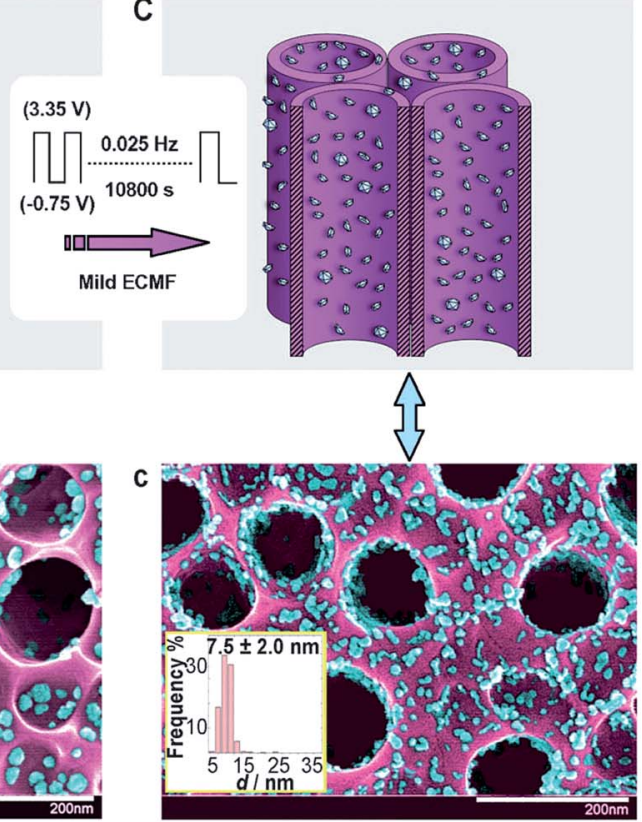

Fig. 11 (A) TNTAs with as-deposited Pd and (a) the corresponding SEM image. (B) TNTAs with Pd after heavy ECMF and (b) the corresponding SEM image. (C) TNTAs with Pd after heavy and mild ECFM and (c) the corresponding SEM image. False coloring of the SEM images shows Pd NPs (light blue) and the TNTA support (violet). The white scale bars in $(\mathrm{a}-\mathrm{c})$ are $200 \mathrm{~nm}$. Figure adapted from ref. 82 with permission.

steps that finally yielded Pd nanocrystals of a small mean particle size of $7 \mathrm{~nm}$ (milling) and high-index facets (faceting) (Fig. 12). The obtained TNTA-modified Pd nanocrystals exhibited improved electrocatalysis towards the EOR (in terms of current density, mass-specific activity, and onset potential) compared to the as-deposited TNTA-Pd.
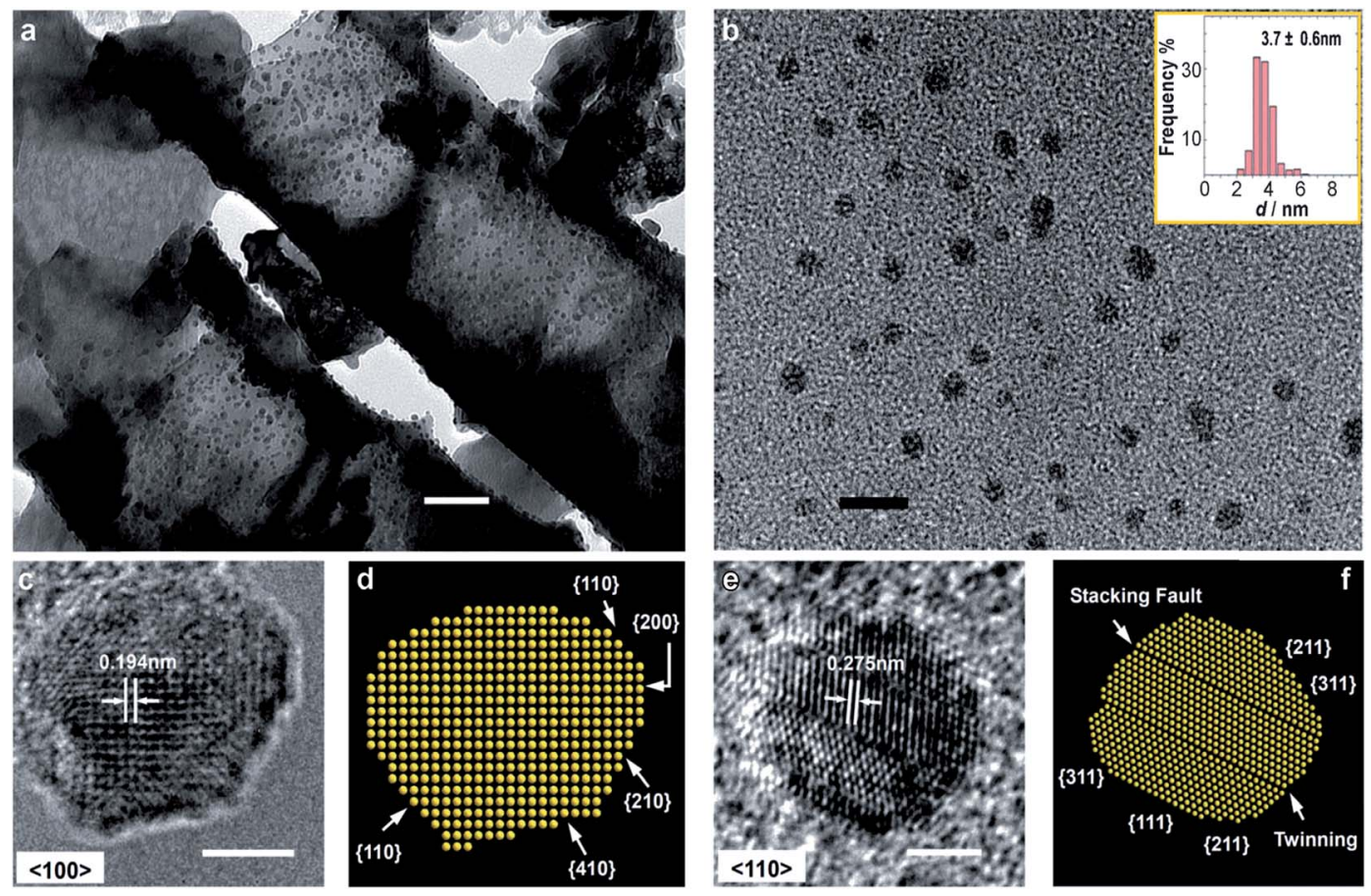

Fig. 12 (a) TEM image of the Pd-loaded TNTA electrode after heavy and mild ECMF (scale bar $=50 \mathrm{~nm}$ ). (b) Pd nanoparticles found in the electrolyte after heavy and mild ECMF (scale bar $=35 \mathrm{~nm}$ ). (c) HRTEM image (scale bar $=2 \mathrm{~nm}$ ) and (d) atomic models with face assignment of the TNTA-supported Pd nanoparticle along the $\{100\}$ direction. (e) HRTEM image (scale bar $=2 \mathrm{~nm}$ ) and (f) face assignment of the TNTA-supported $\mathrm{Pd}$ nanoparticles along the $\{110\}$ direction. Figure adapted from ref. 82 with permission. 


\section{Nanocatalysts for alcohol oxidation reaction (AOR) in alkaline media}

\subsection{Introduction: an overview of the general reaction mechanism}

The various advantages that characterize the use of alkaline media in the efficient electrocatalytic oxidation of alcohols have been elegantly reviewed by Bianchini and Shen. ${ }^{3}$ Some of the advantages include: (i) the possibility to deploy low-cost nonprecious metal catalysts; (ii) improved kinetics at low overpotentials; (iii) reduced ability of the reacting alcohol to crossover from its anodic compartment to the cathodic side; (iv) improved water management of the cell; water is generated at the anodic compartment where water already exists, while water is removed from the cathodic compartment via electro-osmotic drag, thereby preventing the possibility of water-flooding; (v) minimum corrosion risks for the electrode materials; and (vi) minimum risks of the adsorption of the spectator ions onto the MEAs. In addition, catalyst poisoning is very weak in alkaline media. ${ }^{5,6}$

The two most investigated monohydric or primary alcohols are methanol and ethanol, while the polyhydric alcohols are glycerol and ethylene glycol. The popularity of these alcohols in ADAFCs stems from their unique advantages of high gravimetric and volumetric energy densities (Table 3). The volumetric energy density of each of the alcohols (ca. 5.0-7.5 kW h $\mathrm{L}^{-1}$ ) is slightly lower than that of gasoline (ca. $\left.9.5 \mathrm{~kW} \mathrm{~h} \mathrm{~L}^{-1}\right)$ and anthracite coal ( $c a .10 .2 \mathrm{~kW} \mathrm{~h} \mathrm{~L}{ }^{-1}$ ), but much higher than that of hydrogen (1.6 $\left.\mathrm{kW} \mathrm{h} \mathrm{L}{ }^{-1}\right)$ or lithium-ion batteries, or electrochemical capacitors $\left(<0.02 \mathrm{~kW} \mathrm{~h} \mathrm{~L}^{-1}\right)$. Also, one often finds that $\mathrm{KOH}$ is the most important electrolyte for the AFC and ADAFC systems, rather than its $\mathrm{NaOH}$ counterpart, and this should perhaps not be surprising as $\mathrm{KOH}$ is less caustic than $\mathrm{NaOH}$, which means that the degradation of some of the components of a fuel cell, such as the gaskets, will be milder than with $\mathrm{NaOH}$. In addition, $\mathrm{KOH}$ is ionically more conductive than $\mathrm{NaOH}$, which means that the ohmic overpotential losses are higher with $\mathrm{NaOH}$ than with $\mathrm{KOH}$.
With the exception of methanol, which requires 6 electrons for complete oxidation, the oxidation of higher alcohols is more difficult, as they require between 10 and 18 electrons for complete oxidation. Presently, much effort is being devoted to improving their electro-oxidation performance by utilising Pd-based bimetallic and ternary catalysts, and understanding the underlying mechanisms. ${ }^{\mathbf{8 3}-85}$ From the "bi-functional theory", ${ }^{86}$ the electro-oxidation of primary alcohols (e.g., methanol and ethanol) to $\mathrm{CO}_{2}$ and $\mathrm{R}-\mathrm{COOH}\left(\right.$ or $\mathrm{CO}_{3}{ }^{2-}$ and $\mathrm{R}-\mathrm{COO}^{-}$ in alkaline medium) requires the activation of $\mathrm{H}_{2} \mathrm{O}$ under $\mathrm{OH}$ adsorbed species $\left(\mathrm{OH}_{\mathrm{ads}}\right)$ at the catalyst's surface, to provide the extra oxygen atom and to complete the AOR, in accordance with eqn (2)-(6), occurring in alkaline electrolyte:

$$
\begin{gathered}
\mathrm{Pd}+\mathrm{RCH}_{2} \mathrm{OH} \rightarrow \mathrm{Pd}-\left(\mathrm{RCH}_{2} \mathrm{OH}\right)_{\mathrm{ads}} \\
\mathrm{Pd}-\left(\mathrm{RCH}_{2} \mathrm{OH}\right)_{\mathrm{ads}}+3 \mathrm{OH}^{-} \rightarrow \mathrm{Pd}-(\mathrm{RCO})_{\mathrm{ads}}+3 \mathrm{H}_{2} \mathrm{O}+3 \mathrm{e}^{-} \\
\mathrm{Pd}-\mathrm{OH}^{-} \rightarrow \mathrm{Pd}-\mathrm{OH}_{\mathrm{ads}}{ }^{-}+\mathrm{e}^{-} \\
\mathrm{Pd}-(\mathrm{RCO})_{\mathrm{ads}}+\mathrm{Pd}-\mathrm{OH}_{\mathrm{ads}}{ }^{-} \rightarrow \mathrm{Pd}-(\mathrm{RCOOH})+\mathrm{Pd} \mathrm{rds} \\
\mathrm{RCOOH}+\mathrm{OH}^{-} \rightarrow \mathrm{RCOO}^{-}+\mathrm{H}_{2} \mathrm{O}
\end{gathered}
$$

Eqn (2) and (3) relate to the fast dissociative adsorption of alcohol on the catalyst surface. Eqn (5) is the rate-determining step (rds), which means that the AOR strongly depends on the coverage of the adsorbed acyl and hydoxyl species, $\mathrm{RCO}_{\mathrm{ads}}$ and $\mathrm{OH}_{\mathrm{ads}}$, on the surface of the nanocatalyst, generally leading to the formation of the acetate. Nano-sizing of the catalysts improves the rate of hydroxyl adsorption on the catalyst surface. ${ }^{87}$

Some researchers have shown that the catalytic performance of Pd nanocatalysts for the AOR in alkaline media (in respect of activity and stability) can be greatly enhanced by incorporating catalysts with metal oxides (such as $\mathrm{NiO}, \mathrm{CeO}_{2}, \mathrm{Co}_{3} \mathrm{O}_{4}$, and $\left.\mathrm{Mn}_{3} \mathrm{O}_{4}\right){ }^{88-90}$ Indeed, the metal oxides play the same role as $\mathrm{Ru}$ in

\begin{tabular}{|c|c|c|c|c|}
\hline Fuel & $\begin{array}{l}\text { Density at } \\
20^{\circ} \mathrm{C} / \mathrm{g} \mathrm{cm}^{-3}\end{array}$ & $\begin{array}{l}\text { Specific energy } \\
\text { density } / \mathrm{kW} \mathrm{h} \mathrm{kg}^{-1}\end{array}$ & $\begin{array}{l}\text { Volumetric energy } \\
\text { density/kW h L }\end{array}$ & $n$ \\
\hline Methanol & 0.787 & 6.36 & 4.99 & $6 \mathrm{e}^{-}$ \\
\hline Ethylene glycol & 1.113 & 5.30 & 5.87 & $10 \mathrm{e}^{-}$ \\
\hline Glycerol & 1.261 & 5.00 & 6.26 & $14 \mathrm{e}^{-}$ \\
\hline Propan-1-ol & 0.800 & 9.41 & 7.53 & $18 \mathrm{e}^{-}$ \\
\hline Hydrogen (at 700 bar) & & 34.72 & 1.57 & $2 \mathrm{e}^{-}$ \\
\hline Coal (anthracite) & 1.350 & 7.56 & 10.21 & - \\
\hline Coal (lignite) & 0.801 & 4.20 & 3.36 & - \\
\hline Lithium-ion battery (re-chargeable) & - & $0.100-0.245$ & $0.252-0.736$ & - \\
\hline Supercapacitor (EDLC) & - & $0.003-0.010$ & $0.014-0.017$ & - \\
\hline Supercapacitor (pseudocapacitor) & - & 0.009 & 0.013 & - \\
\hline
\end{tabular}
the $\mathrm{PtRu} / \mathrm{C}$ catalysts in the bi-functional mechanism by increasing the concentration of $\mathrm{OH}_{\text {ads }}$ species on the surface of the electrocatalyst for $\mathrm{C}-\mathrm{C}$ bond cleavage and formation of the

Table 3 Physical properties of various alcohol fuels compared with some commonly used fuels and energy storage systems 
final oxidation products. Similarly, the enhancing catalytic role of metal oxides has been attributed to the so-called spillover of the primary oxide $(\mathrm{M}-\mathrm{OH}){ }^{91}$

It should be pointed out that the mechanism of the AOR in alkaline media is intriguing as it is somewhat controversial and unclear. It is undeniable, though, that the reaction steps are mediated by both the solution/electrolyte conditions and metal catalyst. Two recent studies can help explain this point. In 2011, Koper and co-workers ${ }^{92}$ reported that the AOR in alkaline media on a gold electrode follows the Hammett-type correlation (the lower the $\mathrm{p} K_{\mathrm{a}}$ of the alcohol, the higher its reactivity) as exemplified by this trend:

Glycerol $\left(\mathrm{p} K_{\mathrm{a}}=14.15\right)>$ ethylene glycol $\left(\mathrm{p} K_{\mathrm{a}}=14.77\right)>$ ethanol $\left(\mathrm{p} K_{\mathrm{a}}=15.9\right)>$ isopropanol $\left(\mathrm{p} K_{\mathrm{a}}=17.1\right)$

According to the authors, this trend is due to the solution hydroxide, which leads to the initial base-catalysed deprotonation reaction of the alcohol as the rate-determining step (rds), followed by the fast gold-catalysed deprotonation step. They concluded that the "base catalysis is the main driver behind the high oxidation activity of many organic fuels on fuel cell anodes in alkaline media, and not the catalyst interaction with hydroxide" ${ }^{92}$

In 2015, interestingly, Coutanceau and co-workers ${ }^{93}$ studied the same alcohols in alkaline media using Pd-Sn catalysts and obtained exactly the opposite trend:

Isopropanol $\left(\mathrm{p} K_{\mathrm{a}}=17.1\right)>$ ethanol $\left(\mathrm{p} K_{\mathrm{a}}=15.9\right)>$ ethylene glycol $\left(\mathrm{p} K_{\mathrm{a}}=14.77\right)>\operatorname{glycerol}\left(\mathrm{p} K_{\mathrm{a}}=14.15\right)$

According to the authors, the rds is not the initial base catalysis, as in the case of the gold electrode, but the ability of the catalyst surface to dissociatively adsorb the reacting alcohol or quickly desorb the reaction products of the AOR. They attributed the higher reactivity of the isopropanol to the ease by which the acetone desorption (i.e., the rds of isopropanol oxidation on the Pd-Ni catalyst ${ }^{94}$ ) occurs at the catalyst surface, compared to the more difficult dihydroxyacetone desorption (i.e., possible rds of glycerol oxidation) from the catalyst surface.

\subsection{Electro-oxidation of monohydric alcohols}

2.2.1 Methanol oxidation reaction (MOR). The methanol oxidation reaction (MOR) is a well-reviewed subject in the literature. The attention towards the MOR is due to the simplicity of methanol in both structure (it has just one carbon atom) and electrocatalysis (compared to ethanol, with faster electro-oxidation kinetics due to the involvement of a small amount of electrons, coupled with the ease of activation of the $\mathrm{C}-\mathrm{H}$ bond compared to the $\mathrm{C}-\mathrm{C}$ bond). The complete oxidation of methanol to $\mathrm{CO}_{2}$ (or carbonate in alkaline media) requires six electrons (see Fig. 13): ${ }^{95}$

The main disadvantage of methanol is its toxicity. Compared to other known metals, Pt gives the best catalytic activity toward the MOR, both in acidic and alkaline solutions. The activity of Pd toward the MOR in alkaline solution can be greatly enhanced

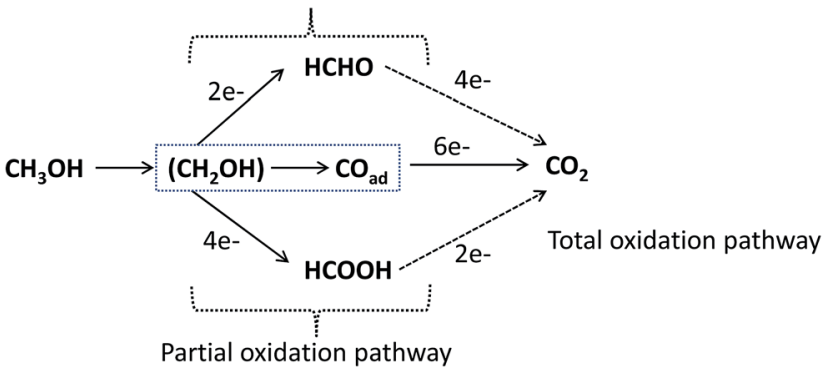

Fig. 13 Schematic of the parallel pathways for the electrocatalytic oxidation of methanol.

by incorporating another metal in the alloyed form (such as Pd$\mathrm{Ni} / \mathrm{C})^{96,97}$ or in the oxide form (such as $\mathrm{Pd}-\mathrm{NiO} / \mathrm{C}$ ), ${ }^{98,99}$ thus explaining the reason why most reports today on the MOR in alkaline media deploy Pd-based bimetallic nanocatalysts. The promoting effect of $\mathrm{Ni}$ or its oxide form should perhaps not be surprising, as Ni has long been known to oxidize primary alcohols to acids, ${ }^{\mathbf{1 0 0}}$ as shown in eqn (7) and (8). When $\mathrm{Ni}$ is placed in alkaline solution, it is covered with a layer of nickel hydroxide; the surface transformation and subsequent electrooxidation of the alcohol to organic acids are normally written as follows: ${ }^{100}$

$$
\begin{gathered}
\mathrm{Ni}(\mathrm{OH})_{2} \rightarrow \mathrm{NiOOH}+\mathrm{H}^{+}+\mathrm{e}^{-} \\
\mathrm{RCH}_{2} \mathrm{OH}+\mathrm{NiOOH} \rightarrow \mathrm{RCOOH}+\mathrm{Ni}(\mathrm{OH})_{2}
\end{gathered}
$$

The NiO is said to promote the anti-poisoning properties of the $\mathrm{PdNiO} / \mathrm{C}$ catalyst. Indeed, the last five years have seen an increase in research activities aimed at improving the catalytic activity of nanostructured Pd-based bimetallic catalysts for the MOR in alkaline media.

Recently, some non-precious metal oxides (notably, oxides of tin, cobalt, and nickel) have been reported as viable nanocatalysts for the MOR. Shi's group ${ }^{\mathbf{1 0 1}}$ showed that nanocomposites of tin oxide nanocrystals $(\sim 3 \mathrm{~nm})$ homogenously decorated on the surface of mesoporous zeolite (i.e., $\mathrm{SnO}_{2} / \mathrm{m}$ ZSM-5) exhibited high and stable electrocatalytic properties for the MOR, comparable to Pt/C. According to the authors, the enhanced performance was related to the excellent tolerance of CO poisoning, stemming from the synergistic interaction between $\mathrm{SnO}_{2}$ and m-ZSM-5. In 2016, Asghari and co-workers ${ }^{102}$ showed that hierarchical nanostructured tin-oxide-decorated polypyrrole on nanoporous copper (porous $\mathrm{Cu} / \mathrm{PPy} / \mathrm{SnO}_{x}$ ) showed enhanced MOR catalysis compared to its smooth $\mathrm{Cu} / \mathrm{PPy} / \mathrm{SnO}_{x}$ and porous $\mathrm{Cu} / \mathrm{PPy}$ counterparts. The improved performance was attributed to factors such as the ability of the $\mathrm{SnO}_{x}$ to bring about the adsorption of MOR intermediates and oxidation of the products, such as $\mathrm{CO}$, permitting the dehydrogenation of the alcohols, including the increased microscopic surface area of the electrodes. Wu et al. ${ }^{103}$ reported that a $\mathrm{Co}_{3} \mathrm{O}_{4} / \mathrm{NiO}$ core-shell nanowire array (with mesoporous nanowire core and branched nanoflake shell), obtained by combined hydrothermal and electrodeposition methods, showed excellent electrocatalysis toward the MOR compared to 
its single $\mathrm{Co}_{3} \mathrm{O}_{4}$ nanowire array. The enhanced performance was attributed to the synergy between the core-shell architecture, which allowed for fast kinetics and a lower overpotential. An interesting finding on the electrocatalytic properties of $\mathrm{NiO}_{x}$ and $\mathrm{MnO}_{x}$ was reported by Saleh's group. ${ }^{\mathbf{1 0 4}}$ According to the authors, electrodeposited $\mathrm{NiO}_{x}$ and $\mathrm{MnO}_{x}$ nanocomposites on glassy carbon provided an excellent catalyst platform for the MOR, but to achieve the desired catalytic effects, $\mathrm{NiO}_{x}$ must be sitting on the $\mathrm{MnO}_{x}$ surface, and not the other way around (i.e., $\mathrm{GC} / \mathrm{MnO}_{x} / \mathrm{NiO}_{x}$ ). The enhanced activity was ascribed to the enhanced adsorbability of $\mathrm{MeOH}$ on the $\mathrm{MnO}_{x}$. Indeed, these reports are highly promising for the development of precious metal-free catalyst design for alcohol oxidation.

2.2.2 Ethanol oxidation reaction (EOR). Ethanol is regarded as the most plausible candidate to replace methanol in DAFCs. Ethanol possesses several advantages over methanol, and these include low toxicity, the ability to be produced on a large scale from renewable sources (e.g., from agricultural products), ease of transportation, and higher energy density compared to methanol (i.e., $8.0 v s$. $6.1 \mathrm{~kW} \mathrm{~h} \mathrm{~kg}^{-1}$ ). It is well established that the main oxidation products of ethanol in acidic media are carbon dioxide $\left(\mathrm{CO}_{2}\right)$, acetaldehyde $\left(\mathrm{CH}_{3} \mathrm{CHO}\right)$, and acetic acid $\left(\mathrm{CH}_{3} \mathrm{COOH}\right)$. As summarized by Camara and Iwasita ${ }^{\mathbf{1 0 5}}$ (and depicted in Fig. 14) the total oxidation to $\mathrm{CO}_{2}$ involves a 12-electron process, while the partial pathway involves 2-electron and 4-electron processes for $\mathrm{CH}_{3} \mathrm{CHO}$ and $\mathrm{CH}_{3} \mathrm{COOH}$, respectively. The breaking of the $\mathrm{C}-\mathrm{C}$ bonds to attain the total oxidation to $\mathrm{CO}_{2}$ (or the carbonate for the alkaline media) is the major problem with the EOR, thus the dominating pathway is the partial oxidation pathway. The partial oxidation pathway simply indicates that the number of electrons extracted during the EOR is grossly limited, meaning that fuel cell utilization efficiency is considerably lowered.

Unlike the MOR, the EOR in alkaline solution is more feasible with a Pd than a Pt catalyst. To realize the bifunctional mechanism, the majority of the EOR studies in alkaline electrolyte in the last five years have focused on Pd-based bimetallic catalysts, such as Pd-Ag, ${ }^{106-109} \mathrm{Pd}-\mathrm{Ni},{ }^{\text {51,110-113 }} \mathrm{Pd}-\mathrm{Sn},{ }^{114-116} \mathrm{Pd}-$ $\mathrm{Pb},{ }^{117} \mathrm{~Pb}-\mathrm{Tb},{ }^{118} \mathrm{Pd}-\mathrm{Bi},{ }^{119} \mathrm{Pd}-\mathrm{In}_{2} \mathrm{O}_{3},{ }^{120} \mathrm{Pd}-\mathrm{NiO},{ }^{90}$ and $\mathrm{Pd}-\mathrm{CeO}_{2},{ }^{90}$ as well as ternary catalysts, such as $\mathrm{Pd}-\mathrm{Ir}-\mathrm{Ni},{ }^{121} \mathrm{Pd}-\mathrm{Ru}-\mathrm{Sn},{ }^{114}$

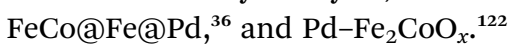

The underlying mechanisms of the Pd-catalyzed EOR in alkaline media, established from in situ spectroscopic techniques, are intricately linked to factors such as the pH electrolyte, electrode potential, water, and adsorbed acyl and hydroxyl species. Recently, using in situ FTIR spectroelectrochemistry,

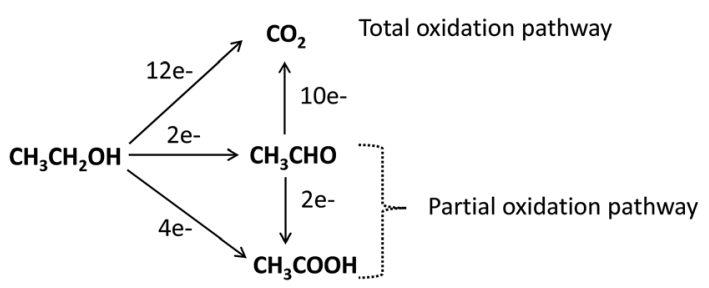

Fig. 14 Schematic of the parallel pathways for the electrocatalytic oxidation of ethanol.
Fang et al. ${ }^{123}$ proved that breaking of the $\mathrm{C}-\mathrm{C}$ bond of ethanol at the Pd electrode is dependent on the $\mathrm{pH}$ of the electrolyte; total $\mathrm{C}-\mathrm{C}$ bond breaking occurs only at $\mathrm{pH} \leq 13$, while at $\mathrm{pH} 14$, partial oxidation occurs, with acetate being the only oxidation product of the EOR, indicating that the faradic efficiency of the EOR with Pd is lowered at an elevated alkaline $\mathrm{pH}$.

The effect of the applied electrode potential on the cleavage of $\mathrm{C}-\mathrm{C}$ bonds in the EOR was recently established by Yang et al., ${ }^{124}$ from in situ attenuated total reflection surface enhanced infrared adsorption spectroscopy (ATR-SEIRAS). From their findings, the authors proposed a 2-way mechanistic pathway (Fig. 15). At the open-circuit potential (OCP) or lower potential $(<-0.1 \mathrm{~V})$ an adsorbed acyl species $\left(\mathrm{CH}_{3} \mathrm{CO}_{\mathrm{ads}}\right)$ is formed, which is further electro-oxidized through a $\mathrm{C} 2$ pathway to form $\mathrm{CH}_{3} \mathrm{COO}^{-}$(at high anode potentials, >-0.4 V) or a $\mathrm{C} 1$ pathway to $\mathrm{CO}_{\mathrm{ad}}$ and $\mathrm{CH}_{x}$ and eventually to $\mathrm{CO}_{2}$ (at low potentials).

A recent study on $a b$ initio molecular dynamics simulations by Sheng et al. ${ }^{\mathbf{1 2 5}}$ demonstrated the importance of water and $\mathrm{OH}_{\text {ads }}$ on the EOR mechanism on a Pd electrode in alkaline media. As depicted in Fig. 16, ethanol adsorbed in the IHP on $\mathrm{Pd}(111)$ overcomes a barrier to produce acetaldehyde $\left(\mathrm{CH}_{3} \mathrm{CHO}\right)$ first. However, because of the weak adsorption of $\mathrm{CH}_{3} \mathrm{CHO}$, the formed $\mathrm{CH}_{3} \mathrm{CHO}$ immediately desorbs to the electrolyte solution, in which a sufficient amount of geminal diol $\left(\mathrm{CH}_{3}\right.$ $\left.\mathrm{CH}(\mathrm{OH})_{2}\right)$ is produced. The $\mathrm{CH}_{3} \mathrm{CH}(\mathrm{OH})_{2}$ is more active than $\mathrm{CH}_{3} \mathrm{CHO}$, to produce acetate $\left(\mathrm{CH}_{3} \mathrm{COO}^{-}\right)$. The authors demonstrated that the EOR in alkaline medium follows a concertedlike dehydrogenation mechanistic pathway in which $\mathrm{OH}_{\mathrm{ads}}$ plays a critical role. In the inner Helmholtz plane (IHP), $\mathrm{OH}_{\mathrm{ads}}$ is the active center for dehydrogenation. The initial generation of $\mathrm{OH}_{\text {ads }}$ is followed by water dissociation (which is the predominant route for the generation of electricity) and then the generation of new $\mathrm{OH}_{\text {ads }}$ for further dehydrogenation. Thus, it is ethanol decomposition and water dissociation that form the complete electrocatalytic cycle, continuously transferring $\mathrm{H}$ to the aqueous electrolyte. The main highlight of this study is that, unlike the traditional multi-step mechanisms that involve several intermediates, the mechanism proposed by these researchers (shown in Fig. 16) involves the generation of both acetaldehyde and acetate in a manner that avoided a variety of intermediates, and is proven with experimental observations from in situ FTIR spectroscopy. As should be expected from electrocatalytic reactions (which take place at the electrodeelectrolyte interface), the authors showed that an $\mathrm{OH}_{\text {ads }}$-assisted

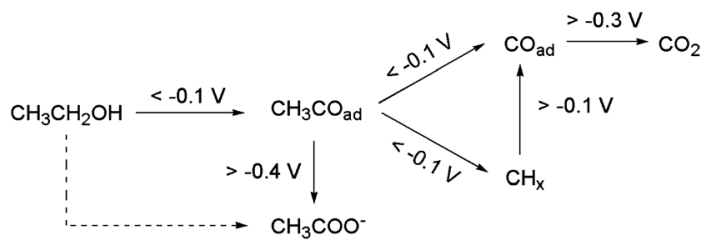

Fig. 15 Reaction pathways for interfacial $\mathrm{CH}_{3} \mathrm{CH}_{2} \mathrm{OH}$ oxidation on a $\mathrm{Pd}$ electrode in alkaline media (the dashed-line arrow is not accompanied by any direct spectral evidence). Figure adapted from ref. 124 with permission. 


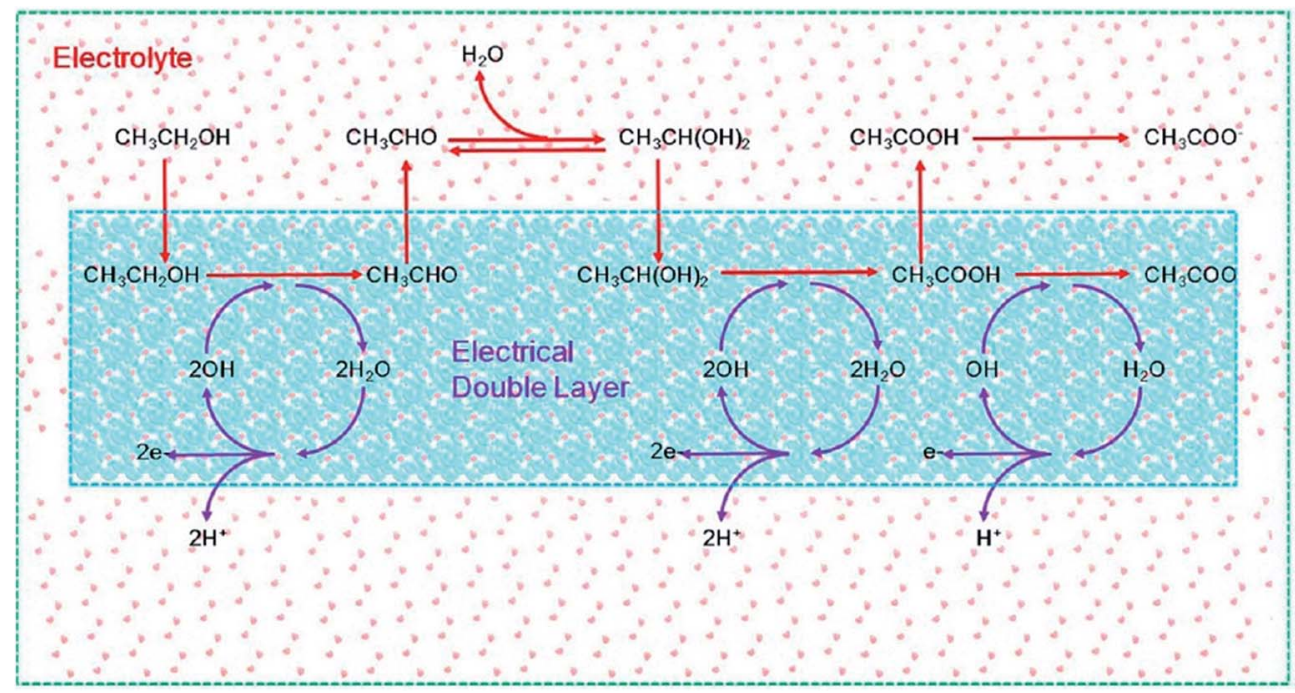

Fig. 16 Schematic of ethanol electrooxidation in a DEFC using a Pd electrode in the presence of an electrical double layer. The red arrows represent the dehydrogenation of ethanol, while the purple arrows represent the dissociation of water. Figure adapted from ref. 125 with permission.

concerted-like mechanism takes place at the IHP (i.e., electrical double layer), while the outer Helmholtz plane (OHP) has little effect on the reaction barriers $(\sim 0.02 \mathrm{eV})$.

\subsection{Oxidation of polyhydric alcohols in alkaline media: ethylene glycol and glycerol}

The oxidation of alcohols, especially the higher alcohols (such as EtOH, EG, and Gly), is better performed in alkaline DAFCs (ADAFCs) than in acidic DAFC devices. The reasons for the deployment of alkaline DAFCs for the higher alcohols are due to the attendant advantages of working in alkaline media, which include; (i) faster anode (AOR) and cathode (ORR) electrode kinetics with the use of non-noble metal catalysts, (ii) little or no poisoning of the non-noble metal catalysts, (iii) faster ORR at high $\mathrm{pH}$, and (iv) higher power density and efficiency compared to acidic DAFCs. Indeed, the highest-performing DAFCs are the AEM-based alkaline DAFC devices.

The most investigated polyhydric alcohols for alkaline DAFCs are EG and Gly, albeit some new ones, such as 1,2propandiol, 1,3-propandiol and 1,4-butandiol, ${ }^{126}$ have recently been introduced. Most of the reports on the oxidation and mechanisms of EG and Gly have been from the group of Vizza and co-workers. ${ }^{127}$ Like ethanol, no one has been able to achieve complete oxidation of EG and Gly to $\mathrm{CO}_{2}$ or carbonate. In fact, the formation of carbonate has generally remained a minor reaction pathway, with a mixture of products being formed. Interestingly, however, Ozoemena and co-workers recently reported how an FeCo@Fe@Pd core-shell-shell nanocatalyst, supported on carboxyl-functionalized multi-walled carbon nanotubes (MWCNT-COOH), electrocatalyzed EG and Gly in an alkaline DAFC device, with high selectivity to carbonate (i.e., 67 and $73 \%$ carbonate for EG and Gly, respectively). ${ }^{26}$ Fig. 17 and 18 show the proposed mechanistic pathways for the excellent oxidation of EG and Gly, giving carbonate as the main products. For the EG, the Pd-based electrocatalysts tend to oxidize one hydroxyl group (i.e., glycolate formation, path a), with a very small amount of oxalate by direct oxidation (path b). By the small amount of oxalate observed, it may be inferred that further oxidation of the glycolate to oxalate (path d) is not preferred, but rather the formation of the carbonate with a minute amount of formate (path c). Compared to Pd/MWCNT-

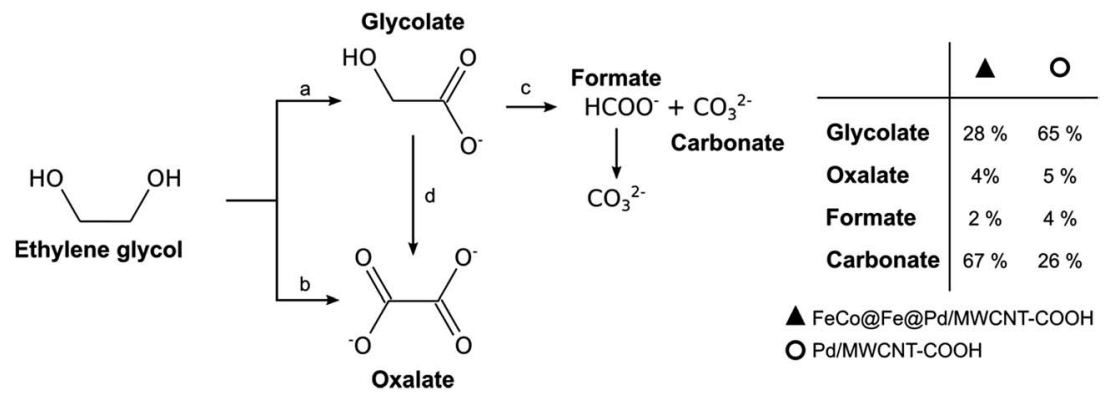

Fig. 17 Proposed reaction pathway for EG electro-oxidation on FeCo@Fe@Pd/MWCNT-COOH and Pd/MWCNT-COOH in alkaline medium. Figure adapted from ref. 26 with permission. 


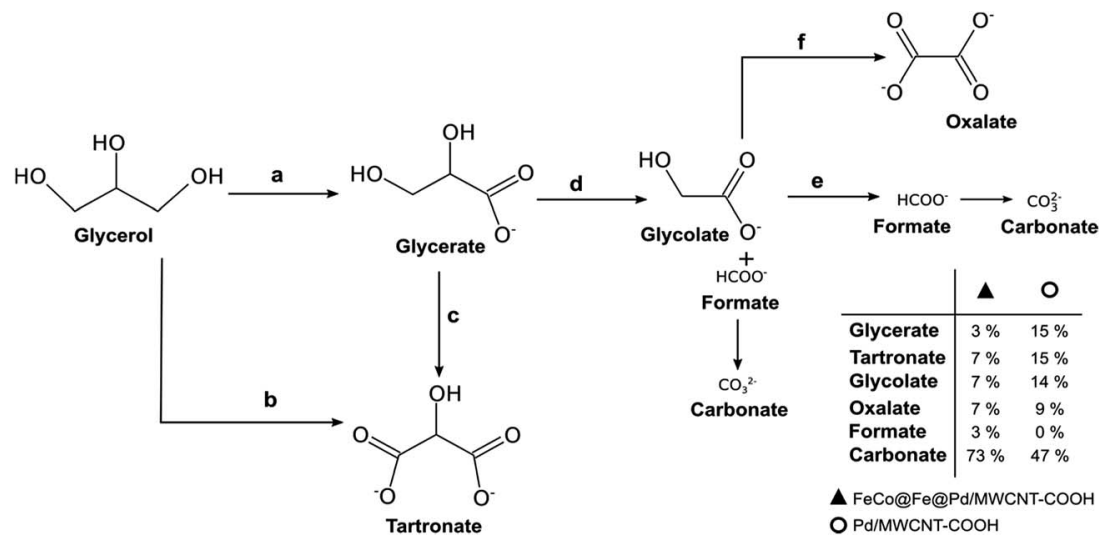

Fig. 18 Proposed reaction pathway for G electro-oxidation on FeCo@FeaPd/MWCNT-COOH and Pd/MWCNT-COOH in alkaline medium. Figure adapted from ref. 26 with permission.

$\mathrm{COOH}$, FeCo@Fe@Pd/MWCNT-COOH showed a stronger ability to break the $\mathrm{C}-\mathrm{C}$ bond, thereby producing a larger amount of carbonate (path c).

From the products of the oxidation of Gly, we proposed that Gly is first oxidized to glycerate (path a), which is further oxidized to tartronate (path c). Direct oxidation of Gly to tartronate (path $\mathrm{b}$ ) is also possible. By cleavage of the $\mathrm{C}-\mathrm{C}$ bond, the tartronate is then converted into glycolate and formate, and finally to carbonate (path d). Also, the glyconate can be oxidised to oxalate (path $\mathrm{f}$ ) as well as to carbonate via the formate route (path e). Interestingly, the oxidation of Gly at the FeCo@Fe@Pd/ MWCNT-COOH gave significant amounts of carbonate (73\%) compared to the Pd/MWCNT-COOH (47\%), clearly suggesting that the Pd-based core-shell catalyst is able to completely electro-oxidize Gly with an enhanced faradaic efficiency. This finding is quite unique, especially when we consider that none of the Pd-based catalysts reported to date (such as $\mathrm{Pd} / \mathrm{C}, \mathrm{PdNi} / \mathrm{C}$, and $\mathrm{PdAu} / \mathrm{C},{ }^{128} \mathrm{PdRh} / \mathrm{C},{ }^{129} \mathrm{PdAu} / \mathrm{C}$ and $\mathrm{PdNi},{ }^{130}$ and $\left.\mathrm{PdPtBi} / \mathrm{C}\right)^{131}$ showed selectivity for the total oxidation of glycerol.

\section{Nanoelectrocatalysts for oxygen reduction reaction (ORR) in alkaline media}

The oxygen reduction reaction (ORR) is notorious for sluggish kinetics. The poor ORR kinetics are related to a variety of factors, notably the electrolyte $\mathrm{pH}$ and reaction temperature. As shown in Fig. 19, ${ }^{132}$ the mechanism of the ORR in acidic and alkaline media is essentially the same: water is the final product in the direct pathway and hydrogen peroxide in the series pathway in acidic media, while the hydroxide anion is the final product in the direct pathway, with generation of peroxide in the series pathway in alkaline media. However, in alkaline media, the ORR is greatly enhanced, both thermodynamically (i.e., occurs at a more positive potential) and kinetically (i.e., due to enhanced charge transfer). Also, the highly alkaline electrolyte $\mathrm{pH}$ provides a less corrosive environment than the acidic media for the utilization of non-precious metal catalysts, especially for the ORR. Importantly, because these catalysts are highly selective for the ORR, the polarization losses that arise from alcohol crossover from the anode to the cathode can be completely avoided. Readers are referred to the most recent review by $\mathrm{He}$ and Cairns, ${ }^{\mathbf{1 3 2}}$ where the ORR in AEM-based alcohol fuel cells has been elegantly described. Here, I will attempt to review some of the latest findings with respect to the ORR, especially with respect to the utilization of non-noble catalysts.

In alkaline media, platinum catalysts are readily replaceable by non-noble metals (and their alloys). Non-noble metal complexes or platinum-free catalysts are generally not active toward the alcohol oxidation reaction, thus their use as cathode catalysts in ADAFCs is a huge advantage, as the consequences of alcohol cross-over to the cathode can be avoided. The Pt-free catalysts for the ORR in alkaline media can be conveniently categorized as (i) transition metal-based alloys and chalcogenides, (ii) non-noble metal oxides, (iii) metal-nitrogen $\left(\mathrm{M}-\mathrm{N}_{x}\right)$ catalysts, and (iv) metal-free carbon materials. The common transition metals (e.g., $\mathrm{Fe}, \mathrm{Co}, \mathrm{Ni}, \mathrm{Cu}$, and $\mathrm{Mn}$ ) mostly exhibit catalytic properties toward the ORR in their alloy forms, rather than their monometallic forms. Typically, these transition metals are alloyed with noble metals to improve the ORR kinetics. Metal alloying, as already described elsewhere in this review, can lead to several advantageous properties, such as changes in the surface morphology, electron density, synergistic

$$
\begin{array}{lll}
\text { Acidic medium } & & \\
\text { Direct pathway: } & \mathrm{O}_{2}+4 \mathrm{H}^{+}+4 \mathrm{e}^{-} \longrightarrow 2 \mathrm{H}_{2} \mathrm{O} & E^{\circ}=1.230 \mathrm{~V} \\
\text { Series pathways: } & \mathrm{O}_{2}+2 \mathrm{H}^{+}+2 \mathrm{e}^{-} \longrightarrow \mathrm{H}_{2} \mathrm{O}_{2} & E^{\circ}=0.695 \mathrm{~V} \\
& \mathrm{H}_{2} \mathrm{O}_{2}+2 \mathrm{H}^{+}+2 \mathrm{e}^{-} \longrightarrow 2 \mathrm{H}_{2} \mathrm{O} & E^{\circ}=1.230 \mathrm{~V} \\
& & \\
\text { Alkaline medium } & & \\
\text { Direct pathway: } & \mathrm{O}_{2}+2 \mathrm{H}_{2} \mathrm{O}+4 \mathrm{e}^{-} \longrightarrow 4 \mathrm{OH}^{-} & E^{\circ}=1.230 \mathrm{~V} \\
\text { Series pathways: } & \mathrm{O}_{2}+\mathrm{H}_{2} \mathrm{O}+2 \mathrm{e}^{-} \longrightarrow \mathrm{H}_{2} \mathrm{O}^{-}+\mathrm{OH}^{-} & E^{\circ}=0.695 \mathrm{~V} \\
& \mathrm{HO}_{2}^{-}+\mathrm{H}_{2} \mathrm{O}+2 \mathrm{e}^{-} \longrightarrow 3 \mathrm{OH}^{-} & E^{\circ}=1.230 \mathrm{~V}
\end{array}
$$

Fig. 19 Reaction pathways for the ORR in acidic and alkaline media. 
effects, and disruption of the crystal lattice structure. Some of the transition-metal-based alloys for the ORR include FeCo@Fe@Pd/C, FeCo@Fe@Pd/MWCNTs, PdCu/rGO, ${ }^{133}$

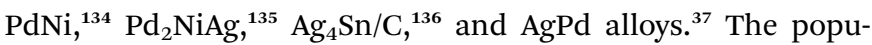
larity of Pd-based transition metal alloys is related to the fact that ORR activity in alkaline media is energetically more favourable on $\mathrm{Pd} / \mathrm{C}$ than on $\mathrm{Pt} / \mathrm{C}$; the activation energy for the ORR on $\mathrm{Pd} / \mathrm{C}\left(39 \mathrm{~kJ} \mathrm{~mol}^{-1}\right)$ is smaller than recorded for the $\mathrm{Pt} / \mathrm{C}$ $\left(48 \mathrm{~kJ} \mathrm{~mol}^{-1}\right)$ at an overpotential of $300 \mathrm{mV} \cdot{ }^{137}$ However, unlike $\mathrm{Pt} / \mathrm{C}, \mathrm{Pd} / \mathrm{C}$ has been shown to undergo oxidation under the operating conditions of the cathode. To avoid the problem of Pd oxidation, it makes sense that Pd-based alloys are explored.

Transition-metal-based chalcogenides (TMC) have been well investigated for the ORR in acidic media (PEMFC) for more than two decades, but the same cannot be said for the ORR in alkaline media. However, interestingly, new reports describing the application of TMCs for the ORR in alkaline fuel cells have continued to emerge. For example, just recently, Verjulio et al. ${ }^{138}$ reported the use of $\mathrm{CoSe}_{2} / \mathrm{C}$ as a viable catalyst in a passive, airbreathing, alkaline anion-exchange membrane micro-direct methanol fuel cell (AEM- $\mu$ DMFC). The catalyst exhibited high tolerance to possible methanol cross-over, thus making the system a potentially suitable device for powering mobile devices. Also, recently, Cao et al. ${ }^{139}$ proved that $\mathrm{Co}_{9} \mathrm{~S}_{8}$ embedded in a porous nitrogen-doped carbon matrix $\left(\mathrm{Co}_{9} \mathrm{~S}_{8} / \mathrm{N}-\mathrm{C}\right.$ hybrid $)$ is an efficient bi-functional catalyst for both the ORR (oxygen reduction reaction) and the OER (oxygen evolution reaction). Interestingly, the $\mathrm{Co}_{9} \mathrm{~S}_{8} / \mathrm{N}-\mathrm{C}$ hybrid exhibited comparable ORR activity with $\mathrm{Pt} / \mathrm{C}(20 \mathrm{wt} \%)$ and superior OER activity over the state-of-the-art system, $\mathrm{RuO}_{2} / \mathrm{C}(20$ wt $\%)$. The enhanced performance of the electrocatalyst was associated with synergistic effects arising from the covalent interaction between the $\mathrm{Co}_{9} \mathrm{~S}_{8}$ and $\mathrm{N}-\mathrm{C}$, as well as the porosity of the $\mathrm{N}-\mathrm{C}$ matrix. In a similar vein, $\mathrm{Ma}$ and $\mathrm{He}^{140}$ reported a new TMC catalyst, comprising $\mathrm{Co}_{4} \mathrm{~S}_{3}, \mathrm{Ni}_{x} \mathrm{~S}_{6}(7 \geq x \geq 6)$, and NiOOH nanocrystals supported on 3D nitrogen-doped graphene-carbon nanotubes (NGC), obtained by an in situ hydrothermal method. The NGC@ $\mathrm{Co}_{4} \mathrm{~S}_{3} / \mathrm{Ni}_{x} \mathrm{~S}_{6}(7 \geq x \geq 6) / \mathrm{NiOOH}$ nanohybrid catalyst exhibited enhanced ORR and OER activities over the state-ofthe-art systems, $20 \mathrm{wt} \% \mathrm{Pt} / \mathrm{C}$ and $\mathrm{RuO}_{2} / \mathrm{C}$. According to the authors, the excellent performance of the TMC system is due to the synergistic effects arising from the multiple active sites of the transition-metal nanocrystals and NGC, coupled with the inherent good conductivity and large specific surface area of the substrates.

The second category, non-noble metal oxides, used in the ORR in alkaline media, include $\mathrm{MnO}_{x},{ }^{141-144} \mathrm{Cu}-\alpha-\mathrm{MnO}_{2}$ nanowires, ${ }^{145} \quad \mathrm{Mn}_{3} \mathrm{O}_{4} / \mathrm{NrGO}$ nanoflakes, ${ }^{146} \quad \mathrm{Mn}_{3} \mathrm{O}_{4} / \mathrm{NrGO}$ nanoparticles ${ }^{147} \mathrm{MnO}_{2}$ layered nanosheets on graphene oxide, ${ }^{148}$ $\mathrm{Fe}_{3} \mathrm{O}_{4} / \mathrm{N}-\mathrm{C},{ }^{149,150} \mathrm{Fe}$-doped $\mathrm{Co}_{3} \mathrm{O}_{4}$ nanofilms, ${ }^{151} \mathrm{Co}-\mathrm{Fe}_{3} \mathrm{O}_{4}$ hybrid nanoparticles, ${ }^{152} \mathrm{Co}_{3} \mathrm{O}_{4} / \mathrm{rGO}$ nanorods $,{ }^{153} \mathrm{~g}^{-} \mathrm{C}_{3} \mathrm{~N}_{4} @ \mathrm{CoO},{ }^{154} \mathrm{Co}-\mathrm{g}$ $\mathrm{C}_{3} \mathrm{~N}_{4} /$ graphene, ${ }^{155} \mathrm{Ni}(\mathrm{OH})_{2} / \mathrm{GO},{ }^{156} \mathrm{Cu} / \mathrm{TiO}_{2},{ }^{157} \mathrm{MnO}_{x}-\mathrm{Co}_{3} \mathrm{O}_{4} / \mathrm{C},{ }^{158}$ $\mathrm{Ni}(\mathrm{OH})_{2}-\mathrm{MnO}_{x} / \mathrm{C}$ nanocomposites, ${ }^{159} \mathrm{Co}_{2} \mathrm{FeO}_{4} / \mathrm{MWCNT}$ hollow nanostructures, ${ }^{160}$ and various spinel nanomaterials, such as $\mathrm{NiCo}_{2} \mathrm{O}_{4},{ }^{161,162} \mathrm{ZnCo}_{2} \mathrm{O}_{4} / \mathrm{NCNT},{ }^{163} \mathrm{CuCo}_{2} \mathrm{O}_{4} / \mathrm{N}-\mathrm{rGO},{ }^{164} \mathrm{CoMn}_{2} \mathrm{O}_{4} /$ PDDA-CNTs, ${ }^{165} \mathrm{CoMn}_{2} \mathrm{O}_{4}$, and $\mathrm{MnCo}_{2} \mathrm{O}_{4} \cdot{ }^{166}$ The $\mathrm{MnO}_{x}$-based catalysts require a special mention, especially considering the high-abundance and low-cost of manganese and its rich chemistry. From the works of Chatenet and co-workers, ${ }^{141-143}$ it is clear that nanostructured $\mathrm{MnO}_{x}$ materials can show excellent ORR activity with high tolerance to ethanol in alkaline media. It has been shown by Su et al. ${ }^{144}$ from first-principles theoretical analysis and experimental electrochemistry, that nanostructured $\alpha-\mathrm{Mn}_{2} \mathrm{O}_{3}$ can serve as a viable bi-functional catalyst for the ORR and oxygen evolution reactions (OER), with the $\mathrm{Mn}_{3} \mathrm{O}_{4}$ and $\mathrm{MnO}_{2}$ showing an enhanced performance for the OER compared to $\mathrm{Mn}_{2} \mathrm{O}_{3}$. The phase and morphology in which the $\mathrm{MnO}_{2}$ exists tends to have a strong influence on its ORR activity. For example, Meng et al. ${ }^{167}$ in 2014 studied $\alpha-, \beta-, \delta$-, and amorphous $\mathrm{MnO}_{2}$ samples and showed that $\alpha-\mathrm{MnO}_{2}$ was able to catalyse the ORR via a 4-electron pathway, while the other $\mathrm{MnO}_{2}$ could only undergo a 2-electron pathway. Interestingly, different morphologies of nanostructured $\alpha-\mathrm{MnO}_{2}$ exhibit different performances toward ORR activity, decreasing as follows: $\alpha-\mathrm{MnO}_{2}$ nanowire $>\alpha-\mathrm{MnO}_{2}$ nanorod $>\alpha-\mathrm{MnO}_{2}$ nanotube $>\alpha-\mathrm{MnO}_{2}$ nanoparticle $>\alpha-\mathrm{MnO}_{2}$ nanoflower. It has been shown by theory ${ }^{168-172}$ and experiment ${ }^{173}$ that oxygen-deficient $\beta-\mathrm{MnO}_{2}$ improves the ORR activity. For example, Cheng and co-workers showed that the introduction of oxygen vacancies in $\beta-\mathrm{MnO}_{2}$ material enhanced the catalytic properties of $\mathrm{MnO}_{2}$ towards the ORR in an alkaline medium (in terms of a lower overpotential and larger current response), following a quasi-4e pathway. This is an important finding, as it provides an important insight into the non-stoichiometric, oxygen-deficient $\mathrm{MnO}_{2}$ species (i.e., $\mathrm{MnO}_{2-\delta}$ ) in oxygen electrochemistry.

The third category of ORR material is the $\mathrm{M}-\mathrm{N}_{x}$-based catalysts. The first $\mathrm{M}-\mathrm{N}_{4}$ macrocyle, iron phthalocyanine (FePc), was accidentally discovered by Linstead in $1934 .{ }^{174}$ There are several works and reviews on the ORR activity on $\mathrm{N}_{4}$-macrocylic complexes. In a recent book chapter by Ozoemena and coworkers, ${ }^{175}$ the authors discussed in detail the fundamental principles of the electrocatalytic properties of $\mathrm{N}_{4}$-macrocylic complexes (metallophthalocyanines and metalloporphyrins) toward the ORR. The ORR is very sensitive to the nature of the metal centre in the $\mathrm{M}-\mathrm{N}_{4}$ macrocycle. As depicted in Fig. 20, an oxygen molecule can interact with the metal centre of the $\mathrm{M}-\mathrm{N}_{4}$ macrocycle via "end-on", "side-on", "bridge-cis" or "bridgetrans" configurations. These possible interactions can reduce the $\mathrm{O}-\mathrm{O}$ bond energy, favoring its rupture.

The Fe and Mn phthalocyanines favour the 4-electron ORR pathway with the rupturing of the $\mathrm{O}-\mathrm{O}$ bond, ${ }^{176-178}$ while the $\mathrm{Co}$, $\mathrm{Ni}$, and $\mathrm{Cu}$ phthalocyanines promote the ORR via the 2-electron

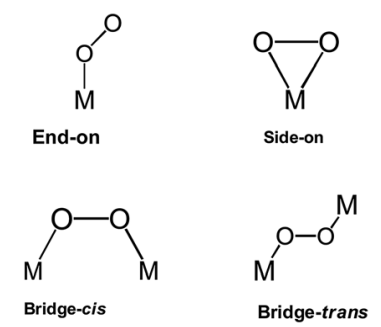

Fig. 20 Different spatial configurations for molecular oxygen when it interacts with metal sites. 
mechanism. Interestingly, the electropolymerized Co(II) tetraaminophthalocyanines promote the 4-electron pathway, ${ }^{\mathbf{1 7 9 , 1 8 0}}$ while the electropolymerized Fe(II) tetra-aminophthalocyanines only favour the 2-electron pathway. ${ }^{181}$ Generally speaking, the net catalytic ORR activity of the $\mathrm{M}-\mathrm{N}_{4}$ macrocycle is intricately linked to the central metal ion, with some degree of d-character to permit the co-ordination of the oxygen molecule. Fig. 21 is a volcano plot of the potential of the MPc complexes for the ORR in an alkaline environment at constant current versus the number of "d" electrons. ${ }^{182}$ The plot shows that MPc catalysts with d character (i.e., CrPc, MnPc, FePc, and CoPc) exhibit a higher ORR activity than those with ligand character (i.e., NiPc and $\mathrm{CuPc}$ ). FePc complexes give the highest ORR activity in alkaline media, followed by MnPc and CoPc, confirming that transition metals with almost half-filled d-energy levels show enhanced catalysis. Thus, it is clear that a redox mechanism does not operate for those metals that cannot show the M(III)/(II) transition in the potential window examined for the ORR, as in the case for the NiPc, CuPc, and ZnPc complexes.

The ORR activity occurs within the reduction potential of the metal- $\mathrm{O}_{2}$-adduct, and the onset potential of the ORR is linked to the redox potential of the central metal; the more positive the redox potential, the higher the ORR activity. The substituents at the peripheral positions of the phthalocyanine rings have a strong influence on the MPc-based ORR. Electronwithdrawing substituents (such as the sulfonate and fluorogroups) on the phthalocyanine ring can stabilize the singly occupied molecular orbital (SOMO), while the opposite is true for the electron-donating substituents (such as the methoxy and neopentoxy groups). In other words, electron-withdrawing groups not only decrease the electron density on the transition metal centre (i.e., creating more positive redox potential for such as Fe, Co, or Mn), but they also decrease the SOMO energy gap between the phthalocyanine and the oxygen. Electronwithdrawing functional groups on the phthalocyanine or porphyrin ring are able to shift the energy of the d-orbitals away from the Fermi level, leading to enhanced ORR activity. It should be noted that most studies on $\mathrm{M}-\mathrm{N}_{4}$ macrocyclic catalysts involve adsorption on a carbon support to improve the ORR activity.

Many theories exist for the explanation of the ORR activity in $3 \mathrm{~d}$ transition-metal coordinated systems and non-metal

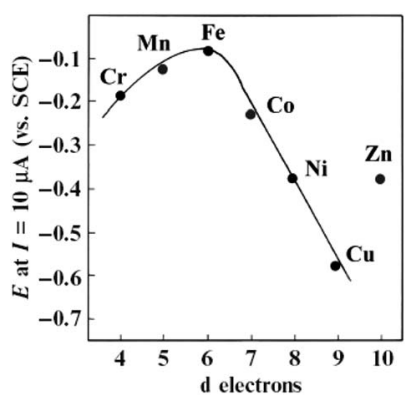

Fig. 21 Volcano plot for the electrocatalytic activity of different $\mathrm{M}$-tetrasulfonated phthalocyanines adsorbed on graphite for $\mathrm{O}_{2}$ reduction in $0.1 \mathrm{M} \mathrm{NaOH}$, as a function of the number of d-electrons in the metal. Figure adapted from ref. 182 with permission. catalysts, including spin density, charge density, and defects. For $\mathrm{M}-\mathrm{N}_{x}$-based catalysts (such as $\mathrm{Fe}-\mathrm{N}_{4}$ and $\mathrm{Co}-\mathrm{N}_{4}$ ), their enhanced ORR activity is thought to originate from their inherent ability to anchor on defects or interplane regions of the carbon-supports. The active sites, as one should expect, are developed by the synthetic methods (e.g., pyrolysis and accompanying temperatures) used in the preparation of the catalysts. For example, it is evident from the work of Mukerjee's group $^{\mathbf{1 8 3}}$ that an optimized pyrolysis method (maximized temperature and atmosphere) is able to integrate $\mathrm{Fe}-\mathrm{N}_{4}$ active sites into the defective pockets on the carbon support, thus enhancing the ORR activity (i.e., large shift of the $\mathrm{Fe}^{2+} / \mathrm{Fe}^{3+}$ redox couple and reduced ORR overpotential).

Since 2010, some researchers have continued to show that alloy-based ORR-active catalysts can be conveniently prepared from metallophthalocyanine (MPc) complexes. For example, $\mathrm{FeCu} / \mathrm{C},{ }^{184-186} \mathrm{FeCo} / \mathrm{C},{ }^{\mathbf{1 8 7}}$ and $\mathrm{FeAg} / \mathrm{C}^{\mathbf{1 8 8}}$ were prepared by simply pyrolyzing the relevant carbon-supported mixed MPc precursors (i.e., FePc, CuPc, AgPc, and CoPc) at high temperatures (600$1000{ }^{\circ} \mathrm{C}$ ). These bicore MPc-based catalysts were shown to be active towards the ORR in alkaline media. Importantly, it is to be cautioned here that both the pyrolyzing temperature and atmosphere could play critical roles in the catalytic performance of the catalyst. It is possible to generate ORR-inactive metallic species if the pyrolyzing temperature exceeds a certain value. ${ }^{189}$ Also, Zhang et al. ${ }^{190}$ showed that Co-based catalysts obtained in a nitrogen atmosphere exhibited better catalysis compared to those prepared in argon or carbon dioxide atmospheres.

The next category of ORR catalysts that have begun to capture major research interest are the metal-free nanocarbons (MFNCs). The interest in MFNCs stems from the fact that most nanocarbons satisfy the critical requirements for the ORR to occur: ability to adsorb oxygen, ability to desorb reduction products, large surface area, and sufficient electronic conductivity, which confer on them the physicochemical properties to serve as powerful electron-transfer building blocks and conduits, ${ }^{191}$ and the ability to maintain electrochemical cycling stability at extreme $\mathrm{pH}$ values. The MFNCs that have attracted major interest include nitrogen-doped carbon nanotubes, ${ }^{192}$ nitrogen-doped carbon nanosheets, ${ }^{\mathbf{1 9 3}, 194}$ nitrogen-boron codoped carbon nanosheets, ${ }^{\mathbf{1 9 5}}$ carbon nitride/carbon composite spheres, ${ }^{196}$ nitrogen-doped carbon molecular sieves, ${ }^{197}$ nitrogen and sulfur co-doped carbon nanosheets, ${ }^{198}$ nitrogen-doped graphene, ${ }^{\mathbf{1 9 9 - 2 0 4}}$ nitrogen-doped reduced graphene oxide, ${ }^{\mathbf{2 0 5}}$ halogen-doped reduced graphene oxide nanosheets, ${ }^{206}$ nitrogen and fluorine co-doped reduced graphene oxide, ${ }^{\mathbf{2 0 7}}$ nitrogendoped carbon nanoribbons, ${ }^{\mathbf{2 0 8}}$ nitrogen and sulfur co-doped graphene, ${ }^{209}$ boron-doped graphene, ${ }^{199,210}$ sulfur-doped graphene, ${ }^{\mathbf{2 1 1}}$ nitrogen and phosphorus co-doped graphene, ${ }^{\mathbf{2 1 2}}$ nitrogen and boron co-doped graphene, ${ }^{213-215}$ nitrogen-doped carbon spheres, ${ }^{216,217}$ nitrogen and sulfur co-doped carbon nanospheres, ${ }^{218}$ and nitrogen-doped carbon nanofibers, ${ }^{219}$ to mention just a few. These MFNCs have proved themselves as efficient and highly stable catalysts for the ORR in alkaline media, compared to commercial Pt/C. The performance of these nanocarbons on the ORR activity is strictly dependent on the 
opened structures of the MFNCs, which allow for enhanced exposure of the active sites of these heteroatoms. This is one of the findings of the recent work by Vazquez-Arenas and coworkers, ${ }^{220}$ in their theoretical and experimental investigation aimed at unravelling the catalytic nitrogen sites on graphene nanosheets for the ORR in alkaline media. However, I should mention that, despite the undeniable role of the heteroatoms on the catalytic activity of the MFCNs, residual metal nanoparticles from the adopted synthesis protocol could also play some role in the ORR activity. For example, in a recent report by Pumera and co-workers, ${ }^{221}$ it was established that the enhanced ORR activity with RGO is due to residual metal particle impurities; a similar finding was published in 2006 by the Compton group, ${ }^{222}$ for electrocatalysis at some carbon nanotube-modified electrodes.

Like the $\mathrm{M}-\mathrm{N}_{x}$ catalyst systems, theoretical explanations for the ORR activities at MFNCs abound. The enhanced ORR activity on graphene (and CNT; after all, the difference between graphene and CNT is that graphene can be regarded as a SWCNT that has been longitudinally unzipped along its axis) is due to the defects and dopants (heteroatoms), which alter the charge density and increase the number of active sites. Lu et al. $^{205}$ showed that RGO was characterized by more defects upon doping with nitrogen (N-RGO), explaining the superior performance of N-RGO over its RGO counterparts towards ORR activity. Indeed, it is now well recognised that one of the key strategies to avoid the inefficient 2-electron pathway and realize the more efficient 4-electron pathway for the ORR is to design electrocatalysts containing dopant heteroatoms and structural defects. From theoretical studies (DFT), Zhang and $\mathrm{Xia}^{223}$ proved that N-doping confers upon graphene asymmetric spin density and atomic charge density, thus making it possible for $\mathrm{N}$-graphene to show superior ORR activity (4-electron pathway). Zhang et al. ${ }^{224}$ reported that the ORR activity of N-doped graphene is largely dependent on the nitrogen concentration, with a value of $24-25 \%$ achieving the favourable 4-electron transfer process.

\section{MEA fabrication and AEM-DAFC: real-time operation and performance of fuel cells}

Most literature reports on nanostructured catalysts for alkaline fuel cells have been based on half-cell reactions (3-electrode configurations) of alcohol oxidation or the ORR, rather than on single-cell reactions (2-electrode configurations). The performance of any fuel cell catalyst is best determined when it is subjected to single-cell operation utilizing the membraneelectrode assembly (MEA). There are a limited number of laboratories across the globe that make efforts to conduct research on AEM-DAFCs. Most MEAs fabricated for AEM-DAFCs employ commercially available AEMs, notably, those produced by Tokuyama ${ }^{\circledR}\left(\mathrm{A} 201, \mathrm{~A} 901\right.$ or A-006), Solvay ${ }^{\circledR}$ and Fumatech $\circledast$.

According to several literature reports, ${ }^{132,134,225,226}$ the fabrication of MEAs for AEM-DAFCs follows some basic steps that can be summarised as follows. First, the catalyst ink for the anode (typically obtained by thoroughly sonicating a mixture of the Pd-based catalyst powder ( $\geq 90 \mathrm{wt} \%$ ) and binding agent, such as PTFE ( $\leq 10 \mathrm{wt} \%)$ in a volatile organic solvent, such as propan-1-ol) is air-brushed onto the liquid diffusion layer (such as carbon cloth or nickel foam) to obtain the required AOR catalyst loading (typically, $1.0 \mathrm{mg}$ metal per $\mathrm{cm}^{2}$ ). For the cathode, a sufficient amount of the ORR catalyst (typically, $\geq 70$ $w t \%)$ is thoroughly blended with an anion-conductive ionomer (e.g., ca. $30 \mathrm{wt} \%$ Tokuyama's AS-4) and then uniformly sprayed onto the AEM (e.g., Tokuyama's A201). Subsequently, a gas diffusion layer (GDL), usually a carbon paper, is placed to completely cover the cathode catalyst. The components of the MEA (anode/AEM/cathode) are mechanically sandwiched in a fuel cell system using silicone-rubber gaskets to obtain efficient sealing of the system (see Fig. 22 for a typical home-made air-breathing DAFC cell, fabricated with Plexiglas and goldplated stainless steel plates as current collectors).

The capacity of the anode compartment is $c a .20 \mathrm{~mL}$, which should allow for an actual fuel solution of $c a .10 \mathrm{~mL}$. In some cases, prior to assembling the fuel cell device, it may be necessary to obtain better contact of the anode/AEM/cathode system by using a hot press (typically $\sim 100{ }^{\circ} \mathrm{C}$ under a pressure of $\sim 2$ bars) for a few minutes. ${ }^{226}$ Also, prior to use, the AEM is pre-treated by first soaking in $1 \mathrm{M} \mathrm{KOH}$ solution for a few

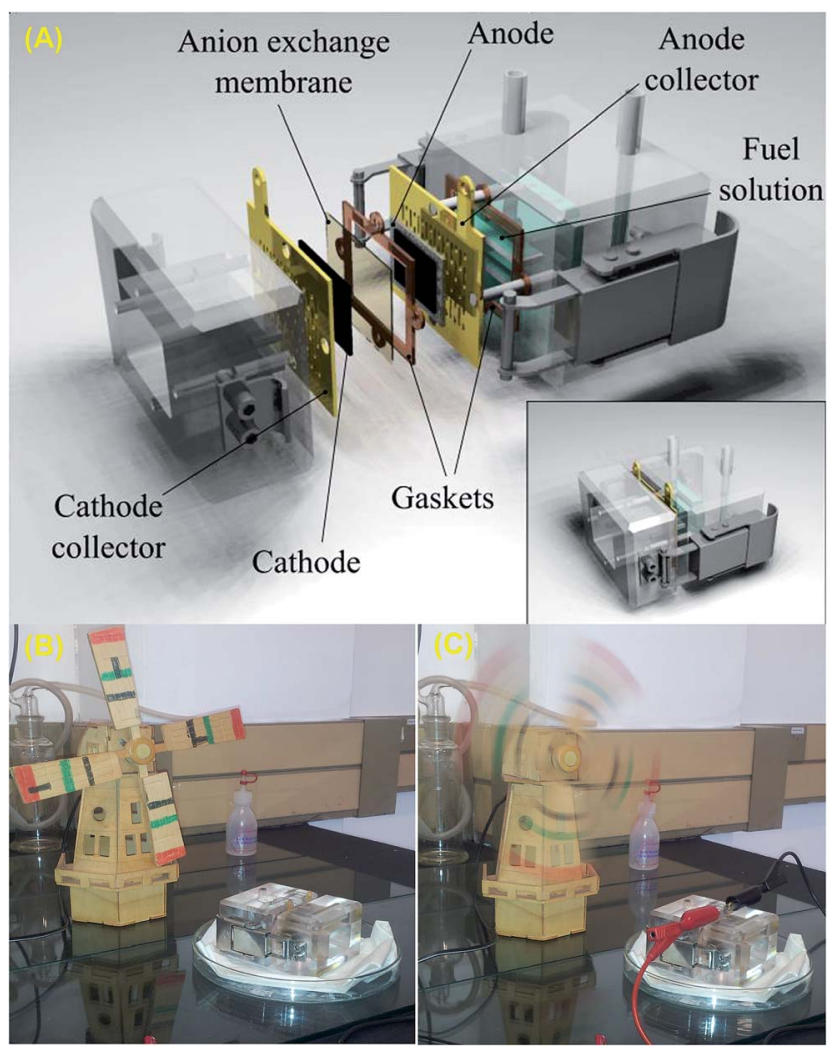

Fig. 22 (A) Components of a home-made air-breathing DAFC cell, fabricated with Plexiglas and gold-plated stainless steel plates as current collectors, and typical laboratory demonstration of a CSIRfabricated air-breathing DAFC driving a windmill, before (B) and after (C) completion of the circuit. Photos donated by Dr Hamish Miller (ICCOM, CNR, Italy) and Dr Mmalewane Modibedi (CSIR, South Africa). 
hours (ca. $2 \mathrm{~h}$ ) at low temperature $\left(\mathrm{ca} .40{ }^{\circ} \mathrm{C}\right)$, followed by immersing in $1 \mathrm{M} \mathrm{KOH}$ solution at ambient temperature for $c a$. $24 \mathrm{~h}$, and finally rinsing with deionised water. The fuel cell device can be used to run both the passive and active AEMDAFCs.

The major difference between a 'passive AEM-DAFC' and an 'active AEM-DAFC' is that the former is completely operated in ambient conditions $\left(\mathrm{ca} .25^{\circ} \mathrm{C}\right.$, in air, with the alcohol solution in the reservoir diffusing into the anode catalyst layer due to the concentration gradient existing between the reservoir and the anode), whereas the latter is more technically sophisticated and is operated under mechanical conditions (usually $25-80{ }^{\circ} \mathrm{C}$, with the alkaline alcohol solutions and pure oxygen gas delivered to the fuel cell system at regulated or controlled flow rates,

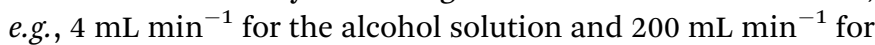
the oxygen gas). For both systems, the anode compartment is usually maintained in a nitrogen atmosphere to protect it from possible contamination from atmospheric $\mathrm{CO}_{2}$.

The performance of AEM-DAFCs (passive or active) is determined by their open-circuit voltage (OCV), peak power density, and operating temperature. Table 4 exemplifies some of the recent reports on active AEM-DAFCs based on ethanol, ethylene glycol, and glycerol, utilizing some of the catalysts already discussed in this review. Table 4 provides some insights that should be emphasized. Firstly, of the three alcohols, ethanol remains the most investigated fuel. For a greener environment, there is a need for increased research on alcohols that can be obtained from renewable biomass feedstocks (such as glycerol). Glycerol is a biodiesel-derived alcohol (i.e., a waste by-product of the transesterification reaction process for the large-scale production of biodiesel). ${ }^{227}$ Unlike other alcohols, there are very limited reports on fuel cells using EG and G as liquid fuels.

Secondly, for the anodic reactions, Pd and Pd-based catalysts are the most preferred, while for the cathode reactions, Febased catalysts (notably, $\mathrm{FeCo} / \mathrm{C}$ and $\mathrm{FeCu} / \mathrm{C}$ ) combined with Tokuyama's AEMs dominate current studies due to their enhancing properties in AEM-DAFCs. It is to be noted that the performance of the simple $\mathrm{Pd} / \mathrm{C}$ can be enhanced by alloy formation (e.g. PdIrNi/C and FeCo@Fe@Pd/C) and exploitation of the strong metal-support interactions by utilizing some metal oxide supports (e.g. $\mathrm{CeO}_{2}, \mathrm{TiO}_{2}$, and $\left.\mathrm{Ni} / \mathrm{NiO}\right)$. The enhanced performance of $\mathrm{Pd}$ nanoparticles supported on titania nanotube arrays (TNTAs) requires some mention as Chen et $a .^{228}$ succeeded in achieving an excellent peak power density $\left(335 \mathrm{~mW} \mathrm{~cm}^{-2}\right.$ ) for AEM-DEFC with $6 \mathrm{mg}_{\mathrm{Pd}} \mathrm{cm}^{-2}$ at $80{ }^{\circ} \mathrm{C}$.

Thirdly, the best operating conditions seem to involve the deployment of a high concentration of the electrolyte (up to $6 \mathrm{M}$ $\mathrm{KOH})$ and fuel concentrations in the 1-3 $\mathrm{M}$ alcohol range. Although a high $\mathrm{KOH}$ concentration is necessary for enhanced ionic conductivity for the membrane and electrode layers, and provides the necessary amount of $\mathrm{OH}^{-}$for the high-pHdependent AOR, closer reading of some literature 226,229 shows that a high $\mathrm{KOH}$ concentration alone is not sufficient to provide the required AEM-DAFC performance in terms of improved kinetics and mass transport. For example, Zhao and coworkers $^{229}$ showed that for an ethanol-based AEM-DAFC operated with $5.0 \mathrm{M}$ ethanol at $40{ }^{\circ} \mathrm{C}$, a higher $\mathrm{KOH}$ concentration impacted negatively on the cell resistance, in that the cell resistance increased (from $c a$. 66.5 to $67.8 \Omega$ ) with an increased $\mathrm{KOH}$ concentration (from 1.0 to $4.5 \mathrm{M}$ ). According to the authors, the increased cell resistance is the result of the increased anode $\mathrm{OH}^{-}$concentration, which impedes the transport of $\mathrm{OH}^{-}$ions from the cathode to the anode. As a contrast, however, Zhang et al. ${ }^{230}$ observed that for a glycerolbased AEM-DAFC operated with $1.0 \mathrm{M}$ glycerol solution at $80^{\circ} \mathrm{C}$, the cell resistance decreased at higher $\mathrm{KOH}$ concentrations (224.9 $\mathrm{m} \Omega \mathrm{cm}^{-2}$ at $2.0 \mathrm{M} \mathrm{KOH}$ compared to $151.9 \mathrm{~m} \Omega \mathrm{cm}^{-2}$ at 6.0 M KOH). The internal resistance of AEM-DAFCs is a function of the cathode and membrane, which is related to their degree of humidification. Both workers used similar AEMs $(28 \mu \mathrm{m}$ thick), the only difference between the two studies being that one used about $30 \mathrm{wt} \%$ of conductive ionomer in the fabrication of their cathode catalyst, while the other lab did not. Considering that the main function of the conductive ionomer is to enhance the electronic and ionic transport, it should perhaps not be completely surprising that the mass transport of the one is better than the other. Therefore, one can infer that the effect of a high $\mathrm{KOH}$ concentration on the performance of AEMDAFCs (especially in terms of the impact on the internal resistance of the system) most likely depends on other factors, such as the type of alcohol being oxidized, operating temperatures,

Table 4 Representative AEM-DAFC systems utilizing ethanol (EtOH), ethylene glycol (EG), and glycerol (Gly) with Pd-based anode catalysts and transition metal-based cathode catalysts

\begin{tabular}{|c|c|c|c|c|c|c|c|}
\hline Fuel & Anode & Cathode & Membrane & $\begin{array}{l}\text { OCV/ } \\
\mathrm{mV}\end{array}$ & $T_{\text {cell }} /{ }^{\circ} \mathrm{C}$ & $\begin{array}{l}P_{\max } / \\
\mathrm{mW} \mathrm{cm}^{-2}\end{array}$ & Ref. \\
\hline $10 \% \mathrm{EtOH}, 2 \mathrm{M} \mathrm{KOH}$ & $\mathrm{Pd} / \mathrm{C}-\mathrm{CeO}_{2} 1 \mathrm{mg} \mathrm{cm}^{-2}$ & $\mathrm{FeCo} / \mathrm{C} 2 \mathrm{mg} \mathrm{cm}^{-2}$ & A201 & 870 & 80 & 140 & 231 \\
\hline $10 \% \mathrm{EtOH}, 2 \mathrm{M} \mathrm{KOH}$ & $\mathrm{Pd} / \mathrm{TNTA}$-web $1.5 \mathrm{mg} \mathrm{cm}^{-2}$ & $\mathrm{FeCo} / \mathrm{C} 2 \mathrm{mg} \mathrm{cm}^{-2}$ & A201 & 600 & 80 & 210 & 228 \\
\hline $10 \%$ EtOH, $2 \mathrm{M} \mathrm{KOH}$ & Pd/TNTA-web $6 \mathrm{mg} \mathrm{cm}^{-2}$ & $\mathrm{FeCo} / \mathrm{C} 2 \mathrm{mg} \mathrm{cm}^{-2}$ & A201 & 900 & 80 & 335 & 228 \\
\hline EtOH $3 \mathrm{M}, 3 \mathrm{M} \mathrm{KOH}$ & $\mathrm{Pd} / \mathrm{Ni}$-foam $3 \mathrm{mg} \mathrm{cm}^{-2}$ & $\mathrm{FeCu} / \mathrm{C} 2 \mathrm{mg} \mathrm{cm}^{-2}$ & A201 & 870 & 60 & 164 & 232 \\
\hline EtOH $3 \mathrm{M}, 5 \mathrm{M} \mathrm{KOH}$ & $\mathrm{PdNi} / \mathrm{C} 2 \mathrm{mg} \mathrm{cm}^{-2}$ & $\mathrm{FeCo} / \mathrm{C} 2 \mathrm{mg} \mathrm{cm}^{-2}$ & A201 & 900 & 80 & 130 & 233 \\
\hline EtOH $3 \mathrm{M}, 5 \mathrm{M} \mathrm{KOH}$ & PdIrNi/C $1 \mathrm{mg} \mathrm{cm}{ }^{-2}$ & $\mathrm{FeCo} / \mathrm{C} 2 \mathrm{mg} \mathrm{cm}^{-2}$ & A201 & 900 & 60 & 92 & 121 \\
\hline EtOH $3 \mathrm{M}, 3 \mathrm{M} \mathrm{KOH}$ & $\mathrm{Pd}_{3} \mathrm{Ru} / \mathrm{C} 1 \mathrm{mg} \mathrm{cm}^{-2}$ & $\mathrm{MnO}_{2}$ nanotube $2 \mathrm{mg} \mathrm{cm}{ }^{-2}$ & A201 & 800 & 80 & 176 & 234 \\
\hline $10 \% \mathrm{EG}, 2 \mathrm{M} \mathrm{KOH}$ & Pd/TNTA-web $1.5 \mathrm{mg} \mathrm{cm}^{-2}$ & $\mathrm{FeCo} / \mathrm{C} 2 \mathrm{mg} \mathrm{cm}^{-2}$ & A201 & 920 & 80 & 170 & 228 \\
\hline $1 \mathrm{M} \mathrm{EG}, 7 \mathrm{M} \mathrm{KOH}$ & PdNi $1 \mathrm{mg} \mathrm{\textrm {cm } ^ { - 2 }}$ & $\mathrm{FeCo} / \mathrm{C} 1 \mathrm{mg} \mathrm{cm}^{-2}$ & PBI & & 90 & 112 & 235 \\
\hline $10 \% \mathrm{G}, 2 \mathrm{M} \mathrm{KOH}$ & Pd/TNTA-web $1.5 \mathrm{mg} \mathrm{cm}^{-2}$ & $\mathrm{FeCo} / \mathrm{C} 2 \mathrm{mg} \mathrm{cm}^{-2}$ & A201 & 940 & 80 & 160 & 228 \\
\hline
\end{tabular}


and electrode fabrication conditions, such as the presence of quality anion-exchange ionomers.

\section{Conclusions \& future perspectives}

Alkaline direct alcohol fuel cells (ADAFCs) have emerged as promising electrochemical power sources for consumer and portable electronics. They represent alternative power sources to the conventional direct methanol fuel cells (DMFC) or proton-exchange membrane fuel cells (PEMFCs). Liquid alcohols (monohydric and polyhydric) are much easier to handle than hydrogen, and possess much higher volumetric energy densities than hydrogen. The emergence of anion-exchange membranes (AEMs) has continued to motivate researchers to focus on developing different kinds of nanostructured electrocatalysts for the development of high-performance ADAFCs. This review has provided some insights into the fundamental principles that allow for the intelligent design and synthesis of various types of catalysts with advantageous features, including platinum-free nanostructured electrocatalysts for the cathode and anode reactions of ADAFCs. Indeed, to improve the performance of ADAFCs in the near future (e.g., improved power output and long-term cycling) there is a need for further development of nanostructured catalysts (especially those with high Miller indices) and their promoter metal oxides, AEMs with improved physicochemical properties (improved ionic conductivity, stability, and ability to perform at $\geq 80^{\circ} \mathrm{C}$ ).

\section{Abbreviations}

$\begin{array}{ll}\text { AA } & \text { Ascorbic acid } \\ \text { AFC } & \text { Alkaline fuel cell (i.e., hydrogen-fed/oxygen system) } \\ \text { DAFC } & \begin{array}{l}\text { Direct alcohol fuel cell }(\text { i.e., performed in acidic } \\ \text { medium) }\end{array} \\ \text { ADAFC } & \text { Alkaline direct alcohol fuel cell } \\ \text { AEM-AFC } & \text { Anion-exchange membrane alkaline fuel cell } \\ \text { AEM- } & \text { Anion-exchange membrane alkaline direct alcohol } \\ \text { ADAFC } & \text { fuel cell } \\ \text { AOR } & \text { Alcohol oxidation reaction } \\ \text { ATR- } & \text { Attenuated total reflectance surface-enhanced } \\ \text { SEIRAS } & \text { infrared absorption spectroscopy } \\ \text { BCBs } & \text { Base-treated carbon blacks } \\ \text { CBs } & \text { Carbon blacks } \\ \text { ECMF } & \text { Electrochemical milling and faceting } \\ \text { EOR } & \text { Ethanol oxidation reaction } \\ \text { EG } & \text { Ethylene glycol } \\ \text { Gly } & \text { Glycerol } \\ \text { GRR } & \text { Galvanic replacement reaction } \\ \text { MEA } & \text { Membrane-electrode assembly } \\ \text { MFNCs } & \text { Metal-free nanocarbons } \\ \text { MITNAD } & \text { Microwave-induced top-down nanostructuring and } \\ & \text { decoration } \\ \text { MOR } & \text { Methanol oxidation reaction } \\ \text { MPc } & \text { Metallophthalocyanine } \\ \text { NCBs } & \text { Neutral-treated carbon blacks } \\ \text { NCs } & \text { Nanocrystals } \\ \text { OCV } & \text { Open-circuit voltage }\end{array}$

OER

ORR

SMG

SOMO

SWPT

TNTA

\section{Acknowledgements}

This work was supported by the CSIR, South Africa. I am grateful to RSC Advances for the invitation to write this critical review, I learnt a lot during this process. The excellent comments by the reviewers are highly appreciated.

\section{References}

1 J. Gosselink, Int. J. Hydrogen Energy, 2002, 27, 1125-1129.

2 M. R. Modibedi, K. I. Ozoemena and M. K. Mathe, Palladium-Based Nanocatalysts for Alcohol Electrooxidation in Alkaline Media, in Electrocatalysis in Fuel Cells: Non- and Low Platinum Approach, Lecture Notes in Energy 9, ed. Minhua Shao, Springer-Verlag, London, 2013, ch. 6, pp. 129-156.

3 C. Bianchini and P. K. Shen, Chem. Rev., 2009, 109, 41834206.

4 Electrocatalysis in Fuel Cells: Non- and Low Platinum Approach, Lecture Notes in Energy 9, ed. M. Shao, SpringerVerlag, London, 2013.

5 A. Tripković, K. Popović, B. Grgur, B. Blizanac, P. Ross and N. Marković, Electrochim. Acta, 2002, 47, 3707-3714.

6 J. Prabhuram and R. Manoharan, J. Power Sources, 1998, 74, 54-61.

7 A. Aricò, V. Baglio and V. Antonucci, Electrocatal. Direct Methanol Fuel Cells From Fundam. to Appl., 2009, pp. 1-78.

8 Modern Aspects of Electrochemistry, ed. J. O. Bockris, B. E. Conway and R. E. White, Kluwer Academic Publishers, Boston, 2002, vol. 34 .

9 C. Lamy, The direct ethanol fuel cell: a challenge to convert bioethanol cleanly into electric energy, 2009.

10 F. Bidault, D. J. L. Brett, P. H. Middleton and N. P. Brandon, J. Power Sources, 2009, 187, 39-48.

11 E. Antolini and E. R. Gonzalez, J. Power Sources, 2010, 195, 3431-3450.

12 E. Roduner, Nanoscopic Materials: Size-Dependent Phenomena, Royal Society of Chemistry, Cambridge, 2006.

13 Catalysis and Electrocatalysis at Nanoparticle Surfaces, ed. A. Wieckowski, E. R. Savinova and C. G. Vayenas, CRC Press, 2003.

14 F. J. Vidal-Iglesias, J. Solla-Gullón, E. Herrero and J. M. Feliu, Au electrocatalysis for oxygen reduction, in Electrocatalysis in Fuel Cells: A Non- and Low-Platinum Approach, Lecture Notes in Energy 9, ed. Minhua Shao, Springer-Verlag, London, 2013, ch. 7, pp. 483-512.

15 D. Hao, S. Xue-Zhao, S. Cheng-Min, H. Chao, X. Zhi-Chuan, L. Chen, T. Yuan, W. Deng-Ke and G. Hong-Jun, Chin. Phys. B, 2010, 19, 106104. 
16 R. Narayanan and M. A. El-Sayed, Nano Lett., 2004, 4, 13431348.

17 A. E. Russell, Faraday Discuss., 2009, 140, 9-10.

18 S.-G. Sun, A.-C. Chen, T.-S. Huang, J.-B. Li and Z.-W. Tian, J. Electroanal. Chem., 1992, 340, 213-226.

19 G. A. Attard, J. Phys. Chem. B, 2001, 105, 3158-3167.

20 N. Tian, Z.-Y. Zhou, S.-G. Sun, Y. Ding and Z. L. Wang, Science, 2007, 316, 732-735.

21 Z. L. Wang, J. Phys. Chem. B, 2000, 104, 1153-1175.

22 M. Shao, A. Peles and K. Shoemaker, Nano Lett., 2011, 11, 3714-3719.

23 M. Mavrikakis, B. Hammer and J. Nørskov, Phys. Rev. Lett., 1998, 81, 2819-2822.

24 W. J. Huang, R. Sun, J. Tao, L. D. Menard, R. G. Nuzzo and J. M. Zuo, Nat. Mater., 2008, 7, 308-313.

25 O. O. Fashedemi, B. Julies and K. I. Ozoemena, Chem. Commun., 2013, 49, 2034-2036.

26 O. O. Fashedemi, H. A. Miller, A. Marchionni, F. Vizza and K. I. Ozoemena, J. Mater. Chem. A, 2015, 3, 7145-7156.

27 M. Shao, A. Peles, K. Shoemaker, M. Gummalla, P. N. Njoki, J. Luo and C.-J. Zhong, J. Phys. Chem. Lett., 2011, 2, 67-72.

28 P. Strasser, S. Koh, T. Anniyev, J. Greeley, K. More, C. Yu, Z. Liu, S. Kaya, D. Nordlund, H. Ogasawara, M. F. Toney and A. Nilsson, Nat. Chem., 2010, 2, 454-460.

29 S. R. Calvo and P. B. Balbuena, Surf. Sci., 2007, 601, 47864792.

30 E. J. Lamas and P. B. Balbuena, J. Chem. Theory Comput., 2006, 2, 1388-1394.

31 J. C. Sotelo and J. M. Seminario, J. Chem. Phys., 2007, 127, 244706.

32 R. Ferrando, J. Jellinek and R. L. Johnston, Chem. Rev., 2008, 108, 845-910.

33 L.-L. Wang and D. D. Johnson, J. Am. Chem. Soc., 2009, 131, 14023-14029.

34 H. Yamauchi, Phys. Rev. B: Condens. Matter Mater. Phys., 1985, 31, 7688-7694.

35 O. O. Fashedemi and K. I. Ozoemena, Phys. Chem. Chem. Phys., 2013, 15, 20982-20991.

36 O. O. Fashedemi and K. I. Ozoemena, Electrochim. Acta, 2014, 128, 279-286.

37 D. A. Slanac, W. G. Hardin, K. P. Johnston and K. J. Stevenson, J. Am. Chem. Soc., 2012, 134, 9812-9819.

38 S. Sharma and B. G. Pollet, J. Power Sources, 2012, 208, 96119.

39 Z. Zhang, T. Shimizu, S. Senz and U. Gösele, Adv. Mater., 2009, 21, 2824-2828.

40 Z. Qiu, H. Huang, J. Du, X. Tao, Y. Xia, T. Feng, Y. Gan and W. Zhang, J. Mater. Chem. A, 2014, 2, 8003.

41 M. S. Wilson, J. Electrochem. Soc., 1993, 140, 2872.

42 K. Philippot and P. Serp, Nanomater. Catal., First edn, 2012, pp. 1-54.

43 X. Yuan, X.-L. Ding, C.-Y. Wang and Z.-F. Ma, Energy Environ. Sci., 2013, 6, 1105-1124.

44 N. T. Cuong, A. Fujiwara, T. Mitani and D. H. Chi, Comput. Mater. Sci., 2008, 44, 163-166.

45 K. N. Wood, R. O'Hayre and S. Pylypenko, Energy Environ. Sci., 2014, 7, 1212.
46 S. Kim and S. J. Park, J. Power Sources, 2006, 159, 42-45.

47 S. Kang, J. Ye and J. Chang, Int. Rev. Chem. Eng., 2013, 5, 133-144.

48 Z.-P. Sun, X.-G. Zhang, R.-L. Liu, Y.-Y. Liang and H.-L. Li, J. Power Sources, 2008, 185, 801-806.

49 Z. P. Sun, X. G. Zhang, Y. Y. Liang and H. L. Li, J. Power Sources, 2009, 191, 366-370.

50 M. Hara, T. Yoshida, A. Takagaki, T. Takata, J. N. Kondo, S. Hayashi and K. Domen, Angew. Chem., Int. Ed., 2004, 43, 2955-2958.

51 T. Ramulifho, K. I. Ozoemena, R. M. Modibedi, C. J. Jafta and M. K. Mathe, Electrochim. Acta, 2012, 59, 310-320.

52 T. Fujigaya, M. Okamoto and N. Nakashima, Carbon, 2009, 47, 3227-3232.

53 I. H. Hafez, M. R. Berber, T. Fujigaya and N. Nakashima, Sci. Rep., 2014, 4, 6295.

54 T. Fujigaya, C. R. Kim, K. Matsumoto and N. Nakashima, Polym. J., 2013, 45, 326-330.

55 M. R. Berber, T. Fujigaya, K. Sasaki and N. Nakashima, Sci. Rep., 2013, 3, 1764.

56 P. M. Ejikeme, K. Makgopa and K. I. Ozoemena, Effects of Catalyst-Support Materials on the Performance of Fuel Cells, in Nanomaterials for Fuel Cell Catalysis, ed. K. I. Ozoemena and S. Chen, Springer Publishing, New York, USA, 2016, ch. 13, pp. 517-550.

57 X. Wang, N. Kariuki, J. T. Vaughey, J. Goodpaster, R. Kumar and D. J. Myers, J. Electrochem. Soc., 2008, 155, B602.

58 V. Raghuveer, P. Ferreira and A. Manthiram, Electrochem. Commun., 2006, 8, 807-814.

59 H. Liu and A. Manthiram, Electrochem. Commun., 2008, 10, 740-744.

60 B. Lim, J. Wang, P. H. C. Camargo, C. M. Cobley, M. J. Kim and Y. Xia, Angew. Chem., Int. Ed., 2009, 48, 6304-6308.

61 Y. W. Lee, D. Kim, J. W. Hong, S. W. Kang, S. B. Lee and S. W. Han, Small, 2013, 9, 660-665.

62 M. Tsuji, T. Kidera, A. Yajima, M. Hamasaki, M. Hattori, T. Tsuji and H. Kawazumi, CrystEngComm, 2014, 16, 2684.

63 R. C. Sekol, X. Li, P. Cohen, G. Doubek, M. Carmo and A. D. Taylor, Appl. Catal., B, 2013, 138-139, 285-293.

64 L. Xu, Z. Luo, Z. Fan, X. Zhang, C. Tan, H. Li, H. Zhang and C. Xue, Nanoscale, 2014, 6, 11738-11743.

65 G.-T. Fu, C. Liu, Q. Zhang, Y. Chen and Y.-W. Tang, Sci. Rep., 2015, 5, 13703.

66 C. Peng, Y. Hu, M. Liu and Y. Zheng, J. Power Sources, 2015, 278, 69-75.

67 N. Abbasi, P. Shahbazi and A. Kiani, J. Mater. Chem. A, 2013, 1, 9966.

68 I. Bakos, A. Paszternák and D. Zitoun, Electrochim. Acta, 2015, 176, 1074-1082.

69 Y. Chen, Q.-L. Zhu, N. Tsumori and Q. Xu, J. Am. Chem. Soc., 2015, 137, 106-109.

70 M. Jin, H. Zhang, Z. Xie and Y. Xia, Angew. Chem., Int. Ed., 2011, 50, 7850-7854.

71 J. Zhang, L. Zhang, S. Xie, Q. Kuang, X. Han, Z. Xie and L. Zheng, Chemistry, 2011, 17, 9915-9919. 
72 W. Niu, W. Zhang, S. Firdoz and X. Lu, Chem. Mater., 2014, 26, 2180-2186.

73 H. Zhang, M. Jin, Y. Xiong, B. Lim and Y. Xia, Acc. Chem. Res., 2013, 46, 1783-1794.

74 X. Xie, G. Gao, Z. Pan, T. Wang, X. Meng and L. Cai, Sci. Rep., 2015, 5, 8515.

75 F. J. Vidal-Iglesias, J. Solla-Gullón, E. Herrero, A. Aldaz and J. M. Feliu, Angew. Chem., Int. Ed., 2010, 49, 6998-7001.

76 Y. Ding, Y. Gao, Z. L. Wang, N. Tian, Z.-Y. Zhou and S.-G. Sun, Appl. Phys. Lett., 2007, 91, 121901.

77 N. Tian, Z.-Y. Zhou, S.-G. Sun, Y. Ding and Z. L. Wang, Science, 2007, 316, 732-735.

78 Z.-Y. Zhou, Z.-Z. Huang, D.-J. Chen, Q. Wang, N. Tian and S.-G. Sun, Angew. Chem., Int. Ed., 2010, 49, 411-414.

79 Z.-Y. Zhou, S.-J. Shang, N. Tian, B.-H. Wu, N.-F. Zheng, B.-B. Xu, C. Chen, H.-H. Wang, D.-M. Xiang and S.-G. Sun, Electrochem. Commun., 2012, 22, 61-64.

80 N. Tian, Z.-Y. Zhou, N.-F. Yu, L.-Y. Wang and S.-G. Sun, J. Am. Chem. Soc., 2010, 132, 7580-7581.

81 P. Wang, X. Lin, B. Yang, J.-M. Jin, C. Hardacre, N.-F. Yu, S.-G. Sun and W.-F. Lin, Electrochim. Acta, 2015, 162, 290299.

82 Y.-X. Chen, A. Lavacchi, S.-P. Chen, F. di Benedetto, M. Bevilacqua, C. Bianchini, P. Fornasiero, M. Innocenti, M. Marelli, W. Oberhauser, S.-G. Sun and F. Vizza, Angew. Chem., Int. Ed., 2012, 51, 8500-8504.

83 F. Hu, C. Chen, Z. Wang, G. Wei and P. K. Shen, Electrochim. Acta, 2006, 52, 1087-1091.

84 U. B. Demirci, J. Power Sources, 2007, 173, 11-18.

85 J. Yang, Y. Zhou, H. Su and S. Jiang, J. Electroanal. Chem., 2011, 662, 251-256.

86 T. Yajima, N. Wakabayashi, H. Uchida and M. Watanabe, Chem. Commun., 2003, 828-829.

87 Z. X. Liang, T. S. Zhao, J. B. Xu and L. D. Zhu, Electrochim. Acta, 2009, 54, 2203-2208.

88 P. K. Shen and C. Xu, Electrochem. Commun., 2006, 8, 184188.

89 C. Xu, Z. Tian, P. Shen and S. P. Jiang, Electrochim. Acta, 2008, 53, 2610-2618.

90 C. Xu, P. kang Shen and Y. Liu, J. Power Sources, 2007, 164, 527-531.

91 J. M. Jaksic, N. V. Krstajic, L. M. Vracar, S. G. Neophytides, D. Labou, P. Falaras and M. M. Jaksic, Electrochim. Acta, 2007, 53, 349-361.

92 Y. Kwon, S. C. S. Lai, P. Rodriguez and M. T. M. Koper, J. Am. Chem. Soc., 2011, 133, 6914-6917.

93 A. Zalineeva, A. Serov, M. Padilla, U. Martinez, K. Artyushkova, S. Baranton, C. Coutanceau and P. Atanassov, Electrochem. Commun., 2015, 57, 48-51.

94 Y. Cheng, Y. Liu, D. Cao, G. Wang and Y. Gao, J. Power Sources, 2011, 196, 3124-3128.

95 E. A. Batista, H. Hoster and T. Iwasita, J. Electroanal. Chem., 2003, 554-555, 265-271.

96 Z. Liu, X. Zhang and L. Hong, Electrochem. Commun., 2009, 11, 925-928.

97 K. S. Kumar, P. Haridoss and S. K. Seshadri, Surf. Coat. Technol., 2008, 202, 1764-1770.
98 P. K. Shen, C. Xu, R. Zeng and Y. Liu, Electrochem. SolidState Lett., 2006, 9, A39-A42.

99 M. Wang, W. Liu and C. Huang, Int. J. Hydrogen Energy, 2009, 34, 2758-2764.

100 M. Fleischmann, K. Korinek and D. Pletcher, J. Electroanal. Chem. Interfacial Electrochem., 1971, 31, 39-49.

101 X. Cui, Y. Zhu, Z. Hua, J. Feng, Z. Liu, L. Chen and J. Shi, Energy Environ. Sci., 2015, 8, 1261-1266.

102 E. Asghari, H. Ashassi-Sorkhabi, A. Vahed, B. RezaeiMoghadam and G. R. Charmi, Thin Solid Films, 2016, 598, 6-15.

103 J. B. Wu, Z. G. Li, X. H. Huang and Y. Lin, J. Power Sources, 2013, 224, 1-5.

104 R. H. Tammam, A. M. Fekry and M. M. Saleh, Int. J. Hydrogen Energy, 2015, 40, 275-283.

105 G. A. Camara and T. Iwasita, J. Electroanal. Chem., 2005, 578, 315-321.

106 S. T. Nguyen, Y. Yang and X. Wang, Appl. Catal., B, 2012, 113-114, 261-270.

107 J. Liu, H. Zhou, Q. Wang, F. Zeng and Y. Kuang, J. Mater. Sci., 2011, 47, 2188-2194.

108 H. Ji, J. Frenzel, Z. Qi, X. Wang, C. Zhao, Z. Zhang and G. Eggeler, CrystEngComm, 2010, 12, 4059.

109 S. T. Nguyen, H. M. Law, H. T. Nguyen, N. Kristian, S. Wang, S. H. Chan and X. Wang, Appl. Catal., B, 2009, 91, 507-515.

110 Z. Qi, H. Geng, X. Wang, C. Zhao, H. Ji, C. Zhang, J. Xu and Z. Zhang, J. Power Sources, 2011, 196, 5823-5828.

111 Y.-C. Wei, C.-W. Liu, W.-D. Kang, C.-M. Lai, L.-D. Tsai and K.-W. Wang, J. Electroanal. Chem., 2011, 660, 64-70.

112 T. Maiyalagan and K. Scott, J. Power Sources, 2010, 195, 5246-5251.

113 Z. Zhang, L. Xin, K. Sun and W. Li, Int. J. Hydrogen Energy, 2011, 36, 12686-12697.

114 R. M. Modibedi, T. Masombuka and M. K. Mathe, Int. J. Hydrogen Energy, 2011, 36, 4664-4672.

115 W. Du, K. E. Mackenzie, D. F. Milano, N. A. Deskins, D. Su and X. Teng, ACS Catal., 2012, 2, 287-297.

116 L.-H. Jou, J.-K. Chang, T.-J. Whang and I.-W. Sun, J. Electrochem. Soc., 2010, 157, D443.

117 Y. Wang, T. S. Nguyen, X. Liu and X. Wang, J. Power Sources, 2010, 195, 2619-2622.

118 S. T. Nguyen, D. S. Ling Tan, J.-M. Lee, S. H. Chan, J. Y. Wang and X. Wang, Int. J. Hydrogen Energy, 2011, 36, 9645-9652.

119 A. O. Neto, M. M. Tusi, N. S. de Oliveira Polanco, S. G. da Silva, M. Coelho dos Santos and E. V. Spinacé, Int. J. Hydrogen Energy, 2011, 36, 10522-10526.

120 D. Chu, J. Wang, S. Wang, L. Zha, J. He, Y. Hou, Y. Yan, H. Lin and Z. Tian, Catal. Commun., 2009, 10, 955-958.

121 S. Shen, T. S. Zhao, J. Xu and Y. Li, Energy Environ. Sci., 2011, 4, 1428.

122 W. Wang, D. Chai, Y. Yang, Y. Liu, Y. Kang and Z. Lei, Int. J. Hydrogen Energy, 2015, 40, 10041-10048.

123 X. Fang, L. Wang, P. K. Shen, G. Cui and C. Bianchini, J. Power Sources, 2010, 195, 1375-1378.

124 Y. Yang, J. Ren, Q. Li, Z. Zhou, S. Sun and W. Cai, ACS Catal., 2014, 4, 798-803. 
125 T. Sheng, W.-F. Lin, C. Hardacre and P. Hu, J. Phys. Chem. C, 2014, 118, 5762-5772.

126 M. Bellini, M. Bevilacqua, J. Filippi, A. Lavacchi, A. Marchionni, H. A. Miller, W. Oberhauser, F. Vizza, S. P. Annen and H. Grützmacher, ChemSusChem, 2014, 7, 2432-2435.

127 A. Marchionni, M. Bevilacqua, C. Bianchini, Y.-X. Chen, J. Filippi, P. Fornasiero, A. Lavacchi, H. Miller, L. Wang and F. Vizza, ChemSusChem, 2013, 6, 518-528.

128 A. Villa, M. Plebani, M. Schiavoni, C. Milone, E. Piperopoulos, S. Galvagno and L. Prati, Catal. Today, 2012, 186, 76-82.

129 R. S. Ferreira Jr, M. Janete Giz and G. A. Camara, J. Electroanal. Chem., 2013, 697, 15-20.

130 M. Simões, S. Baranton and C. Coutanceau, Appl. Catal., B, 2010, 93, 354-362.

131 M. Simões, S. Baranton and C. Coutanceau, Appl. Catal., B, 2011, 110, 40-49.

132 Q. He and E. J. Cairns, J. Electrochem. Soc., 2015, 162, F1504-F1539.

133 J.-J. Lv, S.-S. Li, A.-J. Wang, L.-P. Mei, J.-J. Feng, J.-R. Chen and Z. Chen, J. Power Sources, 2014, 269, 104-110.

134 M. Wang, W. Zhang, J. Wang, D. Wexler, S. D. Poynton, R. C. T. Slade, H. Liu, B. Winther-Jensen, R. Kerr, D. Shi and J. Chen, ACS Appl. Mater. Interfaces, 2013, 5, 1270812715.

135 S. Liu, Q. Zhang, Y. Li, M. Han, L. Gu, C. Nan, J. Bao and Z. Dai, J. Am. Chem. Soc., 2015, 137, 2820-2823.

136 Y. Lu, N. Zhang, L. An, X. Li and D. Xia, J. Power Sources, 2013, 240, 606-611.

137 L. Jiang, A. Hsu, D. Chu and R. Chen, J. Electrochem. Soc., 2009, 156, B370.

138 R. W. Verjulio, J. Santander, J. Ma and N. Alonso-Vante, Int. J. Hydrogen Energy, 2016, DOI: 10.1016/j.ijhydene.2016.01.132.

139 X. Cao, X. Zheng, J. Tian, C. Jin, K. Ke and R. Yang, Electrochim. Acta, 2016, 191, 776-783.

140 X.-X. Ma and X.-Q. He, Electrochim. Acta, 2016, 213, 163173.

141 M. Chatenet, F. Micoud, I. Roche, E. Chainet and J. Vondrák, Electrochim. Acta, 2006, 51, 5452-5458.

142 A. C. Garcia, F. H. B. Lima, E. A. Ticianelli and M. Chatenet, J. Power Sources, 2013, 222, 305-312.

143 A. C. Garcia, J. J. Linares, M. Chatenet and E. A. Ticianelli, Electrocatalysis, 2013, 5, 41-49.

144 H.-Y. Su, Y. Gorlin, I. C. Man, F. Calle-Vallejo, J. K. Nørskov, T. F. Jaramillo and J. Rossmeisl, Phys. Chem. Chem. Phys., 2012, 14, 14010-14022.

145 D. J. Davis, T. N. Lambert, J. A. Vigil, M. A. Rodriguez, M. T. Brumbach, E. N. Coker and S. J. Limmer, J. Phys. Chem. C, 2014, 118, 17342-17350.

146 S. K. Bikkarolla, F. Yu, W. Zhou, P. Joseph, P. Cumpson and P. Papakonstantinou, J. Mater. Chem. A, 2014, 2, 14493.

147 S. Bag, K. Roy, C. S. Gopinath and C. R. Raj, ACS Appl. Mater. Interfaces, 2014, 6, 2692-2699.

148 C. Shi, G.-L. Zang, Z. Zhang, G.-P. Sheng, Y.-X. Huang, G.-X. Zhao, X.-K. Wang and H.-Q. Yu, Electrochim. Acta, 2014, 132, 239-243.
149 Y. Su, H. Jiang, Y. Zhu, X. Yang, J. Shen, W. Zou, J. Chen and C. Li, J. Mater. Chem. A, 2014, 2, 7281.

150 D. Zhou, L. Yang, L. Yu, J. Kong, X. Yao, W. Liu, Z. Xu and X. Lu, Nanoscale, 2015, 7, 1501-1509.

151 J. Zhang, X. Wang, D. Qin, Z. Xue and X. Lu, Appl. Surf. Sci., 2014, 320, 73-82.

152 C.-H. Wang, C.-W. Yang, Y.-C. Lin, S.-T. Chang and S. L. Y. Chang, J. Power Sources, 2015, 277, 147-154.

153 M. Wang, J. Huang, M. Wang, D. Zhang, W. Zhang, W. Li and J. Chen, Electrochem. Commun., 2013, 34, 299-303.

154 J. Jin, X. Fu, Q. Liu and J. Zhang, J. Mater. Chem. A, 2013, 1, 10538.

155 Q. Liu and J. Zhang, Langmuir, 2013, 29, 3821-3828.

156 E. Farjami, M. A. Rottmayer and L. Jay Deiner, J. Mater. Chem. A, 2013, 1, 15501.

157 K. Liu, Y. Song and S. Chen, Nanoscale, 2015, 7, 1224-1232. 158 Y. Wang, X. Ma, L. Lu, Y. He, X. Qi and Y. Deng, Int. J. Hydrogen Energy, 2013, 38, 13611-13616.

159 Q. Wu, L. Jiang, Q. Tang, J. Liu, S. Wang and G. Sun, Electrochim. Acta, 2013, 91, 314-322.

160 J. Wang, H. L. Xin, J. Zhu, S. Liu, Z. Wu and D. Wang, J. Mater. Chem. A, 2015, 3, 1601-1608.

161 Y. Xiao, C. Hu, L. Qu, C. Hu and M. Cao, Chem.-Eur. J., 2013, 19, 14271-14278.

162 Z.-Q. Liu, Q.-Z. Xu, J.-Y. Wang, N. Li, S.-H. Guo, Y.-Z. Su, H.-J. Wang, J.-H. Zhang and S. Chen, Int. J. Hydrogen Energy, 2013, 38, 6657-6662.

163 Z. Pu, Q. Liu, C. Tang, A. M. Asiri, A. H. Qusti, A. O. Al-Youbi and X. Sun, J. Power Sources, 2014, 257, 170-173.

164 R. Ning, J. Tian, A. M. Asiri, A. H. Qusti, A. O. Al-Youbi and X. Sun, Langmuir, 2013, 29, 13146-13151.

165 X. Zhai, W. Yang, M. Li, G. Lv, J. Liu and X. Zhang, Carbon, 2013, 65, 277-286.

166 P. W. Menezes, A. Indra, N. R. Sahraie, A. Bergmann, P. Strasser and M. Driess, ChemSusChem, 2015, 8, 164-171.

167 Y. Meng, W. Song, H. Huang, Z. Ren, S.-Y. Chen and S. L. Suib, J. Am. Chem. Soc., 2014, 136, 11452-11464.

168 J. A. Dawson and I. Tanaka, ACS Appl. Mater. Interfaces, 2014, 6, 17776-17784.

169 D. a. Tompsett, S. C. Parker and M. S. Islam, J. Am. Chem. Soc., 2014, 136, 1418-1426.

170 L. Li, X. Feng, Y. Nie, S. Chen, F. Shi, K. Xiong, W. Ding, X. Qi, J. Hu, Z. Wei, L.-J. Wan and M. Xia, ACS Catal., 2015, 4825-4832.

171 J. A. Dawson, H. Chen and I. Tanaka, ACS Appl. Mater. Interfaces, 2015, 7, 1726-1734.

172 D. Tompsett and M. Islam, J. Phys. Chem. C, 2014, 2500925015.

173 F. Cheng, T. Zhang, Y. Zhang, J. Du, X. Han and J. Chen, Angew. Chem., Int. Ed., 2013, 52, 2474-2477.

174 R. P. Linstead, J. Chem. Soc., 1934, 1016.

175 J. Masa, K. I. Ozoemena, W. Schuhmann and J. H. Zagal, Fundamental Studies on the Electrocatalytic Properties of Metal Macrocyclics and Other Complexes for the Electroreduction of $\mathrm{O}_{2}$, in Electrocatalysis in Fuel Cells: A Non- and Low-Platinum Approach, Lecture Notes in Energy 9, 
ed. Minhua Shao, Springer-Verlag, London, 2013, ch. 7, pp. 157-212.

176 J. Zagal, M. Páez, A. A. Tanaka, J. R. dos Santos and C. A. Linkous, J. Electroanal. Chem., 1992, 339, 13-30.

177 J. H. Zagal, Coord. Chem. Rev., 1992, 119, 89-136.

178 Y.-H. Tse, P. Janda, H. Lam, J. Zhang, W. J. Pietro and A. B. P. Lever, J. Porphyrins Phthalocyanines, 1997, 1, 3-16.

179 G. Ramírez, E. Trollund, M. Isaacs, F. Armijo, J. Zagal, J. Costamagna and M. Aguirre, Electroanalysis, 2002, 14, 540-545.

180 J. Pavez, M. Paez, A. Ringuede, F. Bedioui and J. H. Zagal, J. Solid State Electrochem., 2004, 9, 21-29.

181 G. Lalande, R. Côté, D. Guay, J. P. Dodelet, L. T. Weng and P. Bertrand, Electrochim. Acta, 1997, 42, 1379-1388.

182 J. H. Zagal, S. Griveau, J. F. Silva, T. Nyokong and F. Bedioui, Coord. Chem. Rev., 2010, 254, 2755-2791.

183 N. Ramaswamy, U. Tylus, Q. Jia and S. Mukerjee, J. Am. Chem. Soc., 2013, 135, 15443-15449.

184 M. Piana, M. Boccia, A. Filpi, E. Flammia, H. A. Miller, M. Orsini, F. Salusti, S. Santiccioli, F. Ciardelli and A. Pucci, J. Power Sources, 2010, 195, 5875-5881.

185 Q. He, X. Yang, X. Ren, B. E. Koel, N. Ramaswamy, S. Mukerjee and R. Kostecki, J. Power Sources, 2011, 196, 7404-7410.

186 Q. He, X. Yang, R. He, A. Bueno-López, H. Miller, X. Ren, W. Yang and B. E. Koel, J. Power Sources, 2012, 213, 169179.

187 V. Bambagioni, C. Bianchini, J. Filippi, A. Lavacchi, W. Oberhauser, A. Marchionni, S. Moneti, F. Vizza, R. Psaro, V. Dal Santo, A. Gallo, S. Recchia and L. Sordelli, J. Power Sources, 2011, 196, 2519-2529.

188 H. A. Miller, M. Bevilacqua, J. Filippi, A. Lavacchi, A. Marchionni, M. Marelli, S. Moneti, W. Oberhauser, E. Vesselli, M. Innocenti and F. Vizza, J. Mater. Chem. A, 2013, 1, 13337.

189 L. Li, X. Yuan, Z. Ma and Z.-F. Ma, J. Electrochem. Soc., 2015, 162, F359-F365.

190 H.-J. Zhang, H. Li, X. Li, B. Zhao, Z.-F. Ma and J. Yang, Electrochim. Acta, 2014, 115, 1-9.

191 K. Lawrence, C. L. Baker, T. D. James, S. D. Bull, R. Lawrence, J. M. Mitchels, M. Opallo, O. A. Arotiba, K. I. Ozoemena and F. Marken, Chem.-Asian J., 2014, 9, 1226-1241.

192 K. Gong, F. Du, Z. Xia, M. Durstock and L. Dai, Science, 2009, 323, 760-764.

193 W. Wei, H. Liang, K. Parvez, X. Zhuang, X. Feng and K. Müllen, Angew. Chem., 2014, 126, 1596-1600.

194 Q. Liu, Y. Duan, Q. Zhao, F. Pan, B. Zhang and J. Zhang, Langmuir, 2014, 30, 8238-8245.

195 Y. Zhang, X. Zhuang, Y. Su, F. Zhang and X. Feng, J. Mater. Chem. A, 2014, 2, 7742.

196 X. Fu, X. Hu, Z. Yan, K. Lei, F. Li, F. Cheng and J. Chen, Chem. Commun., 2016, 52, 1725-1728.

197 N. López-Salas, M. C. Gutiérrez, C. O. Ania, M. A. MuñozMárquez, M. Luisa Ferrer and F. del Monte, J. Mater. Chem. A, 2016, 4, 478-488.
198 K. Qu, Y. Zheng, S. Dai and S. Z. Qiao, Nano Energy, 2016, 19, 373-381.

199 X. Xu, T. Yuan, Y. Zhou, Y. Li, J. Lu, X. Tian, D. Wang and J. Wang, Int. J. Hydrogen Energy, 2014, 39, 16043-16052.

200 B. Zheng, J. Wang, F.-B. Wang and X.-H. Xia, Electrochem. Commun., 2013, 28, 24-26.

201 D. W. Chang, H.-J. Choi and J.-B. Baek, J. Mater. Chem. A, 2015, 3, 7659-7665.

202 K. Parvez, S. Yang, Y. Hernandez, A. Winter, A. Turchanin, X. Feng and K. Müllen, ACS Nano, 2012, 6, 9541-9550.

203 Z. Lin, G. H. Waller, Y. Liu, M. Liu and C. Wong, Nano Energy, 2013, 2, 241-248.

204 W. Yan, L. Wang, C. Chen, D. Zhang, A.-J. Li, Z. Yao and L.-Y. Shi, Electrochim. Acta, 2016, 188, 230-239.

205 Z.-J. Lu, M.-W. Xu, S.-J. Bao, K. Tan, H. Chai, C.-J. Cai, C.-C. Ji and Q. Zhang, J. Mater. Sci., 2013, 48, 8101-8107.

206 K. Kakaei and A. Balavandi, J. Colloid Interface Sci., 2016, 463, 46-54.

207 X. Qiao, S. Liao, G. Wang, R. Zheng, H. Song and X. Li, Carbon, 2016, 99, 272-279.

208 M. Liu, Y. Song, S. He, W. W. Tjiu, J. Pan, Y.-Y. Xia and T. Liu, ACS Appl. Mater. Interfaces, 2014, 6, 4214-4222.

209 Z. Zuo, W. Li and A. Manthiram, J. Mater. Chem. A, 2013, 1, 10166.

210 Z.-H. Sheng, H.-L. Gao, W.-J. Bao, F.-B. Wang and X.-H. Xia, J. Mater. Chem., 2012, 22, 390-395.

211 Z. Yang, Z. Yao, G. Li, G. Fang, H. Nie, Z. Liu, X. Zhou, X. Chen and S. Huang, ACS Nano, 2012, 6, 205-211.

212 G. Jo, J. Sanetuntikul and S. Shanmugam, RSC Adv., 2015, 5, 53637-53643.

213 J. Tai, J. Hu, Z. Chen and H. Lu, RSC Adv., 2014, 4, 6143761443.

214 J. Han, J. Y. Cheon, S. H. Joo and S. Park, Solid State Sci., 2014, 33, 1-5.

215 J. Jin, F. Pan, L. Jiang, X. Fu, A. Liang, Z. Wei, J. Zhang and G. Sun, ACS Nano, 2014, 8, 3313-3321.

216 Y. Li, T. Li, M. Yao and S. Liu, J. Mater. Chem., 2012, 22, 10911.

217 Y.-L. Liu, C.-X. Shi, X.-Y. Xu, P.-C. Sun and T.-H. Chen, J. Power Sources, 2015, 283, 389-396.

218 C. You, S. Liao, H. Li, S. Hou, H. Peng, X. Zeng, F. Liu, R. Zheng, Z. Fu and Y. Li, Carbon, 2014, 69, 294-301.

219 J. Yin, Y. Qiu, J. Yu, X. Zhou and W. Wu, RSC Adv., 2013, 3, 15655.

220 J. Vazquez-Arenas, A. Galano, D. U. Lee, D. Higgins, A. Guevara-García and Z. Chen, J. Mater. Chem. A, 2016, 4, 976-990.

221 L. Wang, C. K. Chua, B. Khezri, R. D. Webster and M. Pumera, Electrochem. Commun., 2016, 62, 17-20.

222 C. E. Banks, A. Crossley, C. Salter, S. J. Wilkins and R. G. Compton, Angew. Chem., Int. Ed., 2006, 45, 25332537.

223 L. Zhang and Z. Xia, J. Phys. Chem. C, 2011, 115, 1117011176.

224 Y. Zhang, J. Ge, L. Wang, D. Wang, F. Ding, X. Tao and W. Chen, Sci. Rep., 2013, 3, 2771. 
225 V. Bambagioni, C. Bianchini, A. Marchionni, J. Filippi, F. Vizza, J. Teddy, P. Serp and M. Zhiani, J. Power Sources, 2009, 190, 241-251.

226 R. M. Modibedi, T. Mehlo, K. I. Ozoemena and M. K. Mathe, Int. J. Hydrogen Energy, 2015, 40, 15605-15612.

227 J. Van Gerpen, Fuel Process. Technol., 2005, 86, 10971107.

228 Y. Chen, M. Bellini, M. Bevilacqua, P. Fornasiero, A. Lavacchi, H. A. Miller, L. Wang and F. Vizza, ChemSusChem, 2015, 8, 524-533.

229 Y. S. Li, T. S. Zhao and Z. X. Liang, J. Power Sources, 2009, 187, 387-392.
230 Z. Zhang, L. Xin, J. Qi, D. J. Chadderdon and W. Li, Appl. Catal., B, 2013, 136-137, 29-39.

231 V. Bambagioni, C. Bianchini, Y. Chen, J. Filippi, P. Fornasiero, M. Innocenti, A. Lavacchi, A. Marchionni, W. Oberhauser and F. Vizza, ChemSusChem, 2012, 5, 1266-1273.

232 Y. Li and Y. He, RSC Adv., 2014, 4, 16879.

233 Y. S. Li and T. S. Zhao, Int. J. Hydrogen Energy, 2011, 36, 7707-7713.

234 L. Ma, H. He, A. Hsu and R. Chen, J. Power Sources, 2013, 241, 696-702.

235 L. An, L. Zeng and T. S. Zhao, Int. J. Hydrogen Energy, 2013, 38, 10602-10606. 